Cristiane Junqueira Giovannini

\title{
Construindo Confiança na Era da Desconfiança: Comportamento de Compra por Dispositivos Móveis do Consumidor Brasileiro
}

Tese de Doutorado

Tese apresentada ao Programa de Pós-graduação em Administração de Empresas da PUC-Rio como requisito parcial para obtenção do grau de Doutor em Administração de Empresas.

Orientador: Prof. Angela Maria Cavalcanti da Rocha Co-orientador: Prof. Jorge Brantes Ferreira 


\title{
Cristiane Junqueira Giovannini
}

Construindo Confiança na Era da Desconfiança: Comportamento de Compra por Dispositivos Móveis do Consumidor Brasileiro

Tese apresentada como requisito parcial para obtenção do grau de Doutor pelo Programa de Pósgraduação em Administração de Empresas da PUCRio. Aprovada pela Comissão Examinadora abaixo assinada.

\author{
Profa. Angela Maria Cavalcanti da Rocha \\ Orientadora \\ Departamento de Administração - PUC-Rio \\ Prof. Jorge Brantes Ferreira \\ Co-orientador \\ Departamento de Administração - PUC-Rio \\ Prof. Angilberto Sabino de Freitas \\ Universidade do Grande Rio
}

Prof. Emilio Jose Montero Arruda Filho UNAMA

Prof. Fernando Bins Luce UFRGS

Prof. Marcus Wilcox Hemais

PUC-Rio

Prof. Augusto Cesar Pinheiro da Silva Coordenador Setorial do Centro de Ciências Sociais - PUC-Rio

Rio de Janeiro, 3 de maio de 2018 
Todos os direitos reservados. É proibida a reprodução total ou parcial do trabalho sem autorização da universidade, da autora e do orientador.

\section{Cristiane Junqueira Giovannini}

Mestre em Administração de Empresas pela PUC-Rio (Pontifícia Universidade Católica do Rio de Janeiro), em 2014. Especializada em Educação a Distância pelo SENAC/RJ (Serviço Nacional de Aprendizagem Comercial). Licenciada em Educação Artística com Habilitação em Desenho pela UFRJ (Universidade Federal do Rio de Janeiro). Participou de diversos congressos nacionais e internacionais na área de administração e marketing. Possui artigos publicados em anais de congresso e periódicos científicos nacionais e internacionais.

Ficha Catalográfica

Giovannini, Cristiane Junqueira

Construindo confiança na era da desconfiança : comportamento de compra por dispositivos móveis do consumidor brasileiro / Cristiane Junqueira Giovannini ; orientador: Angela Maria Cavalcanti da Rocha ; coorientador: Jorge Brantes Ferreira. - 2018.

169 f. : il. ; $30 \mathrm{~cm}$

Tese (doutorado)-Pontifícia Universidade Católica do Rio de Janeiro, Departamento de Administração, 2018.

Inclui bibliografia

1. Administração - Teses. 2. Confiança. 3. Confiança móvel. 4. Comércio móvel. 5. Comportamento do consumidor. 6. Intenção de compra. I. Rocha, Angela Maria Cavalcanti da. II. Ferreira, Jorge Brantes. III. Pontifícia Universidade Católica do Rio de Janeiro. Departamento de Administração. IV. Título. 
Para meu namorado, por me mostrar que realizar sonhos requer trabalho.

Para meu cunhado, que deu o apito de partida e penalizou meus oponentes.

Para meus pais, por tudo que fizeram e farão por mim. 


\section{Agradecimentos}

A minha orientadora Professora Angela Maria Cavalcanti da Rocha, Ph.D. pela paciência diante da minha insegurança e conselhos insubstituíveis sem os quais esse trabalho teria se transformado em um monstro invencível de sete cabeças.

Ao meu coorientador Professor Jorge Brantes Ferreira, Ph.D por me apresentar as SEM e ao trabalho de Barbara Byrne.

À CAPES e à PUC-Rio, pelos auxílios concedidos, sem os quais este trabalho não poderia ter sido realizado.

Aos meus amigos, pelos jogos, risadas e companheirismo.

Aos meus pais, por insistir na educação como sua principal herança.

Aos colegas da PUC-Rio, pelas ideias e oportunidades compartilhadas.

Aos professores que participaram da Comissão examinadora, pelas sugestões e conselhos.

A todos os professores e funcionários do Departamento pelos ensinamentos e ajuda oferecidos.

E a todos aqueles que de uma forma ou de outra, conscientemente ou não, me estimularam ou ajudaram durante a realização deste trabalho. 


\section{Resumo}

Giovannini, Cristiane Junqueira; Rocha, Angela Maria Cavalcanti; Ferreira, Jorge Brantes. Construindo Confiança na Era da Desconfiança: Comportamento de Compra por Dispositivos Móveis do Consumidor Brasileiro. Rio de Janeiro, 2018. 169p. Tese de Doutorado - Departamento de Administração, Pontifícia Universidade Católica do Rio de Janeiro.

Confiança é um elemento essencial na construção de relacionamentos. Esta tese de doutorado propõe um modelo que trata a confiança como um construto multidimensional mediador na construção da intenção do consumidor de comprar produtos e serviços usando um dispositivo móvel. O estudo aborda os impactos do tipo de produto sobre as relações entre confiança e intenção de compra via dispositivo móvel, compara três modelos que utilizam diferentes versões do construto confiança e considera características inovadoras da tecnologia móvel na construção da confiança, a fim de aprofundar o conhecimento existente sobre as relações de confiança envolvendo compra de produtos e serviços em contextos móveis. Os dados utilizados foram coletados por meio de um levantamento online e analisados pelo método de modelagem de equações estruturais. Os resultados mostram a importância da utilização de construtos multidimensionais para a confiança e o papel desta como mediadora entre as características inovadoras dos dispositivos móveis e a adoção destes para compras de produtos e serviços, os efeitos dos produtos de busca sobre a atitude e os efeitos dos produtos de experiência sobre a intenção de compra, e a importância da facilidade de uso dos dispositivos móveis e da competência dos vendedores para a adoção e uso de dispositivos móveis para a compra de bens e serviços.

\section{Palavras-chave}

Confiança; confiança móvel; comércio móvel; comportamento do consumidor; intenção de compra; tipo de produto; aceitação de tecnologia. 


\section{Abstract}

Giovannini, Cristiane Junqueira; Rocha, Angela Maria Cavalcanti (Advisor); Ferreira, Jorge Brantes (Advisor). Building Trust in the Age of Distrust: Brazilian Consumer Mobile Shopping Behavior. Rio de Janeiro, 2018. 169p. Tese de Doutorado - Departamento de Administração, Pontifícia Universidade Católica do Rio de Janeiro.

Trust is an core element in relationships. This dissertation proposes a model in which a multidimensional trust construct mediates consumer intention to purchase products and services using a mobile device. This study also analises impacts of product type on the proposed relations and compares three different models each one using an alternative representation of trust in order to expand academic knowledge regarding trusting relationships in mobile contexts. An online survey using social networks provided the data used in a structural equation modeling analysis. Results show that trust constructs should be multidimensional whenever trust is a construct of importance, that trust mediates the relationships between mobile devices innovative characteristics and adoption of mobile commerce, that search and experience products produce different effects, and that ease of use of mobile devices and vendor competence play important parts in the adoption and use of mobile commerce.

\section{Keywords}

Trust; mobile trust; m-commerce; consumer behavior; intention to purchase; product type; technology acceptance. 


\section{Sumário}

1 Introdução 16

$\begin{array}{ll}1.1 \text { Contexto } & 16\end{array}$

$\begin{array}{ll}1.2 \text { Objetivo do Estudo } & 18\end{array}$

$\begin{array}{ll}1.3 \text { Relevância do estudo } & 19\end{array}$

$\begin{array}{ll}1.4 \text { Delimitação do estudo } & 20\end{array}$

2 Revisão da Literatura e Hipóteses 22

2.1 Confiança 22

2.2 Confiança Online 23

2.3 Confiança Móvel $\quad 24$

2.4 As Diferentes Dimensões da Confiança no Comércio Móvel 25

2.5 Confiança, Atitude, Intenção e Comportamento de Compra 26

2.6 Construindo Confiança 29

2.6.1 As Características da Inovação - A Compra por Dispositivos Móveis $\quad 29$

2.7 Características do Produto 32

2.7.1 Efeitos Moderadores do Tipo de Produto - Produtos de Busca ou de Experiência 32

2.8 Modelos e Hipóteses $\quad 34$

$\begin{array}{ll}3 \text { Metodologia } & 37\end{array}$

$\begin{array}{ll}3.1 \text { Tipo de pesquisa } & 37\end{array}$

3.2 Universo e amostra 39

3.2.1 Amostragem por Conveniência e Snowballing 41

Usuários de Redes Sociais $\quad 41$

3.2.2 Eliminação de Questionários Irrelevantes 41

3.3 Coleta de Dados $\quad 42$

3.3.1 Instrumento de coleta de dados - Questionário Online 43

3.3.2 Escolha do tipo de produto avaliado 43

3.3.3 Operacionalização das variáveis 47

3.3.4 Procedimentos de tradução e adaptação das escalas 55

3.3.5 Pré-teste do instrumento de pesquisa 56 
3.4 Análise dos Dados $\quad 57$

3.4.1 Validade e Confiabilidade $\quad 57$

3.4.2 Análises Estatísticas $\quad 59$

3.4.3 Avaliação dos Modelos de Mensuração e Estrutural 60

3.5 Limitações do Método 62

3.5.1 Limitações relacionadas ao critério de amostragem 62

3.5.2 Limitações não relacionadas ao critério de amostragem 63

3.5.3 Limitações relacionadas às análises estatísticas 65

4 Modelagem e Análise dos Dados 66

4.1 Caracterização da Amostra 66

$\begin{array}{ll}4.2 \text { Análises e Resultados } & 67\end{array}$

4.2.1 Avaliação do Modelo de Mensuração 68

4.2.2 Validade e Confiabilidade dos Construtos 69

4.2.3 Análise do Modelo Estrutural 83

4.2.3.1 Normalidade $\quad 83$

4.2.3.2 Ajuste do Modelo Proposto 84

4.2.4 Teste Comparativo entre Modelos 90

4.2.5 Teste das Hipóteses de Pesquisa 92

4.2.5.1 Modelo Dimensões da Confiança 92

4.2.5.1.1 Diferenças Entre as Amostras 101

4.2.5.2 Modelo Confiança de Segunda Ordem 105

4.2.5.2.1 Diferenças Entre as Amostras 113

4.3 Discussão dos Resultados 122

4.3.1 As Diferentes Representações da Confiança 122

4.3.2 O Papel Mediador da Confiança 125

4.3.4 O Impacto dos Fatores Inovadores dos Dispositivos Móveis 126

4.3.5 A Influência do Tipo de Produto 129

4.3.6 Modelo MCTF2 - Determinação do Melhor Modelo 130

5 Conclusões e Recomendações 132

5.1 Sumário do Estudo 132

5.2 Conclusões e Contribuições 134

5.2.1 Contribuições do Estudo 134 
5.2.2 Implicações Teóricas

135

5.2.3 Implicações Práticas

137

5.3 Limitações do Estudo

138

5.4 Sugestões para Pesquisas Futuras

139

6 Referências Bibliográficas

141

Apêndice A Instrumento de Pesquisa - Versão para Impressão 


\section{Lista de Figuras}

Figura $2.1 \quad$ Teoria da Ação Racional................................... 27

Figura 2.2 MTCF 2 - Dimensões da Confiança...................... 35

Figura $\quad 2.3$ MTCF 2 - Confiança de Segunda Ordem................. 35

Figura $\quad 2.4$ MTCF 2 - Confiança Geral................................ 36

Figura $\quad 4.1$ MTCF 2 - Dimensões da Confiança................... 84

Figura $\quad$ 4.2 MTCF 2 - Dimensões da Confiança Modificado........ 86

Figura 4.3 MTCF 2 - Confiança de Segunda Ordem Modificado............................................................. 88

Figura $\quad 4.4$ MTCF 2 - Confiança Geral Modificado..................... 89

Figura 4.5 Coeficientes Padronizados Estimados para o MCTF 2 Dimensões da Confiança (amostra Busca)............ 97

Figura 4.6 Coeficientes Padronizados Estimados para o MCTF 2 Dimensões da Confiança (amostra Experiência).... 100

Figura $\quad 4.7$ Coeficientes Não Padronizados Estimados para o MCTF 2 Dimensões da Confiança (amostras Busca e Experiência).

Figura $\quad 4.8$ Coeficientes Padronizados Estimados para o MCTF 2 Confiança de Segunda Ordem (amostra Busca)....

Figura 4.9 Coeficientes Padronizados Estimados para o MCTF 2 Confiança de Segunda Ordem (amostra Experiência)

Figura 4.10 Coeficientes Não Padronizados Estimados para o MCTF 2 Dimensões da Confiança (amostras Busca e Experiência) 


\section{Lista de Quadros e Tabelas}

Tabela 3.1 Produtos Digitais e Serviços...................................... 44

Tabela 3.2 Produtos Tangíveis............................................... 44

Quadro 3.1 Classificação Final dos Produtos.............................. 47

Quadro 3.2 Construtos e Escalas................................................ 49

Tabela $3.3 \quad$ Variáveis de Controle............................................... 54

Tabela $\quad 3.4 \quad$ Variáveis de Demográficas....................................... 55

Tabela $\quad 4.1$ Caracterização da Amostra........................................ 66

Quadro 4.1 Matriz de Correlação para a amostra Busca do modelo Dimensões da Confiança/Confiança de $2^{\mathrm{a}}$

Ordem

Quadro 4.2 Matriz de Correlação para a amostra Experiência do modelo Dimensões da Confiança/Confiança de $2^{\mathrm{a}}$

Ordem

Quadro 4.3 Matriz de Correlação para a amostra Busca do modelo Confiança Geral.

Quadro 4.4 Matriz de Correlação para a amostra Experiências do modelo Confiança Geral.

Tabela 4.2 Confiabilidade Composta e Variância Extraída Média da amostra Busca do modelo Dimensões da Confiança/Confiança de $2^{\underline{a}}$ Ordem.

Tabela 4.3 Confiabilidade Composta e Variância Extraída Média da amostra Experiência do modelo Dimensões da Confiança/Confiança de $2^{\mathrm{a}}$ Ordem..

Tabela 4.4 Confiabilidade Composta e Variância Extraída Média da amostra Busca do modelo Confiança Geral..

Tabela 4.5 Confiabilidade Composta e Variância Extraída Média da amostra Experiência do modelo Confiança Geral. 
Tabela 4.6 Cargas Fatoriais Padronizadas para os modelos Dimensões da Confiança e Confiança de $2^{\text {a }}$ Ordem (amostra Busca)

Tabela 4.7 Cargas Fatoriais Padronizadas para os modelos Dimensões da Confiança e Confiança de $2^{\underline{a}}$ Ordem (amostra Experiência).

Tabela 4.8 Cargas Fatoriais Padronizadas para o modelo Confiança Geral (amostra Busca).

Tabela 4.9 Cargas Fatoriais Padronizadas para o modelo Confiança Geral (amostra Experiência)

Quadro 4.5 Matrix de Validade Discriminante para os modelos Dimensões da Confiança e Confiança de $2^{\mathrm{a}}$ Ordem (amostra Busca).

Quadro 4.6 Matrix de Validade Discriminante para os modelos Dimensões da Confiança e Confiança de $2^{\mathrm{a}}$ Ordem (amostra Experiência).

Quadro 4.7 Matrix de Validade Discriminante para o modelo Confiança Geral (amostra Busca).

Quadro 4.8 Matrix de Validade Discriminante para o modelo Confiança Geral (amostra Experiência)

Tabela 4.10 Índices de Ajuste do Modelo Dimensões da Confiança

Tabela 4.11 Índices de Ajuste do Modelo Confiança de Segunda Ordem

Tabela 4.12 Índices de Ajuste do Modelo Confiança Geral

Tabela 4.13 Comparação dos Índices de Ajuste dos Modelos......

Tabela 4.14 Efeitos Diretos Modelo Dimensões da Confiança (amostra Busca)

Tabela 4.15 Efeitos Diretos Modelo Dimensões da Confiança (amostra Experiência). 
Tabela 4.16 Efeitos Indiretos Modelo Dimensões da Confiança

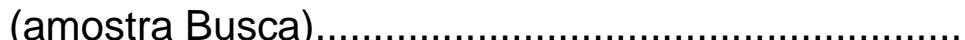

Tabela 4.17 Efeitos Indiretos Modelo Dimensões da Confiança (amostra Experiência).

Tabela 4.18 Efeitos Diretos e Tipo de Moderação Modelo Dimensões da Confiança (amostra Busca).

Tabela 4.19 Efeitos Diretos e Tipo de Moderação Modelo Dimensões da Confiança (amostra Experiência)....... 96

Tabela 4.20 Coeficientes Não Padronizados Estimados, Hipóteses e Significâncias para o modelo MCTF2

Dimensões da Confiança (amostra Busca)

Tabela 4.21 Coeficientes Não Padronizados Estimados, Hipóteses e Significâncias para o modelo MCTF2 Dimensões da Confiança (amostra Experiência).......

Tabela 4.22 Coeficientes Não Padronizados Estimados e Significâncias (comparação entre amostras)

Tabela 4.23 Intervalos de Confiança para os Coeficientes Não Padronizados (comparação entre amostras)

Tabela 4.24 Efeitos Diretos Modelo Confiança de $2^{\mathrm{a}}$ Ordem (amostra Busca)

Tabela 4.25 Efeitos Diretos Modelo Confiança de $2^{\mathrm{a}}$ Ordem (amostra Experiência)

Tabela 4.26 Efeitos Indiretos Modelo Confiança de $2^{\mathrm{a}}$ Ordem (amostra Busca)

Tabela 4.27 Efeitos Indiretos Modelo Confiança de 2 ${ }^{\text {a }}$ Ordem (amostra Experiência).

Tabela 4.28 Efeitos Diretos e Tipo de Moderação Modelo Confiança de 2ª Ordem (amostra Busca).

Tabela 4.29 Efeitos Diretos e Tipo de Moderação Modelo Confiança de 2 ${ }^{\mathrm{a}}$ Ordem (amostra Experiência). 
Tabela 4.30 Coeficientes Não Padronizados Estimados, Hipóteses e Significâncias para o modelo MCTF2

Confiança de $2^{a}$ Ordem (amostra Busca).

Tabela 4.31 Coeficientes Não Padronizados Estimados, Hipóteses e Significâncias para o modelo MCTF2 Confiança de $2^{\mathrm{a}}$ Ordem (amostra Experiência).

Tabela 4.32 Coeficientes Não Padronizados Estimados e Significâncias (comparação entre amostras)

Tabela 4.33 Intervalos de Confiança para os Coeficientes Não Padronizados (comparação entre amostras)

Quadro 4.9 Sumário dos Resultados.

\section{Lista de Termos Adotados}

Confiança Móvel - Traduzido de mobile trust, refere-se a confiança aplicada a contextos que envolvam o uso de dispositivos móveis. Este estudo usa como definição de confiança móvel a disposição de aceitar vulnerabilidade baseada nas expectativas das intenções e comportamentos de outra parte e em como tecnologias móveis disponibilizadas pelo meio de interação com esta outra parte afetam a manifestação dessas expectativas (Definido pela autora).

Era da Desconfiança - Analistas, sociólogos e cientistas políticos afirmam que nas ultimas décadas houve um declínio na confiança depositada pelo público nas instituições públicas e privadas. Este declínio na confiança afeta políticos, partidos, a mídia, agencias governamentais, empresas, peritos, cientistas e até mesmo ONGs. A incerteza econômica e política e a popularização das mídias sociais e da internet (onde verdades e mentiras são disseminadas com igual dedicação), somadas a uma crescente ansiedade diante da insegurança pública e do terrorismo internacional causou uma crise na confiança pública e fez surgir o termo "Era da Disconfiança" para se referir a este momento na história das democracias ocidentais (CLARK, 2016; COHEN, 2016; NANCY, 2016; RAINIE; ANDERSON, 2017; ROSANVALLON, 2008; SCHNEIDER, 1999). 


\section{1 \\ Introdução}

1.1

\section{Contexto}

O consumo de mídias (vídeo, texto, áudio, imagem, jogo etc.) por meio de dispositivos móveis (telefones celulares com capacidade de acessar a internet, smartphones e tablets) cresceu globalmente 277\% de 2011 para 2017. Com esse crescimento pode-se dizer que atualmente os usuários desses dispositivos passam pelo menos uma hora por dia buscando informações ou entretenimento em seus aparelhos. Muitos usuários não conseguem sequer imaginar uma vida sem smartphones e um em cada cinco consumidores realiza pagamentos digitais via dispositivo móvel pelo menos uma vez na semana, sendo os consumidores em economias emergentes os mais propensos a realizar pagamentos e compras por este canal (IPSOS, 2017).

No Brasil, em 2016, cerca de 48 milhões de consumidores realizaram compras online, levando o e-commerce nacional a um faturamento de 44,4 bilhões de reais. Os dispositivos móveis (smartphones e tablets) foram responsáveis por $21,5 \%$ do volume total de compras online em 2016, mais do que o dobro do que em 2014, quando as compras feitas por esses dispositivos foram responsáveis por 9,7\% desse volume (EBIT, 2017). A comodidade e a economia na realização de compras de bens são os principais motivos alegados pelo consumidor para o crescente uso de smartphones na compra de bens e serviços não virtuais. Aplicativos de aquisição de serviços de mobilidade urbana, como o Uber, e entrega de refeições prontas, como o iFood, adquiriram um status distintivo entre os usuários de smartphones (PAIVA, 2016). Esse crescente impacto econômico e social do comércio móvel o torna cada vez mais relevante para pesquisas de mercado e estudos acadêmicos.

As compras online, assim como qualquer outra forma de transação mediada por dispositivos eletrônicos, são caracterizadas pela ausência de fatores tangíveis e da interação humana, que servem para imbuir uma transação com credibilidade e, portanto, são mais sujeitas a ansiedade e desconfiança (FLANAGIN; METZGER; PURE; MARKOV; HARTSELL, 2014; GEFEN, 2000; NILASHI; IBRAHIM; 
MIRABI; EBRAHIMI, 2015). Por outro lado, relacionamentos baseados em confiança parecem trazer benefícios tanto para consumidores quanto para empresas, uma vez que as interações entre as partes passam a tomar a forma de resolução de problemas em comum, reduzindo custos de informação e transação (PEPPERS; ROGERS, 2011). Da mesma forma, a construção de conexões emocionais com seus consumidores parece ser a chave para o desempenho de longo prazo de uma empresa (BINET; FIELD, 2007; 2013). Assim, a falta de confiança pode representar a maior barreira à ocorrência de transações online (BELDAD; JONG; STEEHOUDER, 2010; XU; CENFETELLI; AQUINO; 2016).

Recentemente, avanços tecnológicos e a popularização da internet tornaram quase que ubíqua a presença dos dispositivos móveis no cotidiano. Conforme a quantidade destes dispositivos se multiplica, cria-se um mercado crescente para transações, comunicação e promoção (SHANKAR, VENKATESH; HOFACKER; NAIK, 2010; VARNALI; TOKER, 2010; XU; CENFETELLI; AQUINO; 2016). Apesar dos benefícios distintivos dos serviços móveis, como mobilidade, portabilidade, personalização, consulta e compartilhamento de informação, geolocalização, interatividade e convergência de funções e serviços (PINA; KURTZ; FERREIRA; SILVA; GIOVANNINI, 2016; WANG; MALTHOUSE: KRISHNAMURTHI, 2015), ultrapassar as barreiras impostas pela falta de confiança é um dos maiores desafios para a adoção de serviços e comércio móvel. O consumidor se sente tão desconfortável em partilhar suas informações pessoais e conduzir transações via dispositivos móveis quanto se sente em fazê-lo em seu computador de mesa, se não mais (MOBILE TIME; OPINION BOX, 2016; SIAU; SHENG; HOON; DAVIS, 2004).

Estudos empíricos sugerem que diferentes fatores influenciam as percepções de confiança e do que é confiável em transações online (BART; SHANKAR; SULTAN; URBAN, 2005; BELDAD et al., 2010; URBAN; AMYX; LOTENZON, 2009) e no comércio móvel mais especificamente (LIN; WANG; WANG; LU, 2014; NILASHI; IBRAHIM; MIRABI; EBRAHIMI; ZARE, 2015). Por isso, é certa a existência de diferentes fatores que impactem a confiança do consumidor, entre eles questões pessoais, institucionais, tecnológicas e sociais. 
Este estudo tem como proposta investigar o papel multidimensional da confiança no processo de adoção do comércio móvel pelo consumidor e no seu comportamento de compra via dispositivos móveis, apresentando um modelo que incorpora a influência das características dos dispositivos móveis como inovação tecnológica e das características do tipo de produto ou serviço. Para atingir seus objetivos, este estudo constrói suas bases teóricas sobre: (1) a Teoria de Comprometimento-Confiança (MORGAN; HUNT, 1994), (2) a Teoria do Ação Racional (FISHBEIN; AJZEN, 1975; AJZEN; FISHBEIN, 1980), (3) a Teoria da Difusão de Inovações (ROGERS, 2003) e (4) a tipologia de produto busca/experiência (NELSON, 1970).

Ao adicionar influenciadores específicos do contexto móvel e efeitos moderadores do tipo de produto ou serviço ofertados às diferentes dimensões da confiança em um modelo de intenção de uso e comportamento de compra, este estudo busca melhorar o entendimento sobre o papel da confiança na adoção e uso do comércio móvel pelo consumidor e abrir novos caminhos para a pesquisa sobre confiança em ambientes móveis e problemas de confiança derivados de transações que ocorrem nestes ambientes.

O estudo se inicia com uma revisão da literatura sobre o tema e a definição de conceitos e construtos aplicados ao modelo. Segue-se uma descrição da metodologia envolvida no estudo e da técnica escolhida para a análise dos dados, as equações estruturais. Por fim, o estudo é concluído com a discussão dos resultados obtidos e suas implicações para acadêmicos e praticantes.

\section{2}

\section{Objetivo do Estudo}

Este estudo busca identificar e verificar como as diferentes dimensões da confiança são afetadas por fatores relacionados às características inovadoras dos dispositivos móveis e como afetam a atitude e intenção do consumidor individual de adotar e utilizar o comércio móvel, assim como a influência do tipo de produto sobre as relações encontradas.

São objetivos secundários: 
(1) identificar o papel das diferentes dimensões da confiança no processo de adoção e uso do comércio móvel;

(2) identificar o efeito de diferentes fatores inovadores dos dispositivos móveis na construção das diferentes dimensões da confiança;

(3) identificar o papel mediador da confiança e de suas dimensões no processo de adoção e uso do comércio móvel;

(4) identificar o papel moderador do tipo de produto no processo mediado de adoção e uso do comércio móvel;

(5) propor e testar modelos rivais desenvolvidos com o suporte da literatura estudada.

\section{3 \\ Relevância do estudo}

Primeiramente, o estudo procura analisar o papel mediador da confiança como um construto multidimensional, considerando cada uma de suas dimensões separadamente. Embora as diferentes dimensões da confiança tenham sido utilizadas por alguns estudos na literatura de adoção e difusão de tecnologias, o uso da confiança como construto de segunda ordem ou de suas dimensões em separado, e não como escala somatória, não foi identificado na literatura de adoção e difusão de tecnologias móveis.

Segundo, embora muitos estudos usem a teoria de difusão de inovações (DOI) de Rogers (2003), poucos estudos fazem uso dos construtos propostos pelo autor como influenciadores da adoção e difusão de uma inovação tecnológica, geralmente se utilizando dos construtos propostos pelas teorias da ação racionalizada e do comportamento planejado (AJZEN, 1985; 1991) e pelos modelos Technology Acceptance Model (DAVIS, 1989), Technology Acceptance Model 2 (VENKATESH; DAVIS, 2000), Unified Theory of Acceptance and Use of Technology (VENKATESH; MORRIS; DAVIS; DAVIS, 2003) e Technology Acceptance Model 3 (VENKATESH; BALA, 2008), desenvolvidos com base no fundamento de que a facilidade de uso e utilidade percebida de uma tecnologia são 
determinantes do comportamento do usuário. Mesmo nos estudos em que são utilizados os construtos propostos por Rogers, não se utiliza a confiança como mediadora no processo de adoção de tecnologias móveis. Além disso, só foi localizado um único estudo que faz uso da DOI para explicar a adoção ou uso do comércio móvel.

Terceiro, a literatura sugere forte moderação do tipo de produto sobre o comportamento de compra e processo de decisão de compra por parte do consumidor (ANG; LIM, 2006; PARK; LEE, 2009; PARK; MOON, 2003; MAITY; DASS, 2014; YADAV; VALCK; HENNIG-THURAU; HOFFMAN; SPANN, 2013), mas pouco se sabe sobre os efeitos moderadores do tipo de produto sobre relações de confiança online, sobretudo em ambientes de comércio móvel.

Por fim, os estudos publicados no Brasil sobre o tema confiança do consumidor são poucos, particularmente em ambientes digitais e móveis. Em uma pesquisa feita na base de dados Spell, da Associação Nacional de Pós Graduação e Pesquisa em Administração (ANPAD), em novembro de 2017, foram resgatados 396 artigos contendo a palavra confiança ou a palavra trust em seu título, ou listada como palavra-chave. Desses, 85 estudos tratavam da confiança entre vendedor e consumidor, e os outros 311 tratavam da confiança sob perspectivas interorganizacionais ou de gestão e governança. Dos 85 estudos sobre confiança do consumidor, somente 18 tratavam de confiança em ambientes online e destes apenas dois abordavam a confiança em ambientes móveis. Esses números contrastam com os volumes de pesquisa internacional sobre o tema, cuja busca revelou 39 estudos sobre confiança no comércio móvel entre as 300 respostas mais relevantes pesquisando os termos confiança (trust) e comércio móvel (mobile commerce, mcommerce, m-commerce) para o mesmo período (desde 2012).

\section{4 \\ Delimitação do estudo}

No que se refere ao horizonte espacial, a proposta deste estudo é o de analisar exclusivamente o comportamento de consumo da população economicamente ativa, residente na região metropolitana do Rio de Janeiro, na faixa entre 25 e 65 
anos de idade, de nacionalidade brasileira, que realiza compras online por meio de dispositivos móveis utilizando um levantamento online.

Este estudo considera dispositivos móveis os smartphones, os tablets e os celulares capazes de acessar páginas na Internet.

Quanto ao horizonte temporal, o estudo faz uso de uma amostra não probabilística da população de interesse tomada no primeiro semestre do ano de 2018.

Por fim, este estudo constrói suas bases teóricas sobre: (1) a Teoria de Comprometimento-Confiança (MORGAN; HUNT, 1994), (2) a Teoria do Ação Racional (FISHBEIN; AJZEN, 1975; AJZEN; FISHBEIN, 1980), (3) a Teoria da Difusão de Inovações (ROGERS, 2003) e (4) a tipologia de produto busca/experiência (NELSON, 1970). 


\section{2 \\ Revisão da Literatura e Hipóteses}

Este capítulo apresenta o estado atual do conhecimento sobre confiança e contextualiza a confiança dentro do ambiente dos dispositivos móveis, sobretudo no que diz respeito às compras feitas por meio desses dispositivos. $\mathrm{O}$ capítulo apresenta uma análise do referencial teórico, clarificando as principais questões teóricas pertinentes ao tema, levantando algumas lacunas e delimitando as abordagens teóricas escolhidas para a realização da pesquisa. Ao final do capítulo são apresentados os modelos desenvolvidos com base na análise da literatura e as hipóteses a serem testadas.

\section{1 \\ Confiança}

Confiança é um conceito cuja definição não é compartilhada por todas as disciplinas que o examinam (URBAN et al., 2010; BELDAD et al., 2010). De maneira genérica, as definições de confiança podem ser divididas em duas grandes vertentes. Uma delas trata a confiança como uma expectativa em relação ao comportamento de um parceiro (GARBARINO; JOHNSON, 1999; KOLLER, 1988; MORGAN; HUNT, 1994), enquanto a outra vertente considera a confiança como um estado psicológico que envolve aceitação e exposição à vulnerabilidade (MAYER; DAVIS; SCHOORMAN, 1995; RUSSEAU; SITKIN; BURT; CAMERER, 1998). Além disso, as definições de confiança têm sofrido evolução ao longo da última década e chegaram ao ponto em que alguma consistência nas definições pode ser alcançada, ao focá-las em três das suas possíveis dimensões: integridade/autoconfiança, habilidade/competência e benevolência (URBAN et al., 2009).

Comportamentos relacionados a confiança englobam todos os comportamentos em que um indivíduo, voluntariamente, depende de uma outra parte, sentindo-se relativamente seguro em faze-lo, mesmo diante de possíveis consequências negativas (MCKINGHT; CHERVANY, 2001). São comportamentos que implicam aceitação de risco (MAYER; DAVIS; SCHOORMAN, 1995), como aqueles que envolvem cooperação entre partes, troca 
de informações, aceitação de influência, redução de controle, concessão de autonomia e transações de negócios (MCKINGHT; CHERVANY, 2001).

Segundo a teoria de comprometimento-confiança (MORGAN; HUNT, 1994), o sucesso do marketing de relacionamento depende de comprometimento com a relação de confiança. Confiança e comprometimento se tornam fundamentais, porque encorajam a cooperação entre parceiros, a resistência a alternativas atrativas de curto prazo e a visão de ações potencialmente de alto risco como prudentes, devido à crença de que o parceiro não irá atuar de forma oportunista. Nesse contexto, confiança se torna o construto central em qualquer transação relacional e o determinante principal do comprometimento. Segundo Morgan e Hunt (1994), confiança é uma variável mediadora que reduz a percepção de incerteza envolvida na transação.

\section{2 \\ Confiança Online}

Usando definições baseadas em expectativa como ponto de partida, pesquisadores trabalharam sobre as definições uns dos outros e enfatizaram características específicas dos ambientes online para definir o construto confiança online. Conotações de integridade, confiabilidade, autoconfiança e benevolência, características da confiança em geral, foram preservadas em sua congênere online, mas novas conotações foram a elas adicionadas, tal como a credibilidade da página de internet (BART; SHANKAR; SULTAN; URBAN, 2005).

Entretanto, existem também importantes diferenças entre confiança online e offline no que diz respeito a seus objetos. Enquanto a confiança offline é direcionada apenas a indivíduos ou organizações, confiança online envolve a tecnologia (hardware, software e a própria Internet) e a entidade responsável por apresentá-la ao usuário (BOYD, 2003). Em suma, confiança online é construída quando indivíduos ou organizações formam impressões positivas sobre um meio de interação online e se dispõem a aceitar sua própria vulnerabilidade nessa interação. Outra diferença entre os dois tipos de confiança, segundo Doney e Cannon (1997), é que nas transações tradicionais (offline) a confiança é mediadora do processo de decisão, mas não do comportamento de compra. Já em transações online, pesquisas 
indicam que a confiança parece ter efeito direto tanto sobre a intenção de compra quanto sobre o comportamento do consumidor (SHANKAR; URBAN; SULTAN, 2002). Além disso, indivíduos que tenham participado previamente de transações online, ou que tenham interagido com outras organizações online, apresentam níveis de confiança totalmente distintos daqueles que nunca interagiram online (METZGER, 2006).

\section{3}

\section{Confiança Móvel}

Contextos móveis são similares a contextos online, mas não são exatamente iguais. Serviços móveis se apoiam em redes de telefonia celular e dispositivos móveis, como celulares com acesso à internet, tablets e smartphones, e possuem algumas características que não estão disponíveis para serviços similares online. Características como mobilidade, ubiquidade e oferta contextual são exclusivas dos contextos móveis (CHONG; CHAN; OOI, 2012; SHANKAR; BALASUBRAMANIAN, 2009; LEE, 2005; LIN et al., 2011). Por outro lado, limitações devidas a especificidades das redes de celular e dos dispositivos móveis, tais como velocidade de conexão reduzida, funções simplificadas e instabilidade da rede, se agrupam para construir incerteza e risco que representam, juntos, os maiores obstáculos ao uso de serviços e comércio móvel (LEE, 2005; LI; YEH, 2010; SHARIF et al., 2014; SIAU et al., 2004). Assim, construir confiança em contextos móveis é muito mais difícil do que em contextos online, mesmo que as mesmas definições e conotações do contexto online se apliquem diretamente ao contexto móvel (GIOVANNINI et al. 2015; JOUBERT; VAN BELLE, 2013; LI; YEH, 2010; LU et al., 2011; NILASHI et al. 2015; YEH; LI, 2009).

Com base na literatura sobre confiança e na teoria de comprometimentoconfiança, que coloca a confiança como mediadora central em transações quando o objetivo é a existência de um relacionamento duradouro entre as partes envolvidas, é proposta a seguinte hipótese:

Hipótese 1: A confiança nos serviços móveis de compras media os efeitos dos determinantes da adoção de inovações na adoção do comércio móvel pelo consumidor. 


\section{4 \\ As Diferentes Dimensões da Confiança no Comércio Móvel}

É comum que indivíduos depositem sua confiança em outros devido às inferências que fazem a respeito de atributos e características pessoais (MAYER; DAVIS; SCHOORMAN, 1995; MCKNIGHT; CHERVANY, 2001; YAMAGISHI; YAMAGISHI, 1994). Essas inferências são crenças de que a parte em que se confia possui características benéficas e se desdobram em quatro diferentes dimensões: Competência, Benevolência, Integridade (CHEN; DHILLON, 2003; FANG; GUO; ZHANG, 2015; MAYER; DAVIS; SCHOORMAN, 1995; MCKNIGHT; CHERVANY, 2001) e Previsibilidade (FANG; GUO; ZHANG, 2015; MCKNIGHT; CHERVANY, 2001).

Competência se refere à crença de que o outro, em quem se deposita confiança, tem a habilidade ou poder para fazer o que precisa ser feito ou é esperado (BARBER, 1983; CHEN; DHILLON, 2003; FANG; GUO; ZHANG, 2015; MAYER; DAVIS; SCHOORMAN, 1995; MCKNIGHT; CHERVANY, 2001). No caso de relações online, o consumidor acredita que o vendedor é capaz de fornecer os bens e serviços de forma adequada e conveniente (FANG; GUO; ZHANG, 2015; MCKNIGHT; CHERVANY, 2001;).

Benevolência é a crença de que o outro se importa e possui motivações para agir em função dos interesses e preferências daquele que está depositando a confiança nele (BARBER, 1983; MAYER; DAVIS; SCHOORMAN, 1995; GANESAN; HESS, 1997; MCKNIGHT; CHERVANY, 2001; CHEN; DHILLON, 2003; FANG; GUO; ZHANG, 2015). Um vendedor online benevolente não agirá de forma oportunista ou predatória (MCKNIGHT; CHERVANY, 2001; FANG; GUO; ZHANG, 2015).

Integridade se refere à crença de aquele em quem se confia age de boa-fé, fala a verdade e cumpre as promessas que faz (CHEN; DHILLON, 2003; FANG; GUO; ZHANG, 2015; MAYER; DAVIS; SCHOORMAN, 1995; MCKNIGHT; CHERVANY, 2001; MORGAN; HUNT, 1994). É o grau de conformidade com a norma, o código moral, ou os valores artísticos segundo o padrão vigente (MAYER; DAVIS; SCHOORMAN, 1995; FANG; GUO; ZHANG, 2015). Um vendedor 
online íntegro cumprirá suas promessas de entrega de produtos e serviços e de proteção das informações privadas a ele confiadas (FANG; GUO; ZHANG, 2015; MCKNIGHT; CHERVANY, 2001).

Previsibilidade é a crença de que as ações do outro, sejam boas ou ruins, são consistentes o suficiente para serem prognosticadas (FANG; GUO; ZHANG, 2015; MCKNIGHT; CHERVANY, 2001). Previsibilidade é uma dimensão neutra, diferente da integridade ou da benevolência. Indivíduos com alto grau desta crença acreditam que podem prever o comportamento futuro do vendedor online.

A combinação destas quatro crenças fornece uma base segura para o desenvolvimento de intenções de confiar e para comportamentos relacionados a confiança (MAYER; DAVIS; SCHOORMAN, 1995) como compras online e móveis. Alguns indivíduos e organizações possuem todas as quatro crenças, enquanto outros podem ser fortes em umas e fracos em outras. A importância de cada uma das características varia segundo o contexto (MCKNIGHT; CHERVANY, 2001).

\section{5 \\ Confiança, Atitude, Intenção e Comportamento de Compra}

A Teoria da Ação Racional (TRA) (AJZEN; FISHBEIN, 1980; FISHBEIN; AJZEN, 1975) fornece os fundamentos para a compreensão do relacionamento entre atitudes, intenções e comportamentos, e se baseia na premissa de que o ser humano toma decisões baseado na informação disponível. Segundo a teoria, o melhor determinante do comportamento de um indivíduo é sua intenção, que é a representação cognitiva da prontidão para se engajar em determinado comportamento. Os componentes desta intenção, de acordo com os autores, seriam a norma subjetiva, composta pela percepção do indivíduo de como suas figuras de referência encaram determinado comportamento e sua motivação para persegui-lo e a atitude. A atitude, por seu lado, é uma medida dos sentimentos do indivíduo em relação ao comportamento e é fruto das crenças do indivíduo e de suas avaliações sobre os possíveis resultados de assumir aquele comportamento. A Figura 2.1 ilustra os construtos componentes, assim como suas relações, segundo a Teoria da Ação Racional. 


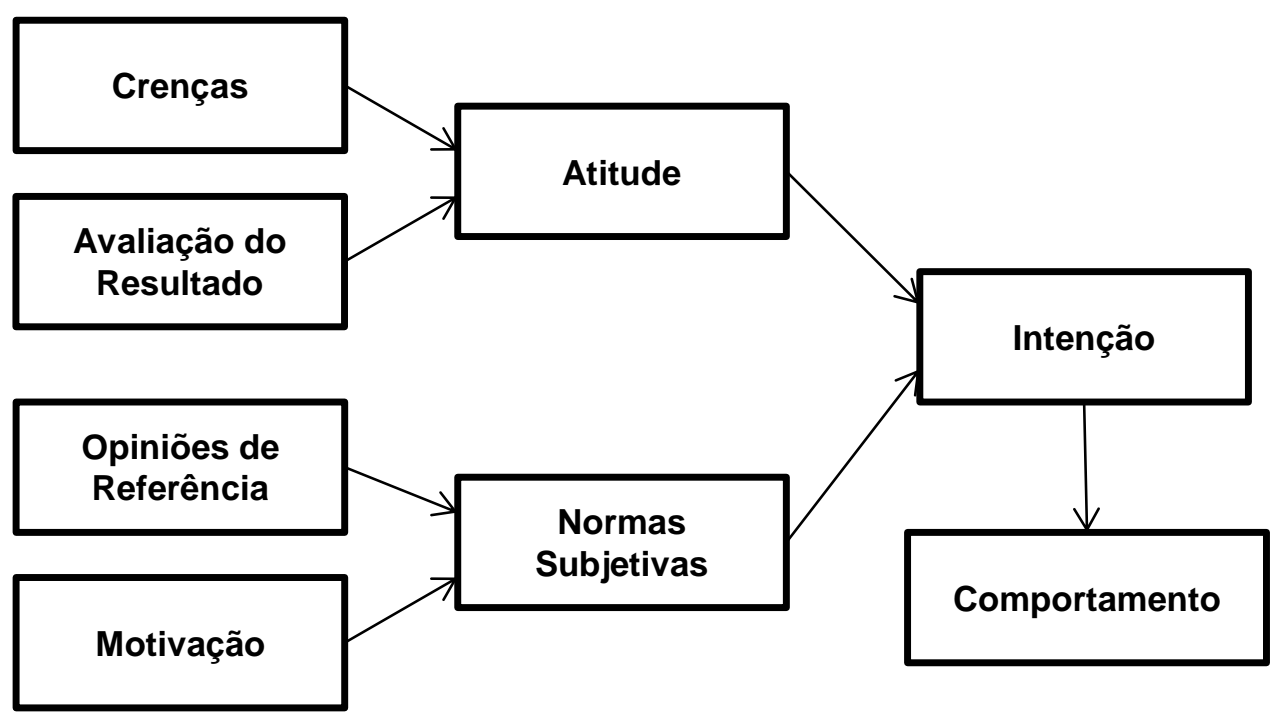

FIGURA 2. 1 - TEORIA DA AÇÃO RACIONAL (TRA) - FISHBEIN E AJZEN, 1975.

Rogers (2003) define adoção como uma decisão de fazer uso de uma inovação. No caso deste estudo, que foca na adoção do comércio móvel, o 'uso da inovação' seria o resultado de uma transação de compra e venda mediada por dispositivo móvel entre o adotante e um vendedor. Diversos fatores são utilizados na literatura como forma de medir a adoção de uma tecnologia e as consequências da confiança em atividades de negócios, entre eles estão a implementação, o uso, a satisfação, a lealdade, a intenção de compra, a intenção de uso e a atitude (ALJABRI; SOHAIL, 2012; KIM; PETERSON, 2017; XU; CENFETELLI; AQUINO, 2016). O comportamento de compra do consumidor é, obviamente, um fator importante na medição dos resultados de uma transação de compra e venda porque é determinante do desempenho financeiro do vendedor e uma medida mais direta do efeito do uso do comércio móvel do que a intenção de uso ou compra frequentemente utilizados como proxy em estudos acadêmicos (XU; CENFETELLI; AQUINO, 2016). Uma vez que a intenção não é suficiente para garantir a compra, este estudo utiliza não apenas a intenção de comprar via comércio móvel como um fator indicativo do comportamento de compra, mas também o montante gasto pelo indivíduo em transações via dispositivo móvel (FAQIH; JARADAT, 2015; KIM; MALHOTRA; NARASIMHAN, 2005; LIN; WANG; WANG, 2014; VENKATESH; BALA, 2008).

Com base na teoria de comprometimento-confiança, que põe a confiança como mediadora central em transações quando o objetivo é a existência de um 
relacionamento duradouro entre as partes envolvidas, e na teoria da ação racional, que propõe a atitude e a intenção comportamental como precursora do comportamento efetivo, são propostas as seguintes hipóteses:

Hipótese 2: A confiança nos serviços móveis de compras tem um efeito positivo e direto sobre a atitude do consumidor em adotar o comércio móvel.

Hipótese 2a: A dimensão benevolência tem um efeito positivo e direto sobre a atitude do consumidor em adotar o comércio móvel.

Hipótese 2b: A dimensão integridade tem um efeito positivo e direto sobre a atitude do consumidor em adotar o comércio móvel.

Hipótese 2c: A dimensão competência tem um efeito positivo e direto sobre a atitude do consumidor em adotar o comércio móvel.

Hipótese 3: A confiança nos serviços móveis de compras tem um efeito positivo e direto sobre a intenção do consumidor em adotar o comércio móvel

Hipótese 3a: A dimensão benevolência tem um efeito positivo e direto sobre a intenção do consumidor em adotar o comércio móvel.

Hipótese 3b: A dimensão integridade tem um efeito positivo e direto sobre a intenção do consumidor em adotar o comércio móvel.

Hipótese 3c: A dimensão competência tem um efeito positivo e direto sobre a intenção do consumidor em adotar o comércio móvel.

Hipótese 4: A atitude do consumidor em adotar o comércio móvel tem um efeito direto e positivo sobre a intenção do consumidor em adotar o comércio móvel.

Hipótese 5: A intenção do consumidor em adotar o comércio móvel tem um efeito direto e positivo sobre a adoção efetiva do comércio móvel pelo consumidor (frequência de compra e montante gasto). 


\section{6 \\ Construindo Confiança}

Estudos empíricos indicam que diversos fatores agem como influenciadores da confiança e das percepções de confiabilidade em interações online. Propensão a confiar, experiência e proficiência no uso da tecnologia, facilidade de uso percebida, qualidade da informação, características gráficas, presença social, customização e personalização, segurança e privacidade, garantia de terceiros, reputação, tamanho da organização e presença offline são antecedentes relevantes da confiança (BELDAD et al., 2010; URBAN et al., 2009). Pesquisadores também identificaram cinco categorias amplas nas quais se baseiam os determinantes da confiança do consumidor: personalidade, conhecimento, instituição, cognição e calculismo (LIN; LU; WANG; WEI, 2011; KIM; FERRIN; RAO, 2008; MCKNIGHT et al., 1998).

No que diz respeito aos serviços móveis, alguns estudos examinaram determinantes e consequentes da confiança. Os resultados indicam que (1) confiança em propaganda pode ser predita pela facilidade de uso e pela disposição para confiança (ZHANG; MAO, 2008), (2) confiança aumenta a intenção comportamental de aceitar propaganda em SMS (ZHANG; MAO, 2008), e (3) componentes da interatividade como controle, resposta, conectividade, ubiquidade e oferta contextual têm efeitos fortes e significativos sobre a confiança do consumidor (LEE, 2005).

\subsection{1}

\section{As Características da Inovação - A Compra por Dispositivos Móveis}

Rogers (2003) propôs pela primeira vez sua Teoria da Difusão de Inovações (DOI) em 1962. Nas décadas seguintes, seu modelo genérico para a difusão de inovações foi modificado e expandido (ROGERS, 2003), sendo utilizado frequentemente em uma variedade de campos de estudo e combinado a diferentes teorias (ZHANG; ZHU; LIU, 2012), inclusive a Teoria do Comportamento Planejado (TPB) (AJZEN, 1991; AJZEN; MADDEN, 1986), uma versão revisada e estendida da TRA (FISHBEIN; AJZEN, 1975; AJZEN; FISHBEIN, 1980). 
Segundo Rogers (2003), as características de uma inovação são o fator determinante central no seu processo de adoção e difusão. $O$ autor aponta cinco características distintas das inovações, vantagem relativa, compatibilidade, complexidade, testabilidade e observabilidade. Vantagem relativa é o grau com que uma inovação é percebida como sendo superior àquilo que vem substituir. Compatibilidade pode ser definida como o grau com que uma inovação é percebida como consistente em relação aos valores, experiência passada e necessidades do adotante em potencial. Complexidade representa o grau de dificuldade percebido no uso e compreensão da inovação pelo potencial adotante. Testabilidade se refere à possibilidade de experimentar a inovação de uma forma limitada antes de decidir adotá-la. Por fim, observabilidade é o grau com que os resultados de uma inovação são visíveis por outros indivíduos.

De forma similar ao TAM (DAVIS, 1989; DAVIS; BAGOZZI; WARSHAW, 1992), que tem suas bases construídas sobre a TRA, e suas extensões TAM2 (VENKATESH; DAVIS, 2000), UTAUT (VENKATESH; MORRIS; DAVIS; DAVIS, 2003) e TAM3 (VENKATESH; BALA, 2008), que têm suas bases construídas sobre a TPB, modelos mais tradicionalmente utilizados em estudos de adoção de tecnologias, a DOI apresenta construtos relacionados à percepção de facilidade de uso e à percepção de utilidade, complexidade e vantagem relativa. A similaridade entre os construtos complexidade e facilidade de uso, assim como entre vantagem relativa e utilidade, é clara (MOORE; BENBASAT, 1991). Assim, o presente estudo utiliza a facilidade de uso como forma de avaliar a percepção de complexidade da inovação. A integração da DOI com a TRA potencialmente fornece uma capacidade de prever e explicar o comportamento de adoção de tecnologias melhor do que a oferecida pelo TAM ou pela DOI separadamente.

Entretanto, apenas vantagem relativa, compatibilidade e complexibilidade (ou Facilidade de Uso) são consistentemente relacionados na literatura à adoção de inovações (ZHANG; ZHU; LIU, 2012). E a influência de cada uma destas três variáveis sobre a intenção, atitude e comportamento efetivo do indivíduo nunca é igual.

Características dos dispositivos móveis como mobilidade, ubiquidade, personalização, conectividade e oferta contextual poderiam ser vistas por seus 
usuários como vantagens relativas das transações comerciais feitas por meio destes dispositivos em relação às formas anteriores utilizadas pelo indivíduo para realizar compras de bens e serviços. Ao mesmo tempo, o uso de dispositivos móveis para a aquisição de bens e serviços pode estar em desacordo com os hábitos e processos de compra geralmente utilizados pelo indivíduo. Assim, são propostas as seguintes hipóteses:

Hipótese 6: A vantagem relativa dos dispositivos móveis tem efeito positivo e direto nas diferentes dimensões que compõem a confiança.

Hipótese 6a: A vantagem relativa dos dispositivos móveis tem efeito positivo e direto sobre a dimensão benevolência.

Hipótese 6b: A vantagem relativa dos dispositivos móveis tem efeito positivo e direto na dimensão competência.

Hipótese 6c: A vantagem relativa dos dispositivos móveis tem efeito positivo e direto na dimensão integridade.

Hipótese 7: A facilidade de uso dos dispositivos móveis tem efeito positivo e direto nas diferentes dimensões que compõem a confiança.

Hipótese 7a: A facilidade de uso dos dispositivos móveis tem efeito positivo e direto sobre a dimensão benevolência.

Hipótese 7b: A facilidade de uso dos dispositivos móveis tem efeito positivo e direto na dimensão competência.

Hipótese 7c: A facilidade de uso dos dispositivos móveis tem efeito positivo e direto na dimensão integridade.

Hipótese 8: A compatibilidade dos dispositivos móveis tem efeito positivo e direto nas diferentes dimensões que compõem a confiança.

Hipótese 8a: A compatibilidade dos dispositivos móveis tem efeito positivo e direto sobre a dimensão benevolência.

Hipótese 8b: A compatibilidade dos dispositivos móveis tem efeito positivo e direto na dimensão competência. 
Hipótese 8c: A compatibilidade dos dispositivos móveis tem efeito positivo e direto na dimensão integridade.

\section{7}

\section{Características do Produto}

Produtos podem ser categorizados de diversas maneiras, seja por seus atributos, origens ou fins. Entre as formas de classificar produtos e serviços encontradas na literatura estão as categorias produtos de negócios versus produtos de consumo, bens tangíveis versus bens intangíveis, bens de crédito versus bens de experiência versus bens de busca, produtos de alto custo versus produtos de baixo custo, bens de conveniência versus bens de consumo versus bens de especialidade, entre outras (HASSANEIN; HEAD, 2005; MAITY; DASS, 2014). Qualquer que seja a categoria em que se encontre o produto (ou serviço) a ser adquirido, este terá influência sobre o comportamento de compra e a atitude do consumidor (BABIN; DARDEN; GRIFFIN, 1994; PARK; LEE, 2009; PARK; MOON, 2003).

Embora existam diversas maneiras de categorizar produtos, uma delas é particularmente pertinente por ser parcimoniosa e representar ambos os extremos dos tipos de produto que define: a distinção entre produtos de busca e de experiência. Para os fins desta investigação, quando houver referência ao tipo de produto utiliza-se a categorização produtos de busca versus produtos de experiência.

\subsection{1}

\section{Efeitos Moderadores do Tipo de Produto - Produtos de Busca ou de Experiência}

Nelson $(1970 ; 1974)$ classifica os produtos em duas categorias, 'busca' e 'experiência', com base no grau em que a busca pré-compra possibilita ao consumidor formar uma avaliação do produto. Produtos de busca têm atributos de fácil avaliação, geralmente objetivos, cuja informação é encontrada facilmente para inspeção antes da compra, como tamanho ou peso (HSIEH; CHIU; CHIANG, 2005; HUANG; LURIE; MITRA, 2009; MUDAMBI; SCHUFF, 2010; MAITY; DASS, 2014; LU; CHANG; CHANG, 2014). Isso permite ao consumidor avaliar em 
primeira mão as características do produto antes da compra. Exemplos de bens de busca incluem câmeras fotográficas, telefones celulares e computadores. Em oposição, produtos de experiência têm atributos cuja avaliação é complexa, ineficiente ou inadequada, porque as informações sobre seus atributos são relativamente difíceis e custosas de obter ou exigem a utilização dos sentidos, como conforto ou sabor (WEATHERS; SHARMA; WOOD, 2007; MUDAMBI; SCHUFF, 2010; MAITY; DASS, 2014; LU; CHANG; CHANG, 2014). Os atributos base dos produtos de experiência são subjetivos, o que obriga o consumidor a avaliar o produto somente após a sua compra ou consumo. Exemplos de produtos de experiência incluem vídeo games e pacotes turísticos.

Consumidores tendem a tomar decisões de compra com base na informação em que depositam mais confiança (CHEN; WANG; XIE, 2011; CHEUNG; XIAO; LIU, 2014). Selecionando produtos de busca o consumidor tem maior probabilidade de obter as informações específicas sobre os principais atributos daquele produto, o que pode alterar suas percepções sobre o mesmo (PARK; LEE, 2009; KING; BALASUBRAMANIAN, 1994). Por outro lado, ao decidir por um produto de experiência, o consumidor fica impossibilitado de obter informações específicas sobre os atributos de interesse daquele produto, o que o levará a dar mais importância a informações que venham sob a forma de recomendações.

Diversos estudos sugerem que atributos de busca e de experiência atuam como moderadores entre construtos antecedentes e o comportamento e atitude do consumidor (MAUTE; FORRESTER, 1991; BONE, 1995; HSIEH et al. 2005; PARK; LEE, 2009; HUANG; LURIE; MITRA, 2009; MAITY; DASS, 2014).

O presente estudo propõe que o tipo de produto atua como moderador das relações entre a confiança e a atitude do consumidor em relação ao uso de dispositivos móveis para compras, entre a confiança e a intenção de compra via dispositivos móveis e entre a intenção de compra via dispositivos móveis e o comportamento de compra efetivo do consumidor. Assim, são propostas as hipóteses:

Hipótese 9: O tipo de produto modera as relações entre a confiança e a atitude de compra do consumidor, de tal forma que os efeitos das dimensões da confiança sobre a atitude do consumidor em relação a comprar via dispositivos móveis serão 
menores para produtos de busca do que para produtos de experiência, por estes serem mais facilmente avaliados durante o processo de decisão de compra exigindo menos confiança no vendedor.

Hipótese 10: $\mathrm{O}$ tipo de produto modera as relações entre a confiança e a intenção de compra do consumidor, de tal forma que os efeitos das dimensões da confiança sobre a intenção de compra serão menores para produtos de busca do que para produtos de experiência, por estes serem mais facilmente avaliados durante o processo de decisão de compra exigindo menos confiança no vendedor.

Hipótese 11: O tipo de produto modera as relações entre intenção de compra e comportamento real de compra, de tal forma que os efeitos da intenção de compra sobre o comportamento real de compra são maiores para produtos de busca do que para produtos de experiência, por estes serem mais facilmente avaliados durante o processo de decisão de compra.

\section{8 \\ Modelos e Hipóteses}

Este estudo apresenta três diferentes modelos teóricos para adoção e uso de dispositivos móveis para compras envolvendo a confiança como construto mediador. Todos os três modelos também consideram os efeitos moderadores do tipo de produto ofertado, de busca ou de experiência. Os modelos foram desenvolvidos com base nas mesmas hipóteses extraídas do referencial teórico apresentada, porém abordam o construto confiança de forma diferenciada.

A primeira versão do modelo, denominada Dimensões da Confiança explora as três dimensões da confiança separadamente, permitindo que sejam analisados os impactos sofridos por e causados em cada dimensão. A segunda versão do modelo, denominada Confiança de Segunda Ordem (Figura 2.3), aplica o conceito de construto de segunda ordem, utilizando as três dimensões como indicadores do construto confiança e fornecendo uma análise holística da confiança sem, no entanto, ignorar as suas diferentes dimensões. A terceira versão, denominada Confiança Geral (Figura 2.4), utiliza um construto holístico para confiança, em que as diferentes dimensões estão contraídas em uma série de itens gerais e, portanto, 
eliminando a importância individual de cada dimensão. O presente estudo compara as três versões do modelo a fim de identificar a mais apropriada na explicação do comportamento do consumidor diante da adoção de dispositivos móveis para a realização da compra de produtos e serviços.

A Figura 2.2 apresenta a versão Dimensões da Confiança do modelo MCTF2 (Mobile Commerce Trust Formation 2) e as figuras 2.3 e 2.4 apresentam respectivamente os modelos rivais, Confiança de Segunda Ordem e Confiança Geral.

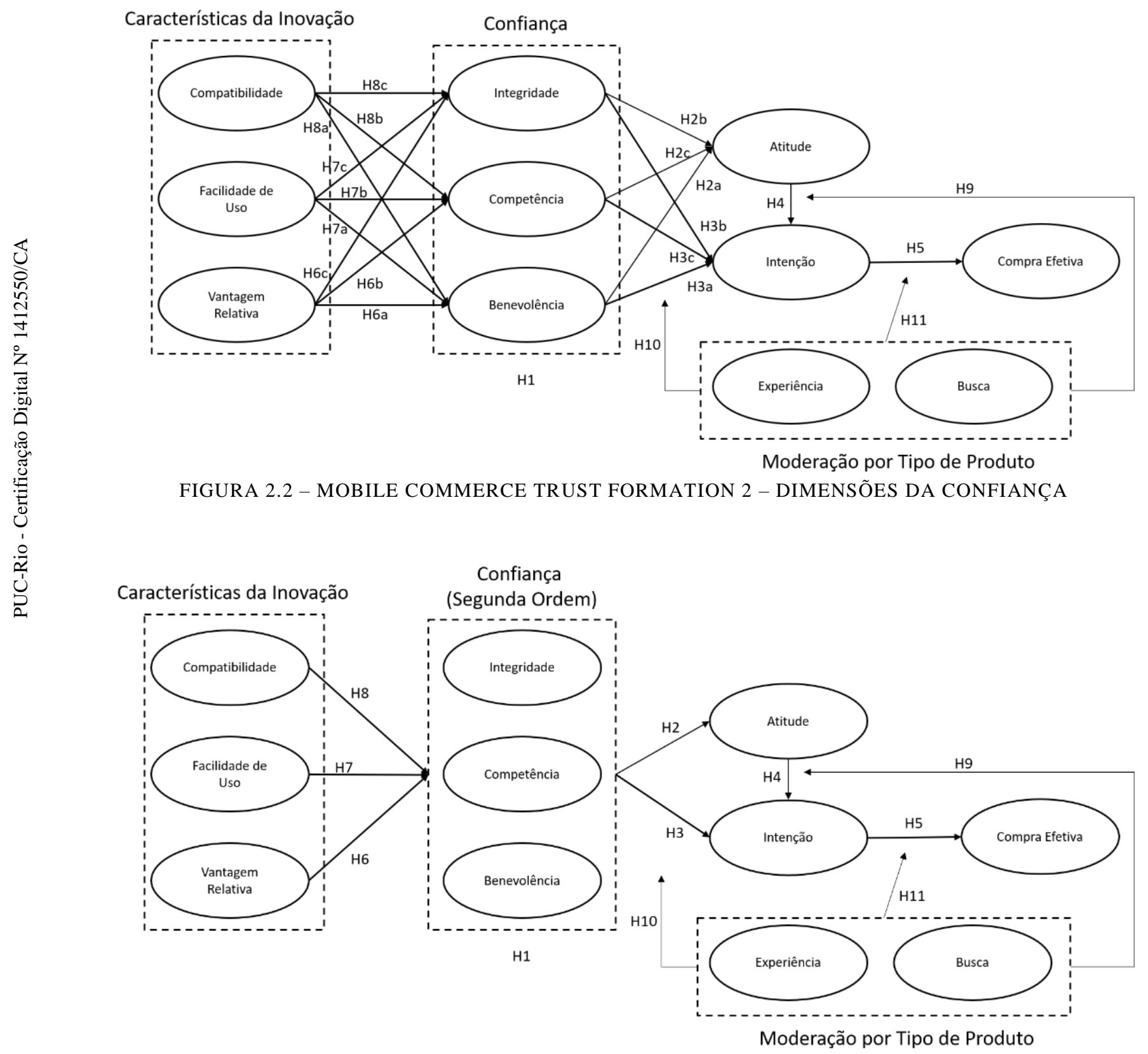

FIGURA 2.3 - MOBILE COMMERCE TRUST FORMATION 2 - CONFIANÇA DE SEGUNDA ORDEM 


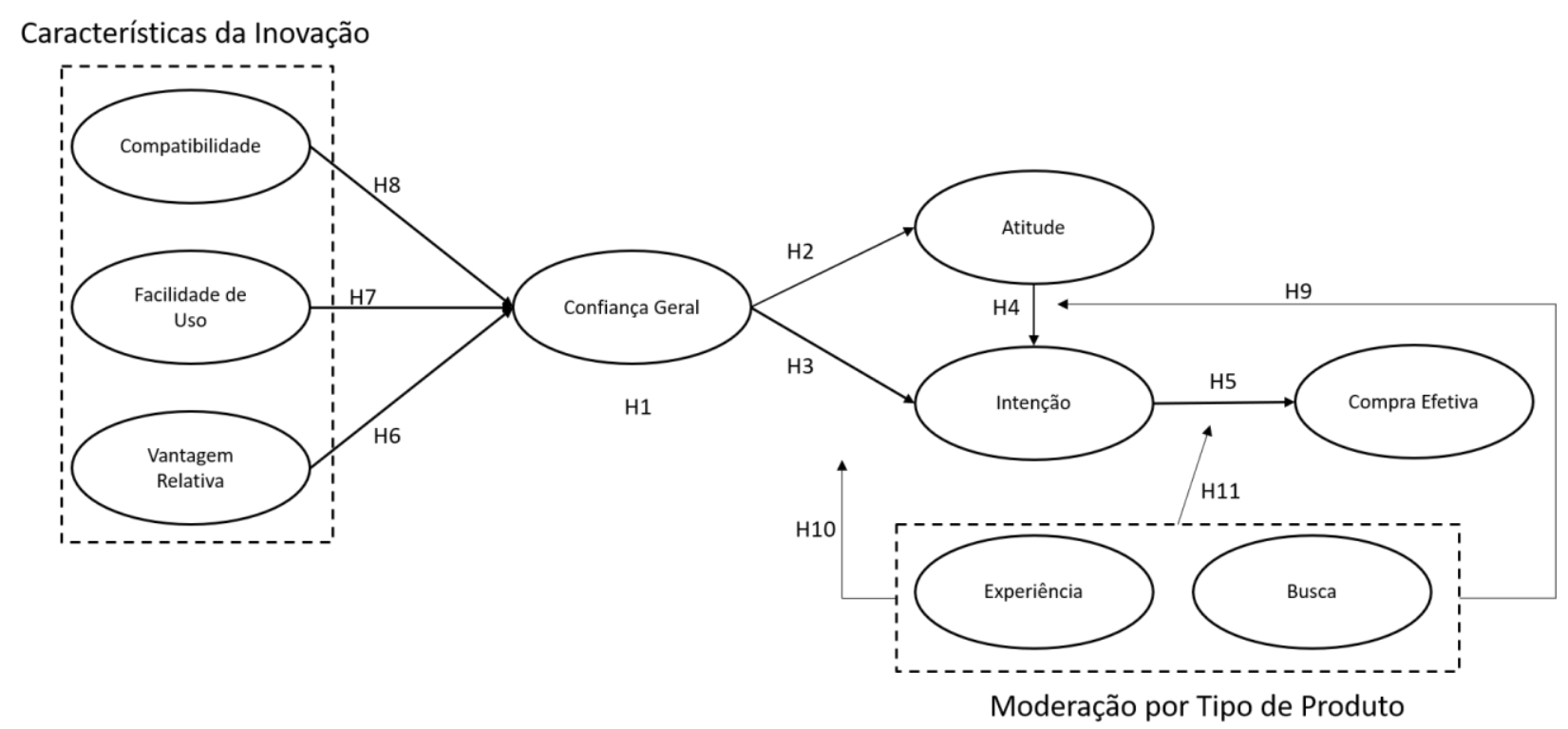

FIGURA 2. 4 - MOBILE COMMERCE TRUST FORMATION 2 - CONFIANÇA GERAL 


\section{3 \\ Metodologia}

Este capítulo descreve a metodologia adotada na execução do trabalho e delimita o escopo dos processos envolvidos. O capítulo apresenta o tipo de pesquisa realizado, a população e a amostra estudadas, o processo de amostragem utilizado, os construtos mensurados e as escalas escolhidas para as variáveis que os definem. Descreve-se o método utilizado para a coleta de dados e as técnicas e procedimentos empregados para o tratamento e análise dos dados. Ao final do capítulo encontramse as limitações inerentes aos métodos escolhidos.

\section{1}

\section{Tipo de pesquisa}

Com o objetivo de realizar o teste das hipóteses formuladas para o estudo realizou-se um levantamento de corte transversal (cross-sectional survey research) com uma amostra não probabilística da população de interesse.

Um levantamento é uma abordagem de coleta e análise de dados na qual indivíduos respondem a questionários contendo perguntas ou afirmações estruturadas previamente (CHURCHILL; IACOBUCCI, 2009; HAIR et al, 2007; PINSONNEAULT; KRAEMER, 1993; BABBIE, 1990). Levantamentos são capazes de caracterizar o conhecimento, as atitudes, as tendências, as opiniões e os comportamentos de grandes agrupamentos de indivíduos com base nas informações obtidas a partir de um subgrupo (CRESWELL, 2009; LEEUW; HOX, 2012; HAIR et al., 2007; KROSNICK, 1999; PINSONNEAULT; KRAEMER, 1993; BABBIE, 1990), ou seja, levantamentos permitem ao pesquisador generalizar os achados sobre atitudes e comportamentos humanos para um grupo de indivíduos maior do que aquele originalmente estudado.

Segundo Pinsonneault e Kraemer (1993), levantamentos utilizados em pesquisas científicas possuem três características distintas e centrais. A primeira é o propósito de fornecer descrições quantitativas de algum aspecto da população sendo estudada. A segunda é que o principal método de coleta de dados consiste de os respondentes fornecerem respostas a questões pré-definidas e estruturadas, que 
podem ser sobre o respondente em si, ou sobre outra unidade de análise. As respostas assim obtidas são a base de dados para a análise posterior. A terceira característica dos levantamentos é que os dados são coletados de uma parcela da população de interesse, ou seja, por meio de amostragem, de tal forma que os achados possam ser generalizados para a população como um todo.

Levantamentos podem ser transversais, permitindo uma descrição da população naquele momento, ou longitudinais, que permitem que o efeito de um fenômeno sobre dada população seja determinado ao realizar coletas de dados antes e depois da ocorrência do fenômeno (PINSONNEAULT; KRAEMER, 1993). Este estudo em particular não tem seu foco nos efeitos da adoção do comércio móvel na população de interesse, e sim na explicação dos antecedentes da intenção comportamental, mediados pela confiança, de adotar o comércio móvel. Assim sendo, optou-se por um levantamento transversal.

O propósito central de um levantamento, seja ele exploratório, descritivo ou explicativo, define a abordagem utilizada no tratamento e análise dos dados. Levantamentos explicativos, como o que se realiza neste trabalho, são focados nas relações entre as variáveis e são utilizados para testar teorias e causalidade (PINSONNEAULT; KRAEMER, 1993). Entretanto, para que isso seja possível, é necessária uma sólida base teórica que explicite o tipo (positivo ou negativo) e a direção (A influencia B) das relações entre as variáveis (PINSONNEAULT; KRAEMER, 1993).

A relevância do levantamento, para este estudo, pode ser melhor verificada diante de suas características e vantagens. Uma vez que levantamentos envolvem a análise de um fenômeno claramente definido pela relação entre grupos de variáveis numa variedade de ambientes naturais, sua aplicação é mais apropriada para (1) responder questões sobre 'o que', 'quanto' (HAIR et al., 2007; PINSONNEAULT; KRAEMER, 1993); (2) identificar relações entre variáveis (HAIR et al., 2010; HAIR et al., 2007); (3) determinar diferenças entre grupos (HAIR et al., 2007); (4) estudar conceitos e relações que não são diretamente mensuráveis (HAIR et al., 2010; HAIR et al., 2007; LEEUW; HOX, 2008); (5) estudar situações onde o controle de variáveis dependentes e independentes não é possível ou desejado (PINSONNEAULT; KRAEMER, 1993). 
Além disso, a maior parte dos estudos sobre difusão e aceitação de tecnologia por consumidores, assim como sobre a influência da confiança no comportamento de compra do indivíduo, utilizam levantamentos de corte transversal (CHILDERS et al., 2001; GARBARINO; JOHNSON, 1999; KUAN; BOCK, 2007; KULVIWAT et al., 2007; LIN et al., 2011; NASCO et al., 2008; YOUSAFZAI et al., 2007).

A pesquisa foi realizada por meio de questionários administrados via Internet (AAKER et al., 2006; BRADLEY et al., 1999), mais especificamente por meio da distribuição de links na rede social Facebook (CALLEGARO; MANFREDA; VEHOVAR, 2015). Os links foram distribuídos através de um perfil organizacional, que obteve respondentes de forma orgânica e através de anúncios veiculados na própria plataforma do Facebook, e por meio de contatos pessoais, que foram requisitados a redistribuir o link da pesquisa em suas redes pessoais (snowballing). O questionário foi apresentado a indivíduos que já tem acesso à Internet e uma questão filtro selecionou aqueles que tem acesso a um dispositivo móvel (celular, smartphone ou tablet) e já tivessem realizado pelo menos uma compra por meio de um destes dispositivos móveis, de maneira a garantir que estes todos tivessem familiaridade com a tecnologia em estudo e seu uso antes do preenchimento do questionário. Desta forma, segundo Kulviwat et al. (2007), os respondentes estariam mais aptos a formar avaliações cognitivas sobre suas funcionalidades e já teriam experimentado à tecnologia e ao seu uso em primeira mão.

\section{2}

\section{Universo e amostra}

Para testar as hipóteses descritas, a amostragem tem as seguintes características:

1. Unidade amostral: consumidor brasileiro individual, usuário de dispositivo móvel com acesso à internet (smartphones, tablets e celulares com acesso à internet), com idade entre 18 e 75 anos e residente na cidade do Rio de Janeiro. 
2. População alvo: consumidores brasileiros economicamente ativos, na faixa entre 25 e 65 anos de idade, com acesso a sites ou aplicativos de compras por meio de smartphones, tablets ou celulares.

3. Amostra: não probabilística por conveniência.

O estudo faz uso de uma amostragem não probabilística por conveniência, uma vez que não foi viável ter acesso a todos os brasileiros que usam seus dispositivos móveis para acessarem a internet ou aplicativos de compras, o que, segundo Parasuraman et al. (2006), seria necessário para uma seleção aleatória adequada.

Realizou-se uma amostragem por convite aberto via perfil organizacional e anúncios no Facebook (CALLEGARO; MANFREDA; VEHOVAR, 2015). O Facebook é o quarto website mais acessado do Brasil (Google.com.br em primeiro, o YouTube em segundo e Google.com em terceiro), de acordo com o site de insight analítico Alexa.com (acesso em 30 de setembro de 2017), o que justificaria a sua escolha como ponto de distribuição dos convites. Além disso o Facebook possui tanto versão de aplicativo para celular quanto versão web compatível com celulares que não possuem acesso a aplicativos, o que deve facilitar o acesso da população de interesse ao link da pesquisa.

Em termos práticos, a diferença entre uma amostra probabilística e uma não probabilística é que a última não usa procedimentos randômicos na seleção da amostra (HAIR et al., 2010; LEEUW; HOX., 2008). Entretanto isso não significa, necessariamente, que a amostra não é representativa da população e sim que não existem bases estatísticas para garantir a sua representatividade (KROSNICK, 1999; LEEUW; HOX, 2008;). Generalizações, portanto, só poderiam ser feitas para populações com as mesmas características da população estudada.

No caso de pesquisas feitas pela internet existem inúmeras soluções para os problemas de amostragem. Cada um dos métodos ou técnicas existentes tem suas próprias vantagens e desvantagens e suas descrições encontram-se, em sua maioria, disponíveis em livros texto sobre estatística e pesquisa de marketing. Cabe a esta pesquisa descrever somente os métodos por ela utilizados: amostragem por conveniência e snowballing. 


\subsection{1}

\section{Amostragem por Conveniência e Snowballing}

Como o nome indica, uma amostragem por conveniência tem seus sujeitos selecionados de acordo com a conveniência do pesquisador. Este usualmente escolhe sujeitos prontamente disponíveis, próximos ou desejosos de participar. Essa amostra tem a tendência de oferecer menor variedade que a população de interesse, porque costuma deixar de fora quaisquer extremos que não estejam imediatamente disponíveis (BLACK, 2010; HAIR et al., 2009; BRADLEY et al.,1999).

Segundo Morgan (2008) e Goodman (1961), a amostragem por bola-deneve (Snowball sampling) é uma técnica de amostragem não probabilística em que sujeitos participantes em um estudo recrutam outros sujeitos dentre indivíduos pertencentes a sua rede de contatos. Conforme o número de participantes cresce, o número de conexões possíveis também se expande. Dessa forma, a amostra parece crescer de maneira similar a uma bola-de-neve rolando declive abaixo. A amostra ganha volume, tornando possível coletar informação pertinente ao estudo de populações, sobretudo aquelas de difícil acesso.

\section{Usuários de Redes Sociais}

Quando se considera o uso de amostragem por bola-de-neve cresce a relevância das redes sociais, sobretudo daquelas acessíveis online. As conexões possíveis por meio das redes sociais potencializam o processo de obtenção de informação por snowballing, tornando a técnica mais eficaz e reduzindo custos de pesquisa (NOY, 2008; BROWNE, 2005).

\subsection{2}

\section{Eliminação de Questionários Irrelevantes}

O termo 'sifting' ou 'peneirar', introduzido por Farmer (1998), designa o processo de rejeitar respostas que não se enquadrem em determinadas condições, ‘filtrando' ou 'peneirando' os questionários obtidos. É recomendada quando o pesquisador aceita que qualquer respondente interessado em participar do estudo o faça, de modo a que se possa chegar a uma melhor composição final da amostra. 
Os critérios utilizados para filtrar os questionários recebidos foram: a realização da compra de um dos produtos listados por meio de um dispositivo móvel (telefone celular, smartphone ou tablet) e a completude do questionário.

\section{3}

\section{Coleta de Dados}

Os dados foram coletados por meio de questionários auto administrados (AAKER et al., 2006; FINK, 2012) online, acessados por meio de links diferenciados disponibilizados por meio de um website de rede social, o Facebook (CALLEGARO; MANFREDA; VEHOFAR, 2015). Os questionários foram distribuídos por meio de postagens em um perfil organizacional, um perfil pessoal e anúncios veiculados apenas para brasileiros maiores de dezoito anos (contendo o link para o questionário). Ambas as postagens do Facebook incluíam um pedido para que o recipiente compartilhasse uma cópia da mensagem com outros indivíduos pertencentes a sua rede de contatos.

É importante apontar que links diferentes foram utilizados para a coleta de dados, separando os respondentes provindos de conexões pessoais daqueles oriundos dos anúncios e permitindo que os diferentes grupos fossem testados separadamente a fim de verificar se havia diferenciação entre eles.

Apesar dos possíveis problemas envolvendo amplitude e tendenciosidade, levantamentos realizados via Internet levam vantagem sobre os métodos tradicionais de preenchimento em termos de velocidade, custo e eficiência (ALBAUM et al., 2010). Miller (2006) afirma que, devido ao anonimato oferecido pelos levantamentos por meio da Internet, os respondentes se sentem livres para expressar suas verdadeiras atitudes e opiniões e são menos influenciados pelos entrevistadores, reduzindo viéses oriundos de respostas socialmente inaceitáveis, conformismo e respostas extremas.

Além disso, um dos princípios amplamente utilizados em levantamentos via Internet é a resposta forçada, que virtualmente elimina a possibilidade de itens omissos, sem, entretanto, afetar as taxas de conclusão de um levantamento ou a opinião de respondente sobre o mesmo (ALBAUM et al, 2010). A possibilidade de 
eliminar omissões nas respostas é obviamente uma vantagem extra, justificando o uso da resposta forçada no instrumento de coleta de dados.

O instrumento de pesquisa (Apêndice A) foi distribuído através de link anônimo divulgado em redes sociais Facebook), ao longo de duas semanas de coleta de dados. O processo de coleta de dados foi iniciado em 26 de março de 2018 e terminado em 7 de abril de 2018. A participação foi voluntária e confidencial. Além disso, era esperado que os respondentes tivessem experiência e/ou familiaridade no uso de dispositivos móveis.

Dos 598 respondentes 63 foram eliminados devido a não atenderem ao requisito de terem realizado pelo menos uma compra de produto ou serviço utilizando um dispositivo móvel. Assim, a amostra final foi composta por 535 questionários válidos.

\subsection{1 \\ Instrumento de coleta de dados - Questionário Online}

Conforme especificado anteriormente, o instrumento de pesquisa é composto por 37 itens oriundos de construtos cognitivos. Além desses itens, o questionário também inclui 16 itens para medir variáveis demográficas e comportamentais dos respondentes (AAKER et al., 2006), totalizando 51 itens. Uma reprodução para impressão do questionário online encontra-se no Apêndice A.

\subsection{2}

\section{Escolha do tipo de produto avaliado}

Uma decisão importante para o estudo é a escolha do produto a ser avaliado pelos consumidores e sobre o qual respondem ao preencherem o questionário.

Aplicativos e websites acessíveis via dispositivos móveis que oferecem serviços e produtos que possam ser divididos por tipo de produto foram pesquisados a fim de fornecer uma base para fazer a escolha dos produtos a serem analisados. Primeiramente, foram selecionados os websites de comércio mais prevalentes entre os 150 sites mais visitados pelos consumidores brasileiros segundo a empresa de insight analítico Alexa.com (acesso em 30 de setembro de 2017), de forma a 
identificar produtos e serviços que tenham apelo para consumidores do e-commerce e do m-commerce e que estejam disponíveis para comprar online tanto por websites quanto por aplicativos de celular. Em seguida, foi verificado se existiam versões dos sites para dispositivos móveis e aplicativos disponíveis para as diferentes plataformas. Os resultados foram inicialmente agrupados em tangíveis, para produtos com características tangíveis claras, e em intangíveis, para serviços e produtos digitais.

Tabela 3.1 - Produtos Digitais e Serviços

\begin{tabular}{c|c}
\hline Categoria & Aplicativo ou site onde adquirir \\
\hline Viagens de avião e Hotéis & Hotel Urbano, Decolar.com, \\
& Booking.com \\
\hline Livros & Amazon.com, amazon.com.br, \\
& saraiva.com.br \\
\hline Música & Spotify, iTunes, \\
\hline
\end{tabular}

Tabela 3.2 - Produtos Tangíveis

\begin{tabular}{c|c}
\hline Categoria & Aplicativo ou site onde adquirir \\
\hline Livros & Amazon.com, amazon.com.br, \\
& saraiva.com.br \\
\hline Roupas e sapatos & Dafiti.com, netshoes.com \\
\hline Refeições (delivery) & iFood, SpoonRocket \\
\hline Eletrônicos (televisores, celulares, & Americanas.com, submarino.com, \\
Womputadores) & $\begin{array}{c}\text { casasbahia.com.br, pontofrio.com.br, } \\
\text { magazineluiza.com.br }\end{array}$ \\
\hline
\end{tabular}


Esta pré-seleção de produtos e serviços foi então verificada em um pré-teste online (a metodologia de coleta de dados foi a mesma utilizada para a pesquisa principal com um total de 107 respondentes) envolvendo a população-alvo, no qual os participantes indicaram sua habilidade de avaliar o desempenho e os atributos de importância de cada item pré-selecionado em duas situações, antes e depois de comprarem ou utilizarem aquele item. Uma escala tipo Likert de sete pontos, indo de 1 (discordo fortemente) a 7 (concordo completamente) com dois itens ("Eu consigo avaliar bem este produto antes de experimentá-lo"; "Eu só consigo avaliar bem este produto depois de experimentá-lo") desenvolvida com base na escala utilizada por Lu, Chang e Chang (2014) foi utilizada na seleção final dos produtos a serem avaliados pelos respondentes.

Produtos e serviços com médias relativamente altas em ambas as escalas utilizadas ("antes de experimentar" e "depois de experimentar") foram classificados como bens de busca, uma vez que os consumidores podem mais facilmente avaliar o desempenho deles com base em informações sobre seus atributos básicos, que são mais objetivos e menos dependentes do uso dos sentidos, tendo-os comprado ou não (LU; CHANG; CHANG, 2014; MUDAMBI; SCUFF, 2010; ZEITHAML, 1981). Por sua vez, produtos e serviços com médias relativamente baixas na escala "antes" e relativamente altas na escala "depois" foram considerados bens de experiência. (KRISHNAN; HARTLINE, 2001; LU; CHANG; CHANG, 2014; MAITY; DASS, 2014), refletindo a dificuldade de se obter informações sobre o desempenho do produto antes do seu uso, uma vez que seus atributos básicos são mais subjetivos e difíceis de comparar, muitas vezes requerendo o uso dos sentidos na avaliação (LU; CHANG; CHANG, 2014; MUDAMBI; SCUFF, 2010; ZEITHAML, 1981).

A amostra para este pré-teste contém 107 respondentes e foi obtida através de metodologia de coleta similar à empregada para o resto do estudo, a distribuição de links para o questionário por meio do Facebook e do Google, sendo 26 respondentes oriundos do Google e 81 do Facebook. O questionário esteve disponível durante três dias no mês de janeiro de 2018.

Com base nos resultados de um Teste $\mathrm{T}$ de amostra em pares, pode-se concluir que (1) as médias para "antes de experimentar" e "depois de experimentar" são 
diferentes para cada produto avaliado; (2) as médias para "antes de experimentar" são menores do que as médias para "depois de experimentar", para cada um dos produtos avaliados; e (3) consistente com a teoria de que produtos de busca são mais fáceis de avaliar do que produtos de experiência (KRISHNAN; HARTLINE, 2001; LU; CHANG; CHANG, 2014; MUDAMBI; SCHUFF, 2010), a diferença entre as médias de "antes de experimentar" e "depois de experimentar" foram menores para os produtos de busca do que para os produtos de experiência (refletindo os resultados "antes de experimentar" alto e "depois de experimentar" alto dos produtos de busca e "antes de experimentar" baixo e "depois de experimentar" alto dos produtos de experiência).

Embora a tipologia de produto de busca e experiência seja bastante relevante como forma de categorizar produtos (HUANG et al. 2009; LU; CHANG; CHANG, 2014; MAITY; DASS, 2014; MUDAMBI; SCHUFF, 2010), existem divergências entre pesquisadores na categorização de produtos que não aparecem na lista original de Nelson (1970, 1974), particularmente considerando a contribuição da Internet para confundir os limites entre produtos de busca e produtos de experiência ao permitir aos consumidores acesso às experiências de outros consumidores, comparando e compartilhando informação a custos reduzidos (MUDAMBI; SCHUFF, 2010; WEATHERS et al., 2007). Quando se considera que a divisão entre produtos de busca e de experiência não é bipolarizada, mas sim um contínuo que vai de produtos puramente de busca até produtos puramente de experiência, então é preciso cuidado em evitar produtos que possam ser difíceis de classificar (MUDAMBI; SCUFF, 2010; ZEITHAML, 1981). Dessa forma, produtos que aparentam estar posicionados no centro foram classificados em um terceiro grupo e eliminados do processo de agrupamento para a moderação no questionário final, embora apareçam como opções viáveis entre os produtos que os respondentes já adquiriram em compras via dispositivos móveis. Os produtos e serviços préselecionados para o estudo, e que passaram pelo pré-teste foram classificados e os resultados estão organizados no quadro 3.1 . 


\section{Quadro 3.1 - Classificação Final dos Produtos}

\begin{tabular}{|c|c|c|c|c|c|}
\hline Produto & $\begin{array}{l}\text { Média } \\
\text { "antes" }\end{array}$ & $\begin{array}{l}\text { Média } \\
\text { "depois" }\end{array}$ & $\begin{array}{l}\text { p-valor } \\
\text { (teste t) }\end{array}$ & $\begin{array}{c}\text { Desvio } \\
\text { (diferença } \\
\text { entre as } \\
\text { médias) }\end{array}$ & Classificação \\
\hline Televisores & 4,24 & 5,12 & 0,004 & 0,88 & Busca \\
\hline Livros & 3,30 & 5,38 & $<0,000$ & 2,08 & Central/Removido \\
\hline Refeições & 3,38 & 5,98 & $<0,000$ & 2,06 & Central/Removido \\
\hline Computadores & 3,94 & 5,36 & $<0,000$ & 1,42 & Busca \\
\hline Sapatos & 3,28 & 5,97 & $<0,000$ & 2,69 & Experiência \\
\hline Hotéis & 3,57 & 5,89 & $<0,000$ & 2,32 & Experiência \\
\hline Música & 2,98 & 5,92 & $<0,000$ & 2,94 & Experiência \\
\hline Smartphones & 3,65 & 6,01 & $<0,000$ & 2,36 & Experiência \\
\hline Roupas & 3,83 & 5,51 & $<0,000$ & 1,68 & Busca \\
\hline $\begin{array}{l}\text { Passagens de } \\
\text { avião }\end{array}$ & 3,68 & 5,62 & $<0,000$ & 1,94 & Busca \\
\hline
\end{tabular}

\subsection{3}

\section{Operacionalização das variáveis}

O estudo faz uso de escalas já elaboradas e testadas na literatura, ou de adaptações de escalas existentes para a medição de todos os construtos envolvidos na estrutura do modelo. Essa decisão foi tomada por três motivos:

1. As escalas já existentes para a medição de construtos foram testadas e refinadas em múltiplos estudos ao longo dos anos, apresentando boas propriedades psicométricas.

2. Utilizando as mesmas escalas escolhidas e usadas por outros pesquisadores em seus estudos para medir os mesmos construtos, este estudo mantém consistência com resultados anteriormente obtidos pela literatura, permitindo comparação.

3. Construtos que ainda não tenham uma escala específica para seu uso em comércio móvel podem ser adaptados quando similares, de forma a garantir que a 
estrutura e as propriedades do construto, assim como suas dimensões, se mantenham próximas às escalas originais e de acordo com a teoria.

O quadro 3.2 apresenta em detalhe as escalas utilizadas para a medição de cada construto, assim como os itens correspondentes a eles no questionário (Apêndice A). A tabela 3.3 apresenta as variáveis usadas para controle da amostra, assim como os itens correspondentes a elas no questionário (Apêndice A). Por fim, a tabela 3.4 apresenta as variáveis demográficas e os itens correspondentes a elas no questionário (Apêndice A). 


\begin{tabular}{|c|c|c|}
\hline Construto & Itens da escala & $\begin{array}{c}\text { Tipo de escala e medidas } \\
\text { operacionais }\end{array}$ \\
\hline $\begin{array}{c}\text { Vantagem Relativa } \\
\text { (VAR) }\end{array}$ & $\begin{array}{l}\text { 1. Usar um dispositivo móvel (smartphone, celular ou tablet) me permite } \\
\text { comprar com maior rapidez. } \\
\text { 2. Usar um dispositivo móvel (smartphone, celular ou tablet) melhora a } \\
\text { qualidade das compras que eu faço. } \\
\text { 3. Usar um dispositivo móvel (smartphone, celular ou tablet) torna } \\
\text { minhas compras mais fáceis. } \\
\text { 4. Usar um dispositivo móvel (smartphone, celular ou tablet) melhora } \\
\text { minha efetividade na hora de comprar. } \\
\text { 5. Usar um dispositivo móvel (smartphone, celular ou tablet) me dá } \\
\text { maior controle sobre como compro. }\end{array}$ & $\begin{array}{l}\text { Apêndice A, questão 12. Escala tipo } \\
\text { Likert de } 5 \text { pontos, adaptação para o } \\
\text { português da escala de Moore e } \\
\text { Benbasat, } 1991 .\end{array}$ \\
\hline $\begin{array}{l}\text { Compatibilidade } \\
\text { (COM) }\end{array}$ & $\begin{array}{l}\text { 1. Usar um dispositivo móvel (smartphone, celular ou tablet) para } \\
\text { comprar produtos ou serviços é compatível com todos os aspectos dos } \\
\text { meus hábitos de compra. } \\
\text { 2. Eu acho que usar um dispositivo móvel (smartphone, celular ou tablet) } \\
\text { para fazer compras é compatível com minha situação atual. }\end{array}$ & $\begin{array}{l}\text { Apêndice A, questão 14. Escala tipo } \\
\text { Likert de } 5 \text { pontos, adaptação para o } \\
\text { português da escala de Moore e } \\
\text { Benbasat, } 1991 .\end{array}$ \\
\hline
\end{tabular}




\begin{tabular}{|c|c|c|}
\hline & $\begin{array}{l}\text { 3. Usar um dispositivo móvel (smartphone, celular ou tablet) tem tudo a } \\
\text { ver com meu estilo de fazer compras. }\end{array}$ & \\
\hline $\begin{array}{l}\text { Facilidade de Uso } \\
\qquad \text { (FAU) }\end{array}$ & $\begin{array}{l}\text { 1. Minhas interações de compras usando um dispositivo móvel } \\
\text { (smartphone, celular ou tablet) são fáceis e claras. } \\
\text { 2. Eu acredito que é fácil fazer um dispositivo móvel (smartphone, } \\
\text { celular ou tablet) fazer aquilo que eu quero que ele faça. } \\
\text { 3. No geral, eu acredito que usar dispositivos móveis (smartphone, } \\
\text { celular ou tablet) para comprar é fácil. } \\
\text { 4. Aprender a usar um dispositivo móvel (smartphone, celular ou tablet) } \\
\text { para fazer comprar produtos e serviços é fácil para mim. }\end{array}$ & $\begin{array}{l}\text { Apêndice A, questão 13. Escala tipo } \\
\text { Likert de } 5 \text { pontos, adaptação para o } \\
\text { português da escala de Moore e } \\
\text { Benbasat, } 1991 .\end{array}$ \\
\hline $\begin{array}{l}\text { Benevolência } \\
\text { (CBE) }\end{array}$ & $\begin{array}{l}\text { 1. Eu acredito que os aplicativos e sites de compras que acesso pelo } \\
\text { (smartphone) agem segundo o que é melhor para mim. } \\
\text { 2. Caso eu precise, os aplicativos e sites de compras que acesso pelo } \\
\text { (smartphone) fariam o melhor possível para me ajudar a decidir. } \\
\text { 3. Os aplicativos e sites de compras que acesso pelo (smartphone) se } \\
\text { preocupam com os meus interesses e não apenas com os deles. }\end{array}$ & $\begin{array}{l}\text { Apêndice A, questão 15. Escala tipo } \\
\text { Likert de } 5 \text { pontos, adaptação para o } \\
\text { português da escala de McKnight, } \\
\text { Choudhury e Kacmar, } 2002 \text {. }\end{array}$ \\
\hline $\begin{array}{l}\text { Integridade } \\
(\mathrm{CIN})\end{array}$ & $\begin{array}{l}\text { 1. Os aplicativos e sites de compras que acesso pelo (smartphone) são } \\
\text { verdadeiros em suas relações comigo. }\end{array}$ & $\begin{array}{l}\text { Apêndice A, questão } 16 \text {. Escala tipo } \\
\text { Likert de } 5 \text { pontos, adaptação para o }\end{array}$ \\
\hline
\end{tabular}




\begin{tabular}{|c|c|c|}
\hline & $\begin{array}{l}\text { 2. Eu considero os aplicativos e sites de compras que acesso pelo } \\
\text { (smartphone) honestos. } \\
\text { 3. Os aplicativos e sites de compras que acesso pelo (smartphone) } \\
\text { mantém os compromissos que assumem. } \\
\text { 4. Os aplicativos e sites de compras que acesso pelo (smartphone) são } \\
\text { autênticos e sinceros. }\end{array}$ & $\begin{array}{l}\text { português da escala de McKnight, } \\
\text { Choudhury e Kacmar, } 2002 .\end{array}$ \\
\hline $\begin{array}{l}\text { Confiança Geral } \\
\text { (CCG) }\end{array}$ & $\begin{array}{l}\text { 1. Eu confio nos aplicativos e sites de compras que acesso pelo } \\
\text { (smartphone). } \\
\text { 2. Eu acho que os aplicativos e sites de compras que acesso pelo } \\
\text { (smartphone) são confiáveis. }\end{array}$ & $\begin{array}{l}\text { Apêndice A, questão } 18 \text {. Escala tipo } \\
\text { Likert de } 5 \text { pontos, adaptação para o } \\
\text { português da escala de Oliveira et al., } \\
2017 .\end{array}$ \\
\hline
\end{tabular}




\begin{tabular}{|c|c|c|}
\hline & $\begin{array}{l}\text { 3. Eu sinto segurança nos aplicativos e sites de compras que acesso pelo } \\
\text { (smartphone). } \\
\text { 4. Eu valorizo as características dignas de confiança dos aplicativos e } \\
\text { sites de compras que acesso pelo (smartphone). }\end{array}$ & \\
\hline $\begin{array}{l}\text { Atitude } \\
\text { (ATT) }\end{array}$ & $\begin{array}{l}\text { 1. Fazer compras usando um dispositivo móvel (smartphone, celular ou } \\
\text { tablet) é uma boa ideia. } \\
\text { 2. Eu sou favorável ao uso de dispositivos móveis (smartphone, celular } \\
\text { ou tablet) para a compra de produtos e serviços. } \\
\text { 3. Comprar usando um dispositivo móvel (smartphone, celular ou tablet) } \\
\text { é uma ideia inteligente. } \\
\text { 4. No geral, minha atitude em relação ao uso de um dispositivo móvel } \\
\text { (smartphone, celular ou tablet) para comprar produtos e serviços é } \\
\text { positiva. }\end{array}$ & $\begin{array}{l}\text { Apêndice A, questão 19. Escala tipo } \\
\text { Likert de } 5 \text { pontos, adaptação para o } \\
\text { português da escala de Feng et al., } \\
2016 .\end{array}$ \\
\hline
\end{tabular}




\begin{tabular}{|c|c|c|}
\hline & $\begin{array}{l}\text { 4. Eu tenho a intenção de nos próximos } 6 \text { meses comprar produtos ou } \\
\text { serviços usando meu dispositivo móvel (smartphone, celular ou tablet). }\end{array}$ & \\
\hline Compra Efetiva & $\begin{array}{l}\text { 1. Com que frequência você compra (produto ou serviço) usando seu } \\
\text { dispositivo móvel (smartphone, celular ou tablet)? } \\
\text { Nunca comprei nada, menos de uma vez por mês, cerca de uma vez por } \\
\text { mês, } 2 \text { a } 3 \text { vezes no mês, várias vezes por mês, pelo menos uma vez por } \\
\text { semana, mais de uma vez na semana } \\
\text { 2. Quanto você gasta em média por mês comprando (produto ou serviço) } \\
\text { pelo seu dispositivo móvel (smartphone, celular ou tablet)? } \\
\text { Nunca comprei nada, menos de } R \$ 100 \text {, entre } R \$ 100 \text { e } R \$ 250 \text {, entre } R \$ \\
250 \text { e } 400 \text {, entre } R \$ 400 \text { e } R \$ 600 \text {, entre } R \$ 600 \text { e } R \$ 1.200 \text {, mais de } R \$ \\
1.200\end{array}$ & $\begin{array}{l}\text { Apêndice A, questão } 20 \text { (frequência } \\
\text { de compra) e questão } 21 \text { (valor } \\
\text { gasto). Escala tipo Likert de } 5 \\
\text { pontos, adaptação para o português } \\
\text { da escala de Moon e Kim, } 2001 \text {. }\end{array}$ \\
\hline
\end{tabular}

Ressalta-se o fato de que diversas escalas existem na literatura para a medição dos construtos destacados. Por fim, o instrumento de pesquisa, formado pelas escalas detalhadas anteriormente, possui um total de 37 itens, sem contar os itens relativos às variáveis demográficas e comportamentais. 
Tabela 3.3 - Variáveis de controle

\begin{tabular}{|c|c|}
\hline Variável Comportamental & Escala \\
\hline Posse de dispositivo móvel & $\begin{array}{l}\text { Smartphone (1), Tablet (2), Celular com acesso a } \\
\text { Internet (3), Não possui dispositivo e usa o de outros } \\
\text { (4), Não possui dispositivo móvel (5); questão } 1\end{array}$ \\
\hline $\begin{array}{l}\text { Compra por meio de } \\
\text { dispositivo móvel }\end{array}$ & Sim (1), Não (2); apêndice A, questão 6 \\
\hline $\begin{array}{l}\text { Dispositivo mais usado em } \\
\text { compras }\end{array}$ & $\begin{array}{l}\text { Smartphone (1), Tablet (2), Celular com acesso a } \\
\text { Internet (3); apêndice A, questão } 2\end{array}$ \\
\hline $\begin{array}{l}\text { Marca e modelo do } \\
\text { dispositivo }\end{array}$ & Variável contínua; apêndice A, questão 8 \\
\hline Método de compra & $\begin{array}{l}\text { Visita a página do vendedor usando o navegador (1), } \\
\text { Usa um aplicativo específico do vendedor (2), Usa um } \\
\text { aplicativo genérico com várias opções de vendedores } \\
\text { (3), Visita um website de buscas e procura o que quer } \\
\text { (4), compra apenas aplicativos (5); apêndice A, } \\
\text { questão } 9\end{array}$ \\
\hline Produtos comprados & $\begin{array}{l}\text { Roupas (1), Sapatos (2), Passagens de avião (3), } \\
\text { Livros (4), Computadores (5), Televisores (6), } \\
\text { Refeições (7), Diárias de hotel (8), Música (9), } \\
\text { Smartphones e celulares (10), Outros produtos não } \\
\text { listados (11), Não compra produtos ou serviços (12); } \\
\text { apêndice A, questão } 10\end{array}$ \\
\hline $\begin{array}{l}\text { Produtos usados na } \\
\text { moderação }\end{array}$ & $\begin{array}{l}\text { Roupas (1), Sapatos (2), Passagens de avião (1), } \\
\text { Computadores (1), Televisores (1), Diárias de hotel (2), } \\
\text { Música (2), Smartphones e celulares (2); apêndice A, } \\
\text { questão } 11\end{array}$ \\
\hline
\end{tabular}


Tabela 3.4 - Variáveis demográficas

\begin{tabular}{|c|c|}
\hline Variável Demográfica & Escala \\
\hline Idade & Variável contínua; apêndice A, questão 4 \\
\hline Sexo & $\begin{array}{l}\text { Masculino (1), Feminino (2); apêndice A, } \\
\text { questão } 7\end{array}$ \\
\hline Nível de escolaridade & $\begin{array}{l}\text { Fundamental incompleto (1), Fundamental } \\
\text { completo (2), Médio incompleto (3), Médio } \\
\text { completo (4), Superior incompleto (5), } \\
\text { Superior completo (6), Pós-graduação } \\
\text { incompleto (7), Pós-graduação completo } \\
\text { (8); apêndice A, questão } 5\end{array}$ \\
\hline Renda familiar & $\begin{array}{l}\text { Acima de } 10.000 \text { reais (1), entre } 6.000 \text { e } \\
10.000 \text { reais (2), entre } 3.500 \text { e } 6.000 \text { reais } \\
\text { (3), entre } 1.500 \text { e } 3.500 \text { reais (4), abaixo } \\
\text { de } 1.000 \text { (5), não desejo declarar (6); } \\
\text { apêndice A, questão } 6\end{array}$ \\
\hline E-mail & Variável nominal; apêndice A, questão 23 \\
\hline
\end{tabular}

Por fim, o instrumento de pesquisa, formado pelas escalas, os itens relativos às variáveis demográficas, e quatro questões de controle possui um total de 49 itens distribuídos em 23 questões.

\subsection{4}

\section{Procedimentos de tradução e adaptação das escalas}

Todas as escalas a serem utilizadas no estudo foram originalmente elaboradas para a língua inglesa. Desta forma, para que fosse possível usar essas escalas com respondentes brasileiros, foi necessária a realização da tradução e adaptação de cada uma delas para a língua portuguesa.

O presente estudo seguiu as recomendações de Sperber (2004), que sugere alguns passos na adaptação de escalas de um idioma para outro. Na etapa inicial da 
tradução, cada um dos itens originais, de cada escala, foi traduzido independentemente por dois profissionais de idiomas experientes em tradução. As duas traduções foram revisadas e comparadas por especialistas no tema (professores doutores pesquisadores de comportamento do consumidor) e fluentes na língua inglesa, para a obtenção da versão para português de cada escala. Após esse passo, foi realizada a retradução (back translation) para o inglês, por profissionais diferentes dos que realizaram a tradução inicial. Segundo Sperber (2004), as retraduções devem resultar em sentenças muito similares às das escalas originais, caso as traduções tenham sido feitas de forma cuidadosa, aproximando, assim, os sentidos em português dos originais em inglês e garantindo a validade de face dos construtos medidos.

\subsection{5}

\section{Pré-teste do instrumento de pesquisa}

Após a verificação das retraduções, os itens foram incluídos no instrumento de pesquisa e foi realizado um pré-teste do questionário, com uma pequena amostra da população de interesse, para avaliar a compreensão dos respondentes sobre esta primeira versão do questionário. Nesta etapa, foi solicitado aos respondentes que anotassem ou apontassem suas dúvidas ou dificuldades sobre a interpretação ou compreensão de qualquer um dos itens do instrumento de pesquisa. Foram também incentivadas sugestões, por parte dos respondentes, com finalidade de melhorar a apresentação do questionário e as instruções de preenchimento do mesmo.

Os resultados obtidos com esse pré-teste inicial serviram para refinar o questionário e elaborar uma segunda versão. Essa versão passou por um pré-teste final online com respondentes da população de interesse, em que se verificou a necessidade de algum ajuste final, tanto no que diz respeito à interpretação como à sua apresentação, particularmente no que diz respeito às funcionalidades da versão online, como botões e barras de progresso. Com os resultados deste último préteste, o instrumento de pesquisa final foi elaborado e pode ser visualizado no apêndice A. 


\section{4}

\section{Análise dos Dados}

Os dados resultantes da aplicação do instrumento de pesquisa foram transcritos para fins de processamento estatístico em bases de dados SPSS. Para as análises foi utilizada a técnica de modelagem de equações estruturais.

O primeiro passo da análise dos dados foi a realização de uma estatística descritiva das variáveis demográfica como forma de caracterizar a amostra e eliminar quaisquer respondentes que não se encaixassem no perfil desejado (estrangeiros, indivíduos que não pertencessem a população alvo, por exemplo). Foi realizado, em seguida, o tratamento dos dados, com o objetivo de detectar e eliminar erros de entrada dos dados e valores ausentes que porventura tivessem ocorrido.

\subsection{1 \\ Validade e Confiabilidade}

A fim de estimar o modelo de mensuração e avaliar os construtos usados no instrumento de pesquisa, particularmente no que diz respeito à unidimensionalidade, confiabilidade e validade, foi realizada uma análise fatorial confirmatória (CFA) com os dados obtidos. Segundo Hair Jr. et al. (2010) e Churchill (1979), a validade de um construto está relacionada ao quanto uma escala de fato reflete o construto latente que ela se propõe a medir. Já a confiabilidade, outro indicador de validade convergente, se relaciona ao quanto uma variável ou conjunto de variáveis é consistente com o que se deseja medir.

A confiabilidade dos construtos foi avaliada pelo Alfa de Cronbach (NUNNALLY, 1978) e pela confiabilidade composta (composite reliability) (NUNNALLY; BERNSTEIN, 1994; HAIR JR et al., 2010; BYRNE, 2010). Hair et al. (2010) e Nunnally e Bernstein (1994) indicam que valores superiores a 0,8 para a confiabilidade composta são considerados adequados, e valores inferiores a 0,8 mas superiores a 0,7 são aceitáveis, os mesmos valores se aplicam ao Alfa de Cronbach (NUNNALLY, 1978).

A validade de um construto é composta por quatro componentes: validade de face, validade nomológica, validade convergente e validade discriminante (HAIR JR et al., 2010). 
A validade de face (consistência entre o conteúdo de cada item em relação ao construto por ele medido) para as escalas utilizadas foi garantida por meio da escolha de escalas utilizadas anteriormente na literatura, da tradução metódica destas escalas, da avaliação de cada item por pesquisadores experientes de comportamento do consumidor e os pré-testes conduzidos com pequenas amostras da população de interesse.

A validade nomológica, que examina se as correlações entre os construtos fazem sentido, foi avaliada com o uso de uma matriz de correlação entre construtos, com o propósito de verificar se os construtos se relacionam entre si conforme previsto pela teoria.

A validade convergente e a validade discriminante dos construtos foram avaliadas por meio do exame das cargas fatoriais dentro de cada um dos construtos e da correlação entre construtos resultantes da CFA feita inicialmente. Primeiramente, para analisar a validade convergente, o grau em que os diferentes indicadores utilizados em cada escala convergem para o mesmo construto, foi usada a variância média extraída (Average Variance Extrated - AVE) (FORNELL; LARCKER, 1981). Em segundo, para analisar a validade discriminante, que informa o quanto um construto é realmente distinto dos outros (GEFEN; STRAUB, 2005; HAIR JR et al., 2010), foi feita uma análise das cargas fatoriais de cada item. Segundo Gefen e Straub (2005), estas cargas devem ser consideravelmente maiores dentro dos construtos aos quais os itens supostamente pertencem do que em relação aos outros construtos presentes no modelo, sendo que cargas maiores do que 0,3 são consideradas significativas, maiores que 0,4 consideradas importantes e as acima de 0,5 consideradas muito significativas. Em seguida, o valor da AVE de cada par de construtos será comparado com o quadrado da estimativa de correlação entre os dois construtos pareados (ASV - Average Shared Variance). O valor da AVE deve ser maior do que o da ASV (FORNELL; LARCKER, 1981; HAIR JR et al., 2010). 


\subsection{2 \\ Análises Estatísticas}

O teste das hipóteses do estudo foi feito por meio de equações estruturais (SEM), com o uso do software AMOS 20.0. O uso de SEM é considerado adequado para responder às questões levantadas por este estudo e aos testes exigidos pelas hipóteses formuladas, pois permite (1) a estimação de relações simultâneas entre múltiplas variáveis independentes e dependentes (BAGOZZI; PHILLIP, 1982; BENTLER, 1988; BYRNE, 2010; HAIR et al., 2010); (2) descrever estruturas latentes ao conjunto de variáveis estudadas e as relações entre variáveis observáveis e latentes (BYRNE, 2010; HAIR JR et al., 2010) e (3) confirmar um modelo e/ou comparar modelos diferentes com base no ajuste de cada um aos dados coletados e/ou desenvolver modelos quando o ajuste do modelo aos dados não é adequado (BYRNE, 2010; HAIR JR et al., 2010). O uso de SEM torna possível a avaliação conjunta dos efeitos dos construtos envolvidos em um modelo, evitando distorções que poderiam surgir na dependência observada entre as variáveis, caso estudadas separadamente (BYRNE, 2010; HAIR JR et al., 2010). Diferente dos métodos tradicionais, modelos de equações estruturais são capazes de estimar erros de medida, evitando imprecisões e problemas que podem surgir ao ignorá-los (BYRNE, 2010; HAIR JR et al., 2010).

Para a estimação do modelo de equações estruturais foi usado o método de máxima verossimilhança (Maximum Likelihood - ML). Embora os dados utilizados possam não apresentar uma distribuição multivariada normal, o que sugeriria maior adequação ao uso de métodos $\mathrm{ADF}$ (asymptotic distribution free estimators) na estimação do modelo, estes, entretanto, requerem uma amostra de pelo menos $\mathrm{n} *(\mathrm{n}+1) / 2$, onde $\mathrm{n}$ é o número de indicadores observáveis (itens). No entanto, em condições não ideais e para modelos com grande número de indicadores, amostras entre 200 e 400 respondentes são consideradas adequadas para o uso do método ML (ANDERSON; GERBING, 1988; HAIR JR et al., 2010). Além disso, estimações por ML são robustas no que se refere a violações à premissa de normalidade, produzindo resultados confiáveis e similares aos obtidos por meio de métodos ADF (OLSSON; FOSS; TROYE; HOWELL, 2000).

A modelagem em si foi dividida em dois estágios, conforme sugerido por Anderson e Gerbing (1988). No primeiro estágio, foi verificado se cada escala 
utilizada mede somente o construto a ela associado por meio de Análise Fatorial Confirmatória (CFA) e o ajuste do modelo de medidas. Em seguida, esse modelo inicial foi refinado, ou seja, ajustes corretivos foram realizados de forma a garantir a validade e a confiabilidade do modelo de mensuração e do modelo estrutural. Nesta fase foram analisados itens que apresentassem baixa confiabilidade (alfa de Cronbach ou Confiabilidade Composta), altos carregamentos cruzados entre dois construtos (validade discriminante), a presença de Viés do Método Comum, entre outros problemas. No segundo estágio, foi estimado o modelo de equações estruturais propriamente dito, sendo realizados os testes das hipóteses do estudo.

\subsection{3}

\section{Avaliação dos Modelos de Mensuração e Estrutural}

Para avaliação e ajuste, tanto do modelo de medida quanto do modelo estrutural, foram utilizados índices sugeridos pela literatura e aplicados em outros estudos similares (FERREIRA; ROCHA; SILVA, 2013; GAO et al., 2012; GARVER; MENTZER, 1999; HAIR et al., 2010). Os índices de ajuste podem ser divididos em índices absolutos, ou seja, índices que indicam o quanto o modelo analisado se ajusta aos dados amostrais (JÖRESKOG; SÖRBOM, 1993), índices incrementais, que comparam o modelo analisado com um modelo-base que tem como hipótese nula a não existência de correlação entre as variáveis (MCDONALD; HO, 2002) e índices de parcimônia, que indicam o ajuste relativo do modelo em relação a sua complexidade e servem para indicar qual modelo em um grupo de modelos concorrentes é o melhor (HAIR JR. et al., 2010).

Cada um destes índices apresenta problemas e seu uso é comumente associado a um índice suplementar, o que faz com que o conjunto dos índices utilizados, e não cada um individualmente, aponte para o bom ajuste do modelo. É o caso da estatística qui-quadrada, que (1) assume uma premissa de normalidade multivariada dos dados e que, em caso de desvios severos, leva à rejeição do modelo mesmo quando adequado (HOOPER; COUGHLAN; MULLEN, 2008; MCINTOSH, 2006), e (2) é sensível ao tamanho da amostra, aumentando a incidência de erros do tipo I (rejeição da hipótese verdadeira) para amostras muito grandes, (HOOPER et al., 2008; JÖRESKOG; SÖRBOM, 1993; TENNANT; 
PALLANT, 2012) ou falhando em diferenciar modelos fracos de modelos fortes em amostras muito pequenas (HOOPER et al., 2008; KENNY; MCCOACH, 2003).

O RMSEA, desenvolvido por Steiger e Lind (1980), por sua vez, é sensível ao número de parâmetros estimados, favorecendo modelos parcimoniosos. Já o SRMR é afetado pelo número de parâmetros e tamanho da amostra, tendendo a indicar um perfeito ajuste em amostras muito grandes com um número elevado de parâmetros (HOOPER et al., 2008). Por sua vez, o TLI é sensível à complexidade do modelo e ao tamanho da amostra, podendo indicar um ajuste ruim mesmo quando todos os outros indicadores apontam para um bom ajuste.

A escolha de quais índices utilizar na análise se torna então essencial para a execução de um estudo criterioso. Hu e Bentler (1999) sugerem o uso do SRMR juntamente com o TLI, o RMSEA ou o CFI. Kline (2005) advoga que o $\chi^{2}$ sempre deve ser apresentado, e recomenda que seja acompanhado pelo RMSEA, o CFI e o SRMR.

Assim, o conjunto de índices a ser utilizado para avaliar o ajuste do modelo de mensuração e o modelo estrutural engloba: o SRMR (standardized root mean square residual), o RMSEA (root mean square error of approximation), o CFI (comparative fit index), o IFI (Bollen's incremental fit index), o TLI (Tucker-Lewis index $)$, o qui-quadrado $\left(\chi^{2}\right)$ e o qui-quadrado normalizado ( $\chi^{2} /$ d.f.). Destes, o $\chi^{2}$, o SRMR e o RMSEA são considerados índices absolutos, ou seja, indicam o quanto o modelo analisado se ajusta aos dados amostrais (JÖRESKOG; SÖRBOM, 1993). Por sua vez, o CFI, o IFI e o TLI são considerados índices incrementais e, portanto, comparam o modelo analisado com um modelo-base que tem como hipótese nula a não existência de correlação entre as variáveis (MCDONALD; HO, 2002).

Todos estes índices, com a exceção da estatística qui-quadrada, são de fácil interpretação por estarem contidos numa escala contínua que vai de 0 a 1 , sendo que os valores ideais para os índices CFI, IFI e TLI ficam próximos ao 1 e os valores ideais para o SRMR e o RMSEA próximos a 0. 


\section{5 \\ Limitações do Método}

A todo método correspondem limitações derivadas de suas características metodológicas e processuais. No caso deste estudo, as limitações estão relacionadas aos métodos de coleta e análise de dados. Levantamentos apresentam as seguintes limitações relacionadas à coleta de dados por questionário estruturado: erro de amostragem, viés de resposta, erros relacionados ao respondente, erros relacionados ao entrevistador, viés do método comum e erros envolvendo a definição e operacionalização das variáveis envolvidas. A seguir são dispostos os vieses que podem ter surgido ao longo do estudo e os métodos utilizados para mitiga-los ou resolve-los.

\subsection{1}

\section{Limitações relacionadas ao critério de amostragem}

A delimitação do universo amostral do estudo e a amostragem por snowballing podem impactar a representatividade da amostra. Erros derivados da diferença entre os achados da pesquisa e as características reais da população, uma limitação inerente as pesquisas que envolvem amostras, podem ser reduzidos por certos procedimentos de amostragem, mas não podem ser excluídos. Como o propósito do estudo é testar a estrutura de relações entre as variáveis propostas e não a validade externa dos resultados, portanto, a representatividade da amostra não é uma questão central. Entretanto houve o cuidado de selecionar indivíduos que efetivamente tivessem comprado produtos ou serviços por meio de dispositivos móveis e correspondessem a faixa etária considerada economicamente ativa (18 a 75 anos). O perfil da amostra em termos de gênero, idade e renda ficou dentro do desejado para representar a população pesquisada e possui boa equivalência com o perfil encontrado entre os compradores online segundo dados do mercado disponibilizados nos relatórios Panorama (MOBILETIME; OPINION BOX, 2016) e Webshoppers 2017 (EBIT, 2017).

Além disso, questionários distribuídos por meio de links disponibilizados livremente em sites também estão sujeitos ao viés de auto seleção, ou seja, sujeitos a tendência que certos indivíduos têm de participarem ou não de levantamentos online, o que pode gerar um viés sistemático (CALLEGARO; MANFREDA; 
VEHOVAR, 2015; WRIGHT, 2005). O questionário que foi disponibilizado nos sites de redes sociais oferecia uma participação em sorteio como premio de forma a estimular a entrada de participantes que geralmente não participam de levantamentos online, o questionário foi também distribuído em um link promocional que estimulava a participação com base no interesse por compras online. Além disso, os participantes do processo de snowballing foram instruídos a estimularem suas redes a responderem e compartilharem o questionário, o que possibilita o acesso a uma população mais diversa.

\section{5 .2}

\section{Limitações não relacionadas ao critério de amostragem}

Erros não amostrais são geralmente fruto de uma dessas quatro fontes: (1) respondentes, (2) definição do problema, (3) operacionalização das variáveis, (4) aplicação do questionário e (5) procedimentos de codificação e entrada de dados (BRYMAN, 2012; HAIR et al., 2010). Geralmente estes erros criam algum tipo de viés ou tendenciosidade sistemática nos dados e podem ser reduzidos ou eliminados pela correta concepção e execução da pesquisa (HAIR et al., 2010).

Questionários autoadministrados podem apresentar altas taxas de erros relacionados ao respondente, entre eles: altos índices de não resposta e erro de resposta (HAIR et al., 2010). O primeiro ocorre quando parte da amostra selecionada não responde ao questionário. Isso foi resolvido utilizando a resposta forçada, cada respondente só poderia passar para a próxima questão tendo respondido todas as anteriores. $\mathrm{O}$ segundo ocorre quando o respondente dá uma resposta incorreta porque não entendeu a pergunta ou não se recorda dos fatos (BRYMAN, 2012). Este problema foi minimizado pelos pré testes, que verificaram a clareza e objetividade das questões, de forma a evitar problemas ligados a interpretação das perguntas. Apenas dois itens do questionário requeriam que os respondentes se recordassem de uma informação, em ambas foi pedido um valor médio e não um específico. Além disso, questionários auto aplicados eliminam os erros derivados do comportamento do entrevistador, como seu viés de afinidade com o respondente ou a forma como faz as perguntas e a anotação das respostas 
Quanto ao erro de não resposta, Babbie (1990) indica que, para pesquisas em ciências sociais cujo objetivo seja o de generalizar os achados com um alto grau de confiança, uma taxa de resposta em torno dos $50 \%$ é considerada adequada. Por outro lado, Krosnick (1999) afirma que não é necessariamente verdade que a representatividade de uma amostra aumente com a taxa de resposta. Levantamentos com baixas taxas de resposta podem ser mais acurados do que outros com taxas de resposta mais elevadas, ou seja, a baixa taxa de resposta de um levantamento não irá, necessariamente, culminar em altos valores de erro de não resposta. Como a amostragem seguiu a técnica de snowballing, não existem valores específicos para a taxa de resposta. O estudo seguiu o disposto por Krosnick (1999) e assume que a representatividade da amostra não foi afetada pela taxa de não resposta.

Erros relacionados à definição de construtos e à operacionalização das variáveis devem ser mitigados pela concepção metódica e sistemática do estudo (BRYMAN, 2012; CHANG et al., 2010; LINDELL; WHITNEY, 2001; PODSAKOFF; MACKENZIE; LEE; PODSAKOFF, 2003).

A estruturação do questionário promove uma padronização das questões e das respostas reduzindo o erro proveniente das diferentes formas de fazer uma pergunta, além de facilitar e aumentar a precisão do processamento de dados (BRYMAN, 2012).

Por fim, questionários auto aplicados são particularmente suscetíveis ao viés do método comum (Common Method Bias ou Common Method Variance), que surge em situações em que medidas perceptuais tanto das variáveis dependentes quanto das variáveis independentes são obtidas ao mesmo tempo do mesmo respondente, podendo inflar as correlações observadas entre as variáveis (CHANG et al., 2010; LINDELL; WHITNEY, 2001; PODSAKOFF et al., 2003). Em termos estatísticos, o viés do método comum é definido como "a variância que é atribuída ao método de mensuração ao invés de aos construtos que essas medidas representam" (FISKE, 1982).

Segundo Podsakoff et al. (2003) e Chang, Witteloostuijn e Eden (2010), vieses derivados do método estão entre as principais fontes de erro de mensuração e são uma ameaça à validade das conclusões tiradas com base nos relacionamentos entre as medidas obtidas em levantamentos. Assim, para garantir que esse viés em 
particular não será um problema, as seguintes medidas corretivas foram tomadas: (1) identificar as medidas em comum entre variáveis dependentes e independentes e eliminá-las ou minimizá-las separando as medidas metodologicamente (CHANG et; al., 2010; PODSAKOFF et al., 2003), (2) proteger a identidade e a privacidade do respondente, reduzindo as respostas socialmente aceitáveis ou complacentes (CHANG et; al., 2010; PODSAKOFF et al., 2003), (3) alterar a ordenação das questões (CHANG et; al., 2010; PODSAKOFF et al., 2003), (4) selecionar escalas melhores e melhorar a compreensão das escalas eliminando ambiguidades e complexidade (CHANG et; al., 2010; PODSAKOFF et al., 2003), (5) utilizar escalas em diferentes formatos para medir variáveis antecedentes e variáveis alvo, no caso intenção e compra efetiva (CHANG et; al., 2010; PODSAKOFF et al., 2003), e (6) diagnosticar estatisticamente a presença do viés do método por meio de um teste que controla os efeitos de fatores únicos latentes não mensurados, utilizando um construto de primeira ordem que tem como indicadores todas as medidas presentes no modelo e realizando a comparação entre parâmetros com e sem a presença deste novo fator latente (PODSAKOFF et al., 2003).

\subsection{3}

\section{Limitações relacionadas às análises estatísticas}

As técnicas de análise estatística aplicáveis são limitadas pelo tamanho da amostra, procedimentos de amostragem e os tipos de variáveis utilizados (BRYMAN, 2012). As técnicas estatísticas empregadas são limitadas ainda por suas características e premissas, sendo a normalidade multivariada uma das principais. E sua escolha foi definida segundo critérios de amostra e complexidade do modelo (HAIR et al., 2010). Essas limitações foram endereçadas durante a análise dos dados e os procedimentos seguidos se encontram expostos quando relevantes. 


\section{4 \\ Modelagem e Análise dos Dados}

Neste capítulo são apresentadas as propriedades estatísticas e métricas da amostra coletada, assim como os resultados dos testes dos modelos de mensuração e estruturais propostos e os resultados dos testes das hipóteses de pesquisa.

\section{1}

\section{Caracterização da Amostra}

A tabela 4.1 ilustra as características da amostra final. Dos 535 respondentes, 290 declararam pertencerem ao gênero feminino (54,2\%) e 245 ao gênero masculino (45,8\%). Quanto à idade, a maioria dos respondentes $(42,2 \%)$ é jovem, entre 19 e 22 anos. A média de idade observada foi de 35 anos, com desvio padrão de 12,2. Em relação ao nível de escolaridade, a maioria dos respondentes possui nível superior completo $(60,4 \%)$ e $29,5 \%$ declararam ter feito pós-graduação. Dos 535 respondentes, 95,3\% (510) utilizam um smartphone como principal dispositivo na realização das suas transações de comércio móvel. Mais da metade dos respondentes já comprou roupas, passagens de avião, livros ou requisitou o delivery de refeições utilizando um dispositivo móvel.

Tabela 4.1 - Características da Amostra

\begin{tabular}{ll}
\hline Característica & Porcentagem dos Respondentes (n) \\
\hline SEXO & $45,8(n=245)$ \\
Masculino & $54,2(n=290) 66$ \\
Feminino & \\
ESCOLARIDADE & $1,1(n=6)$ \\
Fundamental incompleto & $1,3(n=7)$ \\
Fundamental completo & $2,4(n=13)$ \\
Médio incompleto & $18,3(n=98)$ \\
Médio completo & $16,4(n=88)$ \\
Superior incompleto & $24,3(n=130)$ \\
Superior completo & $6,5(n=35)$ \\
Pós-graduação incompleto & $29,5(n=158)$ \\
Pós-graduação completo &
\end{tabular}




\begin{tabular}{|c|c|}
\hline \multicolumn{2}{|l|}{ RENDA FAMILIAR ESTIMADA } \\
\hline Acima de $R \$ 14.000$ & $24,5(n=131)$ \\
\hline Entre $\mathbf{R} \$ 14.000$ e $\mathbf{R} \$ 5.000$ & $32,7(n=175)$ \\
\hline Entre $\mathbf{R} \$ 5.000$ e $\mathbf{R} \$ 3.000$ & $9,5(n=51)$ \\
\hline Entre $\mathbf{R} \$ 3.000$ e $\mathbf{R} \$ 1.000$ & $13,5(n=72)$ \\
\hline Abaixo de $R \$ 1.000$ & $15,1(n=81)$ \\
\hline Não quiseram declarar & $4,7(n=25)$ \\
\hline \multicolumn{2}{|l|}{ IDADE } \\
\hline $15-17$ & $1,5(n=8)$ \\
\hline $18-24$ & $21,5(n=115)$ \\
\hline $25-34$ & $30,4(n=163)$ \\
\hline $34-49$ & $33,1(n=177)$ \\
\hline $50+$ & $13,5(n=72)$ \\
\hline Média & $34,9 \rightarrow 35$ \\
\hline Desvio Padrão & 12,2 \\
\hline Mediana & 33,0 \\
\hline Mínimo 17 & Máximo 76 \\
\hline \multicolumn{2}{|c|}{ PRODUTO OU SERVIÇO COMPRADO USANDO UM DISPOSITIVO MÓVEL } \\
\hline Roupas & $51,6 \%(n=276)$ \\
\hline Sapatos & $40,4 \%(n=216)$ \\
\hline Passagens de avião & $53,1 \%(n=284)$ \\
\hline Livros (digitais ou impressos) & $54 \%(n=289)$ \\
\hline Computadores & $21,5 \%(n=115)$ \\
\hline Televisores & $18,9 \%(n=101)$ \\
\hline Refeições (delivery) & $58,3 \%(n=312)$ \\
\hline Diárias de hotel & $44,3 \%(n=237)$ \\
\hline Música (CDs ou faixas) & $23,9 \%(n=128)$ \\
\hline Celulares e smartphones & $36,3 \%(n=194)$ \\
\hline \multicolumn{2}{|c|}{ TIPO DE PRODUTO OU SERVIÇO COMPRADO } \\
\hline Busca & $46 \%(n=246)$ \\
\hline Experiência & $54 \%(n=289)$ \\
\hline
\end{tabular}

\section{2}

\section{Análises e Resultados}

A seguir são apresentados os resultados dos testes dos modelos de mensuração e estruturais propostos e os resultados dos testes das hipóteses de pesquisa. 


\subsection{1}

\section{Avaliação do Modelo de Mensuração}

O modelo de mensuração é responsável por estabelecer a relação entre as variáveis observáveis e as variáveis latentes (construtos). No caso de modelos onde se propõe a verificação de moderação é feita a separação da amostra em função do critério utilizado, de forma que neste estudo a amostra foi dividida em dois grupos, o primeiro correspondendo aos respondentes que avaliaram produtos de busca e o segundo referente aqueles que avaliaram produtos de experiência. Além disso, como se pretende comparar modelos que utilizam diferentes representações para o construto Confiança, também foram analisados dois conjuntos de variáveis, uma para os modelos Dimensões da Confiança e Confiança de Segunda Ordem, com 33 dos 37 indicadores, e outro para o modelo Confiança Geral, com 26 dos 37 indicadores. Assim, os modelos, por apresentarem diferentes representações da confiança, foram rodados com o número de itens necessários a sua especificação e não com a totalidade de itens disponíveis após a coleta de dados. A amostra de 535 respondentes foi então agrupada em Busca, com 246 respondentes, e Experiência, com 289 respondentes.

Primeiro, foram realizadas duas análises fatoriais confirmatórias (CFA) para os construtos utilizados nos modelos Dimensões da Confiança e Confiança de Segunda Ordem, uma para o grupo Busca e outra para o grupo Experiência. Cada uma das CFA testou 33 indicadores a serem carregados em nove construtos. Ambos os grupos apresentaram bons índices de ajuste, sem necessidade de alteração ou remoção de itens.

Para os modelos Dimensões da Confiança e Confiança de Segunda Ordem, o modelo final de mensuração para o grupo Busca, com 33 indicadores, apresentou bons índices de ajuste (SRMR $=0,058$; RMSEA $=0,070$ com C.I. de 0,064 até 0,075; CFI $=0,917 ; \mathrm{IFI}=0,918 ; \mathrm{TLI}=0,905 ; \chi 2=1002,68$, d.f. $=459, \mathrm{p}<0,001$, $\chi 2 /$ d.f. $=2,184)$. Em conjunto, estes índices representam que os dados para o grupo se ajustam de maneira satisfatória ao modelo proposto.

Para os modelos Dimensões da Confiança e Confiança de Segunda Ordem, o modelo final de mensuração para o grupo Experiência, com 33 indicadores, também apresentou bons índices de ajuste (SRMR $=0,049$; RMSEA $=0,058$ com C.I. de 
0,052 até 0,$064 ; \mathrm{CFI}=0,937 ; \mathrm{IFI}=0,937 ; \mathrm{TLI}=0,927 ; \chi 2=904,45$, d.f. $=459, \mathrm{p}$ $<0,001, \chi 2 /$ d.f. $=1.970)$. Estes índices representam que os dados para o grupo Experiência também se ajustam de maneira satisfatória ao modelo proposto.

Em seguida, foram feitas as duas análises fatoriais confirmatórias (CFA) para os construtos utilizados no modelo Confiança Geral, uma para o grupo Busca e outra para o grupo Experiência. Cada uma das CFA testou 26 indicadores a serem carregados em sete construtos. Novamente, os dois grupos apresentaram bons índices de ajuste, não havendo necessidade de alteração ou remoção de itens.

Para o modelo Confiança Geral, o modelo final de mensuração para o grupo Busca, com 26 indicadores, apresentou bons índices de ajuste (SRMR =0,065; RMSEA $=0,070$ com C.I. de 0,062 até 0,077; CFI =0,936; IFI =0,937; TLI = 0,936; $\chi 2=603,12$, d.f. $=275, p<0,001, \chi 2 /$ d.f. $=2,193)$. Em conjunto, estes índices representam que os dados do grupo Busca se ajustam de maneira satisfatória ao modelo proposto.

Para o modelo Confiança Geral, o modelo final de mensuração para o grupo Experiência, com 26 indicadores, também apresentou bons índices de ajuste $(\mathrm{SRMR}=0,044 ; \mathrm{RMSEA}=0,057$ com C.I. de 0,050 até 0,$065 ; \mathrm{CFI}=0,956 ; \mathrm{IFI}=$ 0,$957 ;$ TLI $=0,948 ; \chi^{2}=536,63$, d.f. $=275, p<0,001, \chi 2 /$ d.f. $\left.=1,951\right) . E m$ conjunto, estes índices representam que os dados do grupo Experiência também se ajustam de maneira satisfatória ao modelo proposto.

\subsection{2}

\section{Validade e Confiabilidade dos Construtos}

De acordo com a revisão de literatura realizada, é esperada uma relação positiva entre os construtos de inovação (facilidade de uso, vantagem relativa, compatibilidade) e os construtos de confiança (benevolência, competência, integridade, confiança geral). A mesma relação positiva é esperada entre os construtos de confiança e a atitude e intenção.

Os quadros 4.1 e 4.2 apresentam, respectivamente, as matrizes de correlação dos construtos estudados para a amostra Busca e a amostra Experiência para o modelo de mensuração Dimensões da Confiança/Confiança de Segunda Ordem. Os 
quadros 4.3 e 4.4 apresentam, respectivamente, as matrizes de correlação dos construtos estudados para a amostra Busca e a amostra Experiência para o modelo de mensuração Confiança Geral.

Quadro 4.1 - Matriz de Correlação para a amostra Busca do modelo Dimensões da Confiança/Confiança de $2^{\mathrm{a}}$ Ordem

\begin{tabular}{|c|c|c|c|c|c|c|c|c|c|}
\cline { 2 - 10 } \multicolumn{1}{c|}{} & FAU & VAR & COM & CIN & CCO & CBE & ATT & INT & CE \\
\hline FAU & 1 & 0,743 & 0,703 & 0,588 & 0,660 & 0,572 & 0,783 & 0,657 & 0,390 \\
\hline VAR & 0,743 & 1 & 0,728 & 0,595 & 0,587 & 0,659 & 0,702 & 0,495 & 0,376 \\
\hline COM & 0,703 & 0,728 & 1 & 0,619 & 0,629 & 0,685 & 0,731 & 0,471 & 0,522 \\
\hline CIN & 0,588 & 0,595 & 0,619 & 1 & 0,819 & 0,746 & 0,555 & 0,428 & 0,331 \\
\hline CCO & 0,660 & 0,587 & 0,629 & 0,819 & 1 & 0,671 & 0,604 & 0,519 & 0,369 \\
\hline CBE & 0,572 & 0,659 & 0,685 & 0,746 & 0,671 & 1 & 0,493 & 0,327 & 0,323 \\
\hline ATT & 0,783 & 0,702 & 0,731 & 0,555 & 0,604 & 0,493 & 1 & 0,660 & 0,417 \\
\hline INT & 0,657 & 0,495 & 0,471 & 0,428 & 0,519 & 0,327 & 0,660 & 1 & 0,355 \\
\hline CE & 0,390 & 0,376 & 0,522 & 0,331 & 0,369 & 0,323 & 0,417 & 0,355 & 1 \\
\hline
\end{tabular}

Quadro 4.2 - Matriz de Correlação para a amostra Experiência do modelo Dimensões da Confiança/Confiança de $2^{\mathrm{a}}$ Ordem

\begin{tabular}{|c|c|c|c|c|c|c|c|c|c|}
\cline { 2 - 9 } \multicolumn{1}{c|}{} & FAU & VAR & COM & CIN & CCO & CBE & ATT & INT & CE \\
\hline FAU & 1 & 0,735 & 0,742 & 0,418 & 0,707 & 0,429 & 0,696 & 0,603 & 0,374 \\
\hline VAR & 0,735 & 1 & 0,558 & 0,373 & 0,548 & 0,399 & 0,596 & 0,511 & 0,348 \\
\hline COM & 0,742 & 0,558 & 1 & 0,385 & 0,541 & 0,518 & 0,629 & 0,544 & 0,480 \\
\hline CIN & 0,418 & 0,373 & 0,385 & 1 & 0,740 & 0,697 & 0,377 & 0,288 & 0,166 \\
\hline CCO & 0,707 & 0,548 & 0,541 & 0,740 & 1 & 0,592 & 0,605 & 0,509 & 0,268 \\
\hline CBE & 0,429 & 0,399 & 0,518 & 0,697 & 0,592 & 1 & 0,281 & 0,219 & 0,209 \\
\hline ATT & 0,696 & 0,596 & 0,629 & 0,377 & 0,605 & 0,281 & 1 & 0,620 & 0,431 \\
\hline INT & 0,603 & 0,511 & 0,544 & 0,288 & 0,509 & 0,219 & 0,620 & 1 & 0,402 \\
\hline CE & 0,374 & 0,348 & 0,480 & 0,166 & 0,268 & 0,209 & 0,431 & 0,402 & 1 \\
\hline
\end{tabular}

Onde:

-FAU = Facilidade de Uso

- VAR = Vantagem Relativa

- $\mathrm{COM}=$ Compatibilidade
- $\mathrm{CBE}=$ Benevolência

- $\mathrm{CCG}=$ Confiança Geral

- ATT = Atitude 
$-\mathrm{CIN}=$ Integridade

- $\mathrm{CCO}=$ Competência
- INT = Intenção de Compra

- $\mathrm{CEF}=$ Compra Efetiva

Quadro 4.3 - Matriz de Correlação para a amostra Busca do modelo Confiança Geral

\begin{tabular}{|c|c|c|c|c|c|c|c|}
\cline { 2 - 8 } \multicolumn{1}{c|}{} & FAU & VAR & COM & CCG & ATT & INT & CE \\
\hline FAU & 1 & 0,733 & 0,704 & 0,557 & 0,783 & 0,658 & 0,387 \\
\hline VAR & 0,733 & 1 & 0,735 & 0,451 & 0,706 & 0,493 & 0,382 \\
\hline COM & 0,704 & 0,735 & 1 & 0,555 & 0,733 & 0,474 & 0,523 \\
\hline CCG & 0,557 & 0,451 & 0,555 & 1 & 0,540 & 0,456 & 0,278 \\
\hline ATT & 0,783 & 0,706 & 0,733 & 0,540 & 1 & 0,661 & 0,416 \\
\hline INT & 0,658 & 0,493 & 0,474 & 0,456 & 0,661 & 1 & 0,356 \\
\hline CE & 0,387 & 0,382 & 0,523 & 0,278 & 0,416 & 0,356 & 1 \\
\hline
\end{tabular}

Quadro 4.4 - Matriz de Correlação para a amostra Experiência do modelo Confiança Geral

\begin{tabular}{|c|c|c|c|c|c|c|c|}
\cline { 2 - 8 } \multicolumn{1}{c|}{} & FAU & VAR & COM & CCG & ATT & INT & CE \\
\hline FAU & 1 & 0,727 & 0,744 & 0,548 & 0,696 & 0,603 & 0,385 \\
\hline VAR & 0,727 & 1 & 0,571 & 0,454 & 0,604 & 0,519 & 0,373 \\
\hline COM & 0,744 & 0,571 & 1 & 0,502 & 0,630 & 0,546 & 0,489 \\
\hline CCG & 0,548 & 0,454 & 0,502 & 1 & 0,613 & 0,529 & 0,321 \\
\hline ATT & 0,696 & 0,604 & 0,630 & 0,613 & 1 & 0,619 & 0,441 \\
\hline INT & 0,603 & 0,519 & 0,546 & 0,529 & 0,619 & 1 & 0,408 \\
\hline CE & 0,385 & 0,373 & 0,489 & 0,321 & 0,441 & 0,408 & 1 \\
\hline
\end{tabular}

Onde:

- FAU = Facilidade de Uso

- VAR = Vantagem Relativa

- $\mathrm{COM}=$ Compatibilidade

$\bullet \mathrm{CIN}=$ Integridade

- $\mathrm{CCO}=$ Competência
- $\mathrm{CBE}=$ Benevolência

- $\mathrm{CCG}=$ Confiança Geral

- $\mathrm{ATT}=$ Atitude

- INT = Intenção de Compra

- $\mathrm{CEF}=$ Compra Efetiva 
Todas as correlações dispostas nos quadros 4.1 a 4.4 se apresentaram significativas a um nível de significância de 0,001. Uma vez que todas as correlações são positivas e consistentes com a teoria aplicada, pode-se concluir que os construtos utilizados apresentam validade nomológica.

Para avaliar a consistência interna e confiabilidade das escalas, foram utilizados o alfa de Cronbach e a confiabilidade composta, que refletem a consistência interna de indicadores que medem um mesmo fator (FORNELL; LARCKER, 1981). Em relação à confiabilidade composta e o alfa são recomendados valores acima de 0,7 . Conforme pode ser observado por meio das tabelas 4.2 e 4.3 para as amostras Busca e Experiência, respectivamente, para o modelo Dimensões da Confiança/Confiança de Segunda Ordem, e das tabelas 4.4 e 4.5 para as amostras Busca e Experiência, respectivamente, para o modelo Confiança Geral, todas as escalas utilizadas atendem aos níveis mínimos de confiabilidade considerados adequados pela literatura, com exceção da escala de compra efetiva para as duas amostras de Experiência,. Uma vez que os valores de confiabilidade composta e alfa de Cronbach estão próximos ao recomendado, o construto compra efetiva é considerado como tendo consistência interna e confiabilidade suficientes para ser utilizado no modelo estrutural.

Já a validade convergente foi avaliada calculando-se a variância extraída média para cada construto (average variance extracted - AVE). Fornell e Larcker (1981) afirmam que valores de AVE maiores do que 0,50 indicam validade convergente adequada. Uma vez que todos os valores de AVE calculados, para as duas amostras em ambos os modelos, estão acima do valor recomendado, fica evidente a validade convergente das escalas utilizadas. As Tabelas 4.2 a 4.5 apresentam os valores da variância extraída média de cada construto, juntamente com sua confiabilidade. 
Tabela 4.2 - Confiabilidade Composta e Variância Extraída Média da amostra Busca do modelo Dimensões da Confiança/Confiança de $2^{\text {a }}$ Ordem

\begin{tabular}{l|c|c|c}
\hline \multicolumn{1}{c|}{ Escala } & $\begin{array}{c}\text { Confiabilidade } \\
\text { Composta }\end{array}$ & $\begin{array}{c}\text { Alfa de } \\
\text { Cronbach }\end{array}$ & AVE \\
\hline Facilidade de Uso & 0,88 & 0,87 & 0,64 \\
Vantagem Relativa & 0,87 & 0,86 & 0,56 \\
Compatibilidade & 0,87 & 0,86 & 0,70 \\
Benevolência & 0,87 & 0,87 & 0,69 \\
Competência & 0,90 & 0,90 & 0,69 \\
Integridade & 0,90 & 0,89 & 0,69 \\
Atitude & 0,93 & 0,93 & 0,77 \\
Intenção de Compra & 0,95 & 0,95 & 0,82 \\
Compra Efetiva & 0,70 & 0,73 & 0,54 \\
\hline
\end{tabular}

Tabela 4.3 - Confiabilidade Composta e Variância Extraída Média da amostra Experiência do modelo Dimensões da Confiança/Confiança de $2^{\mathrm{a}}$ Ordem

\begin{tabular}{l|c|c|c}
\hline \multicolumn{1}{c|}{ Escala } & $\begin{array}{c}\text { Confiabilidade } \\
\text { Composta }\end{array}$ & $\begin{array}{c}\text { Alfa de } \\
\text { Cronbach }\end{array}$ & AVE \\
\hline Facilidade de Uso & 0,87 & 0,86 & 0,62 \\
Vantagem Relativa & 0,86 & 0,86 & 0,55 \\
Compatibilidade & 0,88 & 0,88 & 0,71 \\
Benevolência & 0,86 & 0,84 & 0,67 \\
Competência & 0,87 & 0,86 & 0,62 \\
Integridade & 0,89 & 0,88 & 0,66 \\
Atitude & 0,93 & 0,93 & 0,76 \\
Intenção de Compra & 0,95 & 0,95 & 0,84 \\
Compra Efetiva & 0,67 & 0,64 & 0,52 \\
\hline
\end{tabular}


Tabela 4.4 - Confiabilidade Composta e Variância Extraída Média da amostra Busca do modelo Confiança Geral

\begin{tabular}{l|c|c|c}
\hline \multicolumn{1}{c|}{ Escala } & $\begin{array}{c}\text { Confiabilidade } \\
\text { Composta }\end{array}$ & $\begin{array}{c}\text { Alfa de } \\
\text { Cronbach }\end{array}$ & AVE \\
\hline Facilidade de Uso & 0,88 & 0,86 & 0,64 \\
Vantagem Relativa & 0,86 & 0,86 & 0,55 \\
Compatibilidade & 0,87 & 0,88 & 0,70 \\
Confiança Geral & 0,91 & 0,84 & 0,72 \\
Atitude & 0,93 & 0,93 & 0,76 \\
Intenção de Compra & 0,95 & 0,95 & 0,82 \\
Compra Efetiva & 0,70 & 0,71 & 0,54 \\
\hline
\end{tabular}

Tabela 4.5 - Confiabilidade Composta e Variância Extraída Média da amostra Experiência do modelo Confiança Geral

\begin{tabular}{l|c|c|c}
\hline \multicolumn{1}{c|}{ Escala } & $\begin{array}{c}\text { Confiabilidade } \\
\text { Composta }\end{array}$ & $\begin{array}{c}\text { Alfa de } \\
\text { Cronbach }\end{array}$ & AVE \\
\hline Facilidade de Uso & 0,87 & 0,86 & 0,62 \\
Vantagem Relativa & 0,85 & 0,86 & 0,54 \\
Compatibilidade & 0,88 & 0,88 & 0,71 \\
Confiança Geral & 0,93 & 0,84 & 0,76 \\
Atitude & 0,93 & 0,93 & 0,76 \\
Intenção de Compra & 0,95 & 0,95 & 0,84 \\
Compra Efetiva & 0,66 & 0,64 & 0,51 \\
\hline
\end{tabular}

Foram também avaliadas as cargas fatoriais padronizadas para cada variável observável (item) nas variáveis latentes (construtos), assim como suas respectivas significâncias. Quanto maiores forem essas cargas, maior é a certeza de que as variáveis medidas representam os construtos aos quais estão associadas, indicando tanto validade convergente e quanto unidimensionalidade. Garver e Mentzer (1999) sugerem que estimativas maiores do que 0,70 , significativas e na direção esperada pela teoria apontam para a unidimensionalidade e validade convergente de um construto. 
As tabelas 4.6 e 4.7 apresentam as cargas fatoriais padronizadas e suas significâncias para cada um dos construtos presentes no modelo Dimensões da Confiança/Confiança de $2^{\text {a }}$ Ordem. Já as tabelas 4.8 e 4.9 apresentam as cargas fatoriais padronizadas e suas significâncias para cada um dos construtos presentes no modelo Confiança Geral.

Tabela 4.6 - Cargas Fatoriais Padronizadas (amostra Busca)

\begin{tabular}{|c|c|c|}
\hline Construto/Indicador & $\begin{array}{c}\text { Carga Fatorial } \\
\text { Padronizada }\end{array}$ & p-valor \\
\hline \multicolumn{3}{|l|}{ Facilidade de Uso } \\
\hline FAU1 & 0,760 & $<0,001$ \\
\hline FAU2 & 0,729 & $<0,001$ \\
\hline FAU3 & 0,891 & $<0,001$ \\
\hline FAU4 & 0,810 & $<0,001$ \\
\hline \multicolumn{3}{|l|}{ Vantagem Relativa } \\
\hline VAR1 & 0,709 & $<0,001$ \\
\hline VAR2 & 0,739 & $<0,001$ \\
\hline VAR3 & 0,767 & $<0,001$ \\
\hline VAR4 & 0,827 & $<0,001$ \\
\hline VAR5 & 0,706 & $<0,001$ \\
\hline \multicolumn{3}{|l|}{ Compatibilidade } \\
\hline COM1 & 0,890 & $<0,001$ \\
\hline COM2 & 0,725 & $<0,001$ \\
\hline COM3 & 0,881 & $<0,001$ \\
\hline \multicolumn{3}{|l|}{ Integridade } \\
\hline CIN1 & 0,797 & $<0,001$ \\
\hline CIN2 & 0,866 & $<0,001$ \\
\hline CIN3 & 0,796 & $<0,001$ \\
\hline CIN4 & 0,834 & $<0,001$ \\
\hline \multicolumn{3}{|l|}{ Benevolência } \\
\hline CBE1 & 0,882 & $<0,001$ \\
\hline CBE2 & 0,840 & $<0,001$ \\
\hline CBE3 & 0,770 & $<0,001$ \\
\hline \multicolumn{3}{|l|}{ Competência } \\
\hline CCO1 & 0,875 & $<0,001$ \\
\hline $\mathrm{CCO} 2$ & 0,861 & $<0,001$ \\
\hline
\end{tabular}




\begin{tabular}{lll}
\hline CCO3 & 0,861 & $<0,001$ \\
CCO4 & 0,718 & $<0,001$ \\
Atitude & & \\
ATT1 & 0,854 & $<0,001$ \\
ATT2 & 0,874 & $<0,001$ \\
ATT3 & 0,881 & $<0,001$ \\
ATT4 & 0,890 & $<0,001$ \\
Intenção & & \\
INT1 & 0,882 & $<0,001$ \\
INT2 & 0,945 & $<0,001$ \\
INT3 & 0,928 & $<0,001$ \\
INT4 & 0,873 & $<0,001$ \\
Compra Efetiva & & $<0,001$ \\
CE1 & 0,732 & $<0,001$ \\
CE2 & 0,738 & \\
\hline
\end{tabular}

Tabela 4.7 - Cargas Fatoriais Padronizadas (amostra Experiência)

\begin{tabular}{lcc}
\hline \multicolumn{1}{c}{ Construto/Indicador } & $\begin{array}{c}\text { Carga Fatorial } \\
\text { Padronizada }\end{array}$ & p-valor \\
\hline Facilidade de Uso & 0,714 & $<0,001$ \\
FAU1 & 0,774 & $<0,001$ \\
FAU2 & 0,870 & $<0,001$ \\
FAU3 & 0,789 & $<0,001$ \\
FAU4 & & \\
Vantagem Relativa & 0,768 & $<0,001$ \\
VAR1 & 0,721 & $<0,001$ \\
VAR2 & 0,800 & $<0,001$ \\
VAR3 & 0,811 & $<0,001$ \\
VAR4 & 0,607 & $<0,001$ \\
VAR5 & & $<0,001$ \\
Compatibilidade & 0,828 & $<0,001$ \\
COM1 & 0,877 & $<0,001$ \\
COM2 & 0,824 & \\
COM3 & &
\end{tabular}




\begin{tabular}{|c|c|c|}
\hline \multicolumn{3}{|c|}{ Integridade } \\
\hline CIN1 & 0,776 & $<0,001$ \\
\hline CIN2 & 0,855 & $<0,001$ \\
\hline CIN3 & 0,757 & $<0,001$ \\
\hline CIN4 & 0,864 & $<0,001$ \\
\hline \multicolumn{3}{|c|}{ Benevolência } \\
\hline CBE1 & 0,819 & $<0,001$ \\
\hline CBE2 & 0,842 & $<0,001$ \\
\hline CBE3 & 0,753 & $<0,001$ \\
\hline \multicolumn{3}{|c|}{ Competência } \\
\hline CCO1 & 0,813 & $<0,001$ \\
\hline $\mathrm{CCO} 2$ & 0,821 & $<0,001$ \\
\hline $\mathrm{CCO} 3$ & 0,816 & $<0,001$ \\
\hline CCO4 & 0,686 & $<0,001$ \\
\hline \multicolumn{3}{|c|}{ Atitude } \\
\hline ATT1 & 0,811 & $<0,001$ \\
\hline ATT2 & 0,922 & $<0,001$ \\
\hline ATT3 & 0,855 & $<0,001$ \\
\hline ATT4 & 0,902 & $<0,001$ \\
\hline \multicolumn{3}{|c|}{ Intenção } \\
\hline INT1 & 0,921 & $<0,001$ \\
\hline INT2 & 0,963 & $<0,001$ \\
\hline INT3 & 0,931 & $<0,001$ \\
\hline INT4 & 0,840 & $<0,001$ \\
\hline \multicolumn{3}{|c|}{ Compra Efetiva } \\
\hline CE1 & 0,871 & $<0,001$ \\
\hline CE2 & 0,526 & $<0,001$ \\
\hline
\end{tabular}

Ressalte-se que as cargas fatoriais de todos os indicadores são significativas e apresentam a direção esperada. A avaliação da magnitude das cargas estimadas para as duas amostras do modelo Dimensões da Confiança/ Confiança de $2^{\text {a }}$ Ordem que todas tem carga padronizada superior ao valor 0,70 sugerido pela literatura (GARVER; MENTZER, 1999), com exceção do item 5 da vantagem relativa, do item 4 da competência e do item 2 da compra efetiva para a amostra Experiência, cujas cargas padronizadas são superiores a 0,5 para seus respectivos fatores e não carregam em outros fatores com valores superiores a 0,4 , o que permite a sua 
aceitação. Uma análise da matriz de correlações e uma análise fatorial exploratória, associadas aos valores superiores a 0,5 (considerados significativos) nas cargas fatoriais padronizadas, indicam o correto posicionamento dos itens em seus respectivos construtos Assim sendo, pode-se considerar verificadas tanto a unidimensionalidade quanto a validade convergente dos construtos para ambas as amostras do modelo Dimensões da Confiança/ Confiança de $2^{\mathrm{a}}$ Ordem.

Tabela 4.8 - Cargas Fatoriais Padronizadas (amostra Busca)

\begin{tabular}{|c|c|c|}
\hline Construto/Indicador & $\begin{array}{l}\text { Carga Fatorial } \\
\text { Padronizada }\end{array}$ & p-valor \\
\hline \multicolumn{3}{|l|}{ Facilidade de Uso } \\
\hline FAU1 & 0,757 & $<0,001$ \\
\hline FAU2 & 0,728 & $<0,001$ \\
\hline FAU3 & 0,890 & $<0,001$ \\
\hline FAU4 & 0,815 & $<0,001$ \\
\hline \multicolumn{3}{|l|}{ Vantagem Relativa } \\
\hline VAR1 & 0,709 & $<0,001$ \\
\hline VAR2 & 0,716 & $<0,001$ \\
\hline VAR3 & 0,747 & $<0,001$ \\
\hline VAR4 & 0,839 & $<0,001$ \\
\hline VAR5 & 0,710 & $<0,001$ \\
\hline \multicolumn{3}{|l|}{ Compatibilidade } \\
\hline COM1 & 0,890 & $<0,001$ \\
\hline COM2 & 0,732 & $<0,001$ \\
\hline COM3 & 0,876 & $<0,001$ \\
\hline \multicolumn{3}{|l|}{ Confiança Geral } \\
\hline CCG1 & 0,872 & $<0,001$ \\
\hline CCG2 & 0,947 & $<0,001$ \\
\hline CCG3 & 0,898 & $<0,001$ \\
\hline CCG4 & 0,652 & $<0,001$ \\
\hline \multicolumn{3}{|l|}{ Atitude } \\
\hline ATT1 & 0,853 & $<0,001$ \\
\hline ATT2 & 0,873 & $<0,001$ \\
\hline ATT3 & 0,881 & $<0,001$ \\
\hline ATT4 & 0,891 & $<0,001$ \\
\hline Intenção & & \\
\hline
\end{tabular}




\begin{tabular}{lll}
\hline INT1 & 0,882 & $<0,001$ \\
INT2 & 0,943 & $<0,001$ \\
INT3 & 0,928 & $<0,001$ \\
INT4 & 0,874 & $<0,001$ \\
Compra Efetiva & & \\
CE1 & 0,721 & $<0,001$ \\
CE2 & 0,749 & $<0,001$ \\
\hline
\end{tabular}

Tabela 4.9 - Cargas Fatoriais Padronizadas (amostra Experiência)

\begin{tabular}{|c|c|c|}
\hline Construto/Indicador & $\begin{array}{c}\text { Carga Fatorial } \\
\text { Padronizada }\end{array}$ & p-valor \\
\hline \multicolumn{3}{|l|}{ Facilidade de Uso } \\
\hline FAU1 & 0,718 & $<0,001$ \\
\hline FAU2 & 0,776 & $<0,001$ \\
\hline FAU3 & 0,866 & $<0,001$ \\
\hline FAU4 & 0,789 & $<0,001$ \\
\hline \multicolumn{3}{|l|}{ Vantagem Relativa } \\
\hline VAR1 & 0,757 & $<0,001$ \\
\hline VAR2 & 0,696 & $<0,001$ \\
\hline VAR3 & 0,774 & $<0,001$ \\
\hline VAR4 & 0,823 & $<0,001$ \\
\hline VAR5 & 0,597 & $<0,001$ \\
\hline \multicolumn{3}{|l|}{ Compatibilidade } \\
\hline COM1 & 0,826 & $<0,001$ \\
\hline COM2 & 0,883 & $<0,001$ \\
\hline COM3 & 0,818 & $<0,001$ \\
\hline \multicolumn{3}{|l|}{ Confiança Geral } \\
\hline CCG1 & 0,890 & $<0,001$ \\
\hline CCG2 & 0,935 & $<0,001$ \\
\hline CCG3 & 0,890 & $<0,001$ \\
\hline CCG4 & 0,770 & $<0,001$ \\
\hline \multicolumn{3}{|l|}{ Atitude } \\
\hline ATT1 & 0,813 & $<0,001$ \\
\hline ATT2 & 0,918 & $<0,001$ \\
\hline ATT3 & 0,856 & $<0,001$ \\
\hline ATT4 & 0,904 & $<0,001$ \\
\hline
\end{tabular}




\begin{tabular}{lll}
\hline Intenção & \\
INT1 & 0,922 & $<0,001$ \\
INT2 & 0,963 & $<0,001$ \\
INT3 & 0,930 & $<0,001$ \\
INT4 & 0,839 & $<0,001$ \\
Compra Efetiva & & \\
CE1 & 0,849 & $<0,001$ \\
CE2 & 0,540 & $<0,001$ \\
\hline
\end{tabular}

Ressalte-se que as cargas fatoriais de todos os indicadores são significativas e apresentam a direção esperada. A avaliação da magnitude das cargas estimadas para as duas amostras do modelo Dimensões da Confiança/ Confiança de $2^{\text {a }}$ Ordem que todas tem carga padronizada superior ao valor 0,70 sugerido pela literatura (GARVER; MENTZER, 1999), com exceção do item 4 da confiança geral para a amostra Busca e dos itens 2 e 5 da vantagem relativa e do item 2 da compra efetiva para a amostra Experiência. A ausência de carregamento destes itens em outros fatores com valores superiores a 0,5, associada aos valores superiores a 0,5 (considerados significativos) nas cargas fatoriais padronizadas, indicam o correto posicionamento dos itens em seus respectivos construtos. Desta forma, podem-se considerar verificadas tanto a unidimensionalidade quanto a validade convergente dos construtos para ambas as amostras do modelo Dimensões da Confiança/ Confiança de $2^{\mathrm{a}}$ Ordem.

Para a avaliação da validade discriminante, em que cada um dos itens de um construto deve se relacionar mais fortemente com o construto ao qual deveriam se referir do que com outros construtos presentes no modelo, é importante que a variância compartilhada entre os itens de cada construto seja maior do que a variância compartilhada entre aquele construto e os outros construtos. Para tanto, Fornell e Larcker (1981) sugerem que seja feita uma comparação entre a variância extraída média (AVE) de cada construto e a variância compartilhada (o quadrado do coeficiente de correlação) entre todos os pares de construtos. A validade discriminante seria então verificada quando todos os construtos apresentam variâncias extraídas maiores do que as respectivas variâncias compartilhadas. 
Os quadros 4.5 e 4.6 apresentam as matrizes para a análise da validade discriminante para o modelo Dimensões da Confiança/Confiança de $2^{\mathrm{a}}$ Ordem, com a diagonal principal contendo a AVE para cada construto e as demais células apresentando o quadrado dos coeficientes de correlação entre cada par de construtos. Sua análise mostra que as variâncias compartilhadas são inferiores à AVE para todos os construtos, indicando validade discriminante adequada.

Quadro 4.5 - Matriz de Validade Discriminante (amostra Busca)

\begin{tabular}{|c|c|c|c|c|c|c|c|c|c|}
\cline { 2 - 10 } \multicolumn{1}{c|}{} & VAR & COM & FAU & CBE & CCO & CIN & ATT & INT & CE \\
\hline VAR & 0,56 & 0,53 & 0,55 & 0,43 & 0,34 & 0,35 & 0,49 & 0,24 & 0,14 \\
\hline COM & 0,53 & 0,70 & 0,49 & 0,47 & 0,40 & 0,38 & 0,53 & 0,22 & 0,27 \\
\hline FAU & 0,55 & 0,49 & 0,64 & 0,33 & 0,43 & 0,35 & 0,61 & 0,43 & 0,15 \\
\hline CBE & 0,43 & 0,47 & 0,33 & 0,69 & 0,45 & 0,56 & 0,24 & 0,11 & 0,10 \\
\hline CCO & 0,34 & 0,40 & 0,43 & 0,45 & 0,69 & 0,67 & 0,36 & 0,27 & 0,14 \\
\hline CIN & 0,35 & 0,38 & 0,35 & 0,56 & 0,67 & 0,69 & 0,31 & 0,18 & 0,11 \\
\hline ATT & 0,49 & 0,53 & 0,61 & 0,24 & 0,36 & 0,31 & 0,77 & 0,43 & 0,17 \\
\hline INT & 0,24 & 0,22 & 0,43 & 0,11 & 0,27 & 0,18 & 0,43 & 0,82 & 0,13 \\
\hline CE & 0,14 & 0,27 & 0,15 & 0,10 & 0,14 & 0,11 & 0,17 & 0,13 & 0,54 \\
\hline
\end{tabular}

Quadro 4.6 - Matriz de Validade Discriminante (amostra Experiência)

\begin{tabular}{|c|c|c|c|c|c|c|c|c|c|}
\cline { 2 - 10 } \multicolumn{1}{c|}{} & VAR & COM & FAU & CBE & CCO & CIN & ATT & INT & CE \\
\hline VAR & 0,55 & 0,31 & 0,54 & 0,16 & 0,30 & 0,14 & 0,35 & 0,26 & 0,12 \\
\hline COM & 0,31 & 0,71 & 0,55 & 0,27 & 0,29 & 0,15 & 0,40 & 0,30 & 0,23 \\
\hline FAU & 0,58 & 0,54 & 0,62 & 0,18 & 0,50 & 0,17 & 0,48 & 0,36 & 0,14 \\
\hline CBE & 0,16 & 0,27 & 0,18 & 0,67 & 0,35 & 0,49 & 0,08 & 0,05 & 0,04 \\
\hline CCO & 0,30 & 0,29 & 0,50 & 0,35 & 0,62 & 0,55 & 0,37 & 0,26 & 0,07 \\
\hline CIN & 0,14 & 0,15 & 0,17 & 0,49 & 0,55 & 0,66 & 0,31 & 0,18 & 0,11 \\
\hline ATT & 0,35 & 0,40 & 0,48 & 0,08 & 0,37 & 0,31 & 0,76 & 0,38 & 0,19 \\
\hline INT & 0,26 & 0,30 & 0,36 & 0,05 & 0,26 & 0,18 & 0,38 & 0,84 & 0,16 \\
\hline CE & 0,12 & 0,23 & 0,14 & 0,04 & 0,07 & 0,11 & 0,19 & 0,16 & 0,52 \\
\hline
\end{tabular}

Os quadros 4.7 e 4.8 apresentam as matrizes para a análise da validade discriminante para o modelo Confiança Geral, com a diagonal principal contendo a AVE para cada construto e as demais células apresentando o quadrado dos coeficientes de correlação entre cada par de construtos. Sua análise mostra que as variâncias 
compartilhadas são inferiores à AVE para a todos os construtos, indicando validade discriminante adequada.

Quadro 4.7 - Matriz de Validade Discriminante (amostra Busca)

\begin{tabular}{|c|c|c|c|c|c|c|c|}
\cline { 2 - 8 } \multicolumn{1}{c|}{} & VAR & COM & FAU & CCG & ATT & INT & CE \\
\hline VAR & 0,55 & 0,33 & 0,54 & 0,20 & 0,50 & 0,24 & 0,15 \\
\hline COM & 0,33 & 0,70 & 0,50 & 0,31 & 0,54 & 0,22 & 0,27 \\
\hline FAU & 0,54 & 0,50 & 0,64 & 0,31 & 0,61 & 0,43 & 0,15 \\
\hline CCG & 0,20 & 0,31 & 0,31 & 0,72 & 0,29 & 0,21 & 0,08 \\
\hline ATT & 0,50 & 0,54 & 0,61 & 0,29 & 0,76 & 0,43 & 0,17 \\
\hline INT & 0,24 & 0,22 & 0,43 & 0,21 & 0,43 & 0,82 & 0,13 \\
\hline CE & 0,15 & 0,27 & 0,15 & 0,08 & 0,17 & 0,13 & 0,54 \\
\hline
\end{tabular}

Quadro 4.8 - Matriz de Validade Discriminante (amostra Experiência)

\begin{tabular}{|c|c|c|c|c|c|c|c|}
\cline { 2 - 8 } \multicolumn{1}{c|}{} & VAR & COM & FAU & CCG & ATT & INT & CE \\
\hline VAR & 0,54 & 0,32 & 0,53 & 0,21 & 0,36 & 0,27 & 0,14 \\
\hline COM & 0,32 & 0,71 & 0,55 & 0,25 & 0,40 & 0,30 & 0,24 \\
\hline FAU & 0,53 & 0,55 & 0,62 & 0,30 & 0,48 & 0,36 & 0,15 \\
\hline CCG & 0,21 & 0,25 & 0,30 & 0,76 & 0,38 & 0,28 & 0,10 \\
\hline ATT & 0,36 & 0,40 & 0,48 & 0,38 & 0,76 & 0,38 & 0,19 \\
\hline INT & 0,27 & 0,30 & 0,36 & 0,28 & 0,38 & 0,84 & 0,17 \\
\hline CE & 0,14 & 0,24 & 0,15 & 0,10 & 0,19 & 0,17 & 0,51 \\
\hline
\end{tabular}

O último teste realizado para os modelos de mensuração diz respeito ao viés do método comum. Os resultados do teste indicaram uma pequena variância originada em um fator latente não mensurado no item 3 da benevolência, mas cuja magnitude (0,249 de variância) pode ser ignorada. Assim, pode-se afirmar que, em termos gerais, não há efeitos significativos do método sobre os dados coletados.

Por fim, uma análise coletiva dos resultados apresentados indica que o modelo de mensuração proposto atende aos requisitos necessários de validade de face, validade nomológica, confiabilidade, unidimensionalidade, validade convergente e validade discriminante, tornando viável uma investigação das relações entre os construtos latentes com o uso de um modelo estrutural. 


\subsection{3}

\section{Análise do Modelo Estrutural}

Os modelos propostos e as hipóteses de pesquisa foram testados pela técnica de modelagem de equações estruturais (SEM), com o uso do software AMOS 20. Segundo Byrne (2010), em modelagem de equações estruturais, a significância dos coeficientes estimados para as relações presentes no modelo indica se a hipótese de uma relação entre construtos é verificada ou não.

Como forma de complementar o estudo, Anderson e Gerbing (1988) sugerem que seja feita uma comparação do modelo proposto com outros modelos alternativos ou rivais. Dessa forma, é feita uma modelagem da estrutura proposta inicialmente, e sua adequabilidade é então verificada por meio dos índices de ajuste relevantes. Em seguida, o ajuste do modelo proposto é comparado ao ajuste de modelos alternativos, permitindo uma melhor avaliação da força e relevância de diferentes relações entre os construtos investigados.

\subsubsection{1 Normalidade}

Numa análise de modelagem de equações estruturais por estimação por Máxima Verossimilhança (ML) é uma premissa importante que os dados utilizados apresentem uma distribuição multivariada normal. No entanto, Olsson et al. (2000) afirmam que estimações por ML são robustas contra violações da premissa de normalidade, sendo até mais precisas e estáveis do que outras técnicas de estimação que não apresentam a premissa de normalidade

Sendo assim, antes da análise dos resultados, verificou-se se a condição de normalidade multivariada foi satisfeita. Uma análise de normalidade disponibilizada pelo software AMOS 20, que fornece os valores para as curtoses univariadas de cada indicador, assim como valores para a curtose multivariada, permitiu a verificação desta premissa. Os resultados dos testes, quando comparados com os valores sugeridos pela literatura (BYRNE, 2010; FERREIRA et al., 2013), permitem concluir que não há presença de curtose univariada substancial nos itens utilizados. Nenhum dos itens utilizados (amostras Busca e Experiência para os dois conjuntos de variáveis) apresenta valor para curtose univariada maior que 2,9 (com 
a maioria inferior a 1) e Byrne (2010) sugere que apenas os valores acima de 7,0 devem ser considerados indicativos de fuga da normalidade. Por outro lado, a razão crítica indica que os dados das duas amostras utilizadas (Busca e Experiência em todos os modelos) não apresentam normalidade multivariada, pois seus valores são superiores a 5,0 (BYRNE, 2010). Ainda sim, o método ML foi utilizado com base na sua robustez (OLSSON et al., 2000), nos resultados obtidos por estudos similares (FERREIRA et al., 2013; GAO et al., 2012; GIOVANNINI et al. 2015 ; KULVIWAT et al., 2007; NASCO et al., 2008) e pela impossibilidade da aplicação adequada de outros métodos de estimação devido ao tamanho da amostra.

\subsubsection{2}

\section{Ajuste do Modelo Proposto}

O ajuste dos modelos MCTF2 Dimensões da Confiança, Confiança de Segunda Ordem e Confiança Geral foram examinados com o uso de diversos índices recomendados pela literatura de modelagem de equações estruturais (HAIR et al., 2009; HOOPER et al.; 2008; SCHREIBER et al., 2006; KLINE, 2005; GARVER; MENTZER, 1999; HU; BENTLER, 1999), e aplicados na realização de estudos similares a este (FERREIRA, 2013; GAO et al., 2012; KIM et al., 2010; LI et al., 2012).

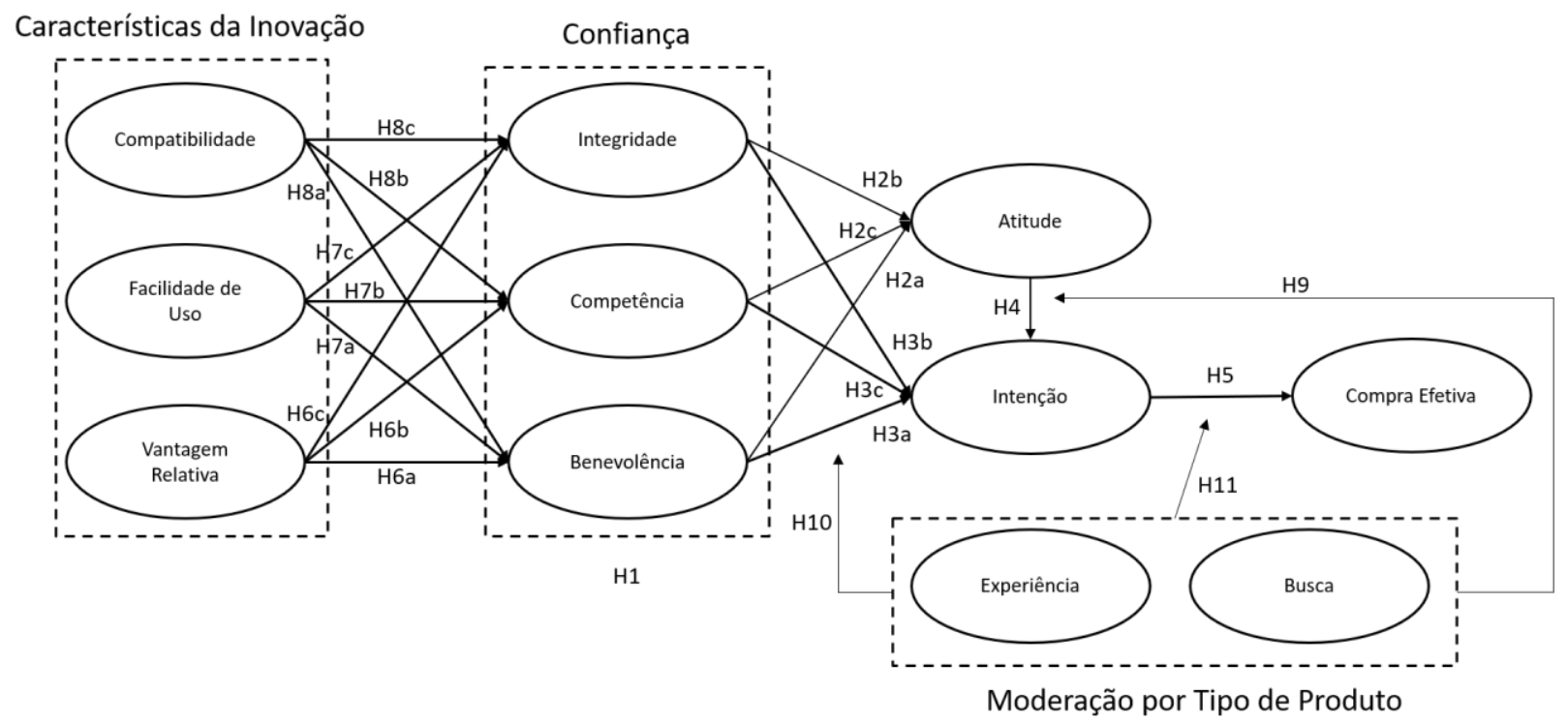

FIGURA 4.1 - MOBILE COMMERCE TRUST FORMATION 2 - DIMENSÕES DA CONFIANÇA 
Embora os índices para ambas as amostras do modelo Dimensões da Confiança tenham sido razoáveis no primeiro teste, os índices de modificação apresentados indicaram relações entre os construtos facilidade de uso, vantagem relativa e compatibilidade que não poderiam ser negligenciados $($ amostra Busca $=$ compatibilidade $\rightarrow$ facilidade I.M. 107,233, facilidade $\leftarrow \rightarrow$ vantagem relativa I.M. 127,153, compatibilidade $\rightarrow$ vantagem relativa I.M. 70,954; amostra Experiência $=$ compatibilidade $\rightarrow$ facilidade I.M. 107,233, facilidade $\leftarrow \rightarrow$ vantagem relativa I.M. 127,153, compatibilidade $\rightarrow$ vantagem relativa I.M. 70,954). Essas relações não haviam sido apresentadas a priori, mas foram incorporadas aos modelos propostos devido ao suporte encontrado na literatura para sua presença.

O construto vantagem relativa do trabalho de Moore e Benbasat (1991), utilizado aqui, deriva do construto utilidade percebida de Davis (1989). O modelo TAM de Davis (1989) prevê efeitos da facilidade de uso sobre a percepção de utilidade de um sistema. Estudos extensivos utilizando o TAM e o TAM2 dão suporte a essa relação. Parece razoável afirmar que o mesmo se aplica a relação entre facilidade de uso e vantagem relativa, ou seja, que a percepção de que comprar via dispositivos móveis é fácil e livre de esforços exerceria influência na percepção de sua vantagem sobre outras formas de comprar produtos e serviços.

Hipótese 12: A facilidade de uso dos dispositivos móveis tem efeito positivo e direto sobre a percepção de vantagem relativa dos mesmos.

Segundo Moore e Benbasat (1991), compatibilidade e vantagem relativa frequentemente carregam como um único construto em análises fatoriais exploratórias livres (sem definição de quantidade de construtos), indicando que são vistos como um único fator pelos respondentes ou que há uma relação de causalidade entre ambos. Não é difícil imaginar o quão improvável seria que um indivíduo percebesse vantagens na realização de compras com dispositivos móveis se esse uso não fosse compatível com sua experiência pessoal e estilo de fazer compras. Assim, é proposta a seguinte hipótese:

Hipótese 13: A compatibilidade dos dispositivos móveis tem efeito positivo e direto sobre a percepção de vantagem relativa dos mesmos. 
Quanto aos efeitos da compatibilidade sobre a facilidade de uso, não foi encontrada na literatura evidência de que a relação tenha sido testada. Entretanto essa relação não seria surpresa, pois a presença de compatibilidade entre a realização de compras via dispositivos móveis e a experiência pessoal de um indivíduo contribuiria para sua percepção de facilidade de uso do dispositivo para a realização de compras de produtos e serviços. Assim, é proposta a seguinte hipótese:

Hipótese 14: A compatibilidade dos dispositivos móveis tem efeito positivo e direto sobre a percepção de facilidade de uso dos mesmos.

As três novas hipóteses foram então incorporadas aos três diferentes modelos a serem testados e comparados, gerando uma melhora significativa em seus índices de ajuste. Dessa forma, o modelo de Dimensões da Confiança testado estruturalmente é o apresentado na figura 4.2.

\section{Características da Inovação}

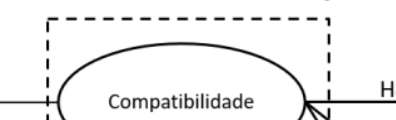

Compatibilidade

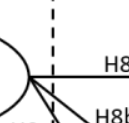

Confiança

H14

Facilidade de

(8)

(1c)

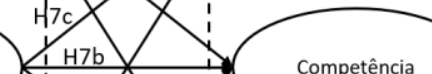

Competência

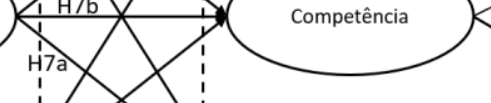

12

Vantagem Relativa i Relativa

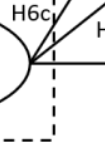

Benevolência

FIGURA 4.2 - MOBILE COMMERCE TRUST FORMATION 2 - DIMENSÕES DA CONFIANÇA MODIFICADO E TESTADO

A estatística qui-quadrada obtida para o modelo multigrupo Dimensões da Confiança (formado pelas amostras Busca e Experiência) foi estatisticamente significativa $\left(\chi^{2}=2029,438\right.$; d.f. $\left.=938 ; \mathrm{p}<0,001\right)$. É importante observar que diversos autores aconselham que ela seja utilizada com cautela, uma vez que é sensível ao tamanho da amostra (TENNANT; PALLANT, 2012; HOOPER et al., 2008; KENNY; MCCOACH, 2003; JÖRESKOG; SÖRBOM, 1993; BENTLER, 
1990) e a violações da premissa de normalidade (HOOPER et al., 2008; MCINTOSH, 2006; BENTLER, 1990).

Todos os outros índices indicaram um bom ajuste do modelo aos dados. A razão $\chi 2 /$ d.f. foi de 2,164, inferior ao valor de 3,0 sugerido por Byrne (2010). O SRMR (standardized root mean square residual) foi de 0,0729, inferior a 0,08, indicando também adequação do modelo. Por sua vez, o RMSEA (root mean square error of approximation) foi de 0,047 (C. I. de 0,044 até 0,050) ficando abaixo do valor sugerido de 0,08 (HU; BENTLER, 1998). Além disso, os índices de ajuste incrementais ficaram dentro do patamar de 0,90 (BENTLER; BONNET, 1980), com um CFI (comparative fit index) de 0,920, um TLI (Tucker-Lewis index) de 0,910 e um IFI (incremental fit index) de 0,921. Estes resultados encontram-se resumidos na tabela 4.10. Dados os índices apresentados, pode-se concluir que o ajuste do modelo proposto é satisfatório.

Tabela 4.10 - Índices de Ajuste do Modelo Dimensões da Confiança

\begin{tabular}{ccc}
\hline Índice de Ajuste & MCTF2 Dimensões & Valor Sugerido \\
\hline$\chi^{2} /$ d.f. & 2,164 & $\leq 3,0$ \\
SRMR & 0,073 & $\leq 0,08$ \\
RMSEA & 0,047 & $\leq 0,08$ \\
CFI & 0,920 & $\geq 0,90$ \\
IFI & 0,921 & $\geq 0,90$ \\
TLI & 0,910 & $\geq 0,90$ \\
\hline
\end{tabular}

O modelo Confiança de Segunda Ordem testado estruturalmente é o apresentado na figura 4.3. 


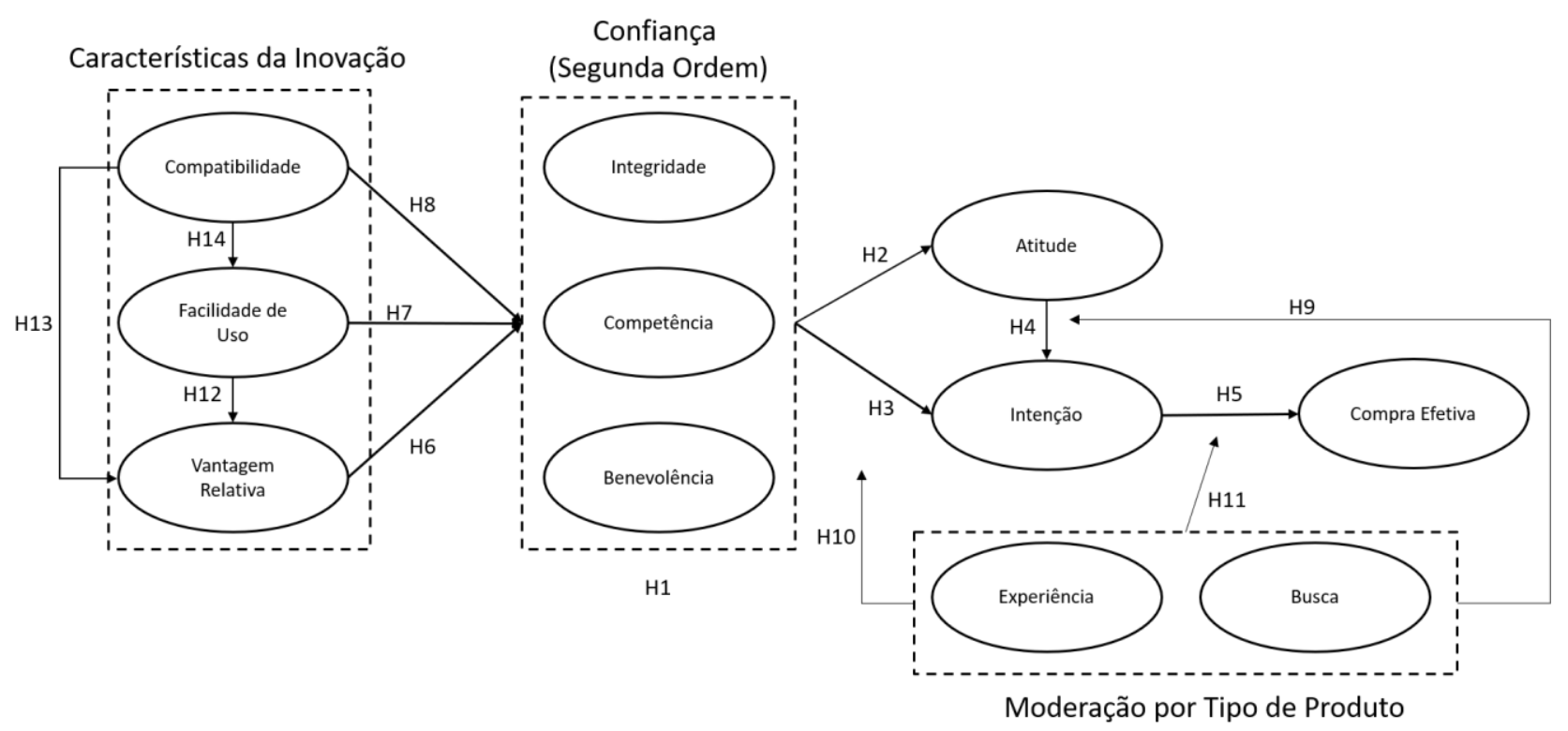

FIGURA 4.3 - MOBILE COMMERCE TRUST FORMATION 2 - CONFIANÇA DE SEGUNDA ORDEM MODIFICADO E TESTADO

A estatística qui-quadrada obtida para o modelo multigrupo Confiança de Segunda Ordem (formado pelas amostras Busca e Experiência) foi estatisticamente significativa $(\chi 2=1993,599 ;$ d.f. $=958 ; \mathrm{p}<0,001)$.

Todos os outros índices indicaram um bom ajuste do modelo aos dados. A razão $\chi 2 /$ d.f. foi de 2,081, inferior ao valor de 3,0 sugerido por Byrne (2010). O SRMR (standardized root mean square residual) foi de 0,0751 , inferior a 0,08 , indicando também adequação do modelo. Por sua vez, o RMSEA (root mean square error of approximation) foi de 0,045 (C. I. de 0,042 até 0,048) ficando abaixo do valor sugerido de 0,08 (HU; BENTLER, 1998). Além disso, os índices de ajuste incrementais ficaram dentro do patamar de 0,90 (BENTLER; BONNET, 1980), com um CFI (comparative fit index) de 0,924, um TLI (Tucker-Lewis index) de 0,916 e um IFI (incremental fit index) de 0,925. Estes resultados encontram-se resumidos na tabela 4.11, u. Dados os índices apresentados, pode-se concluir que o ajuste do modelo proposto é satisfatório. 
Tabela 4.11 - Índices de Ajuste do Modelo Confiança de Segunda Ordem

\begin{tabular}{ccc}
\hline Índice de Ajuste & MCTF2 2 ${ }^{\mathbf{a}}$ Ordem & Valor Sugerido \\
\hline$\chi^{\mathbf{2} / \text { d.f. }}$ & 2,081 & $\leq 3,0$ \\
SRMR & 0,0751 & $\leq 0,08$ \\
RMSEA & 0,045 & $\leq 0,08$ \\
CFI & 0,924 & $\geq 0,90$ \\
IFI & 0,925 & $\geq 0,90$ \\
TLI & 0,916 & $\geq 0,90$ \\
\hline
\end{tabular}

O modelo Confiança Geral testado estruturalmente é o apresentado na figura 4.4 .

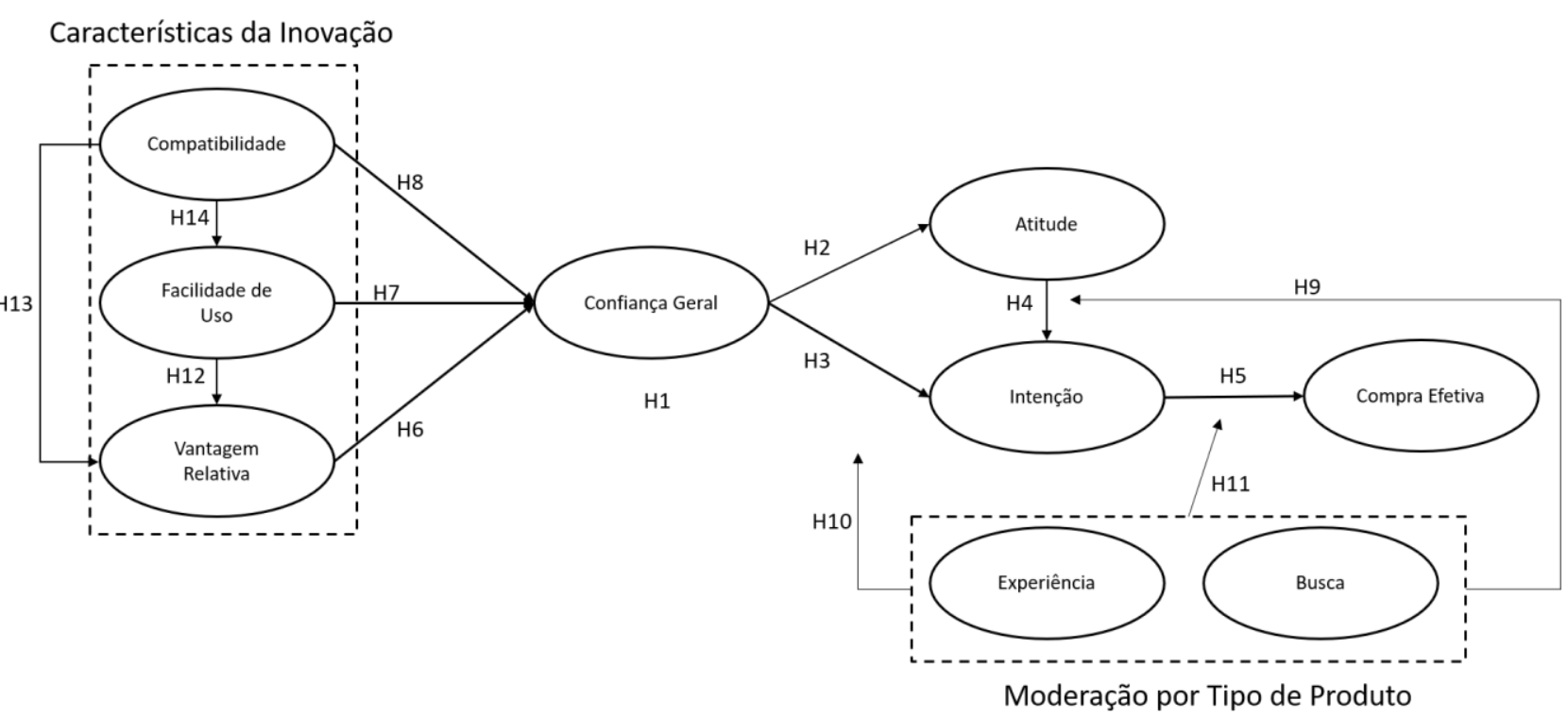

FIGURA 4.4 - MOBILE COMMERCE TRUST FORMATION 2 - CONFIANÇA GERAL MODIFICADO E TESTADO

A estatística qui-quadrada obtida para o modelo multigrupo Confiança Geral (formado pelas amostras Busca e Experiência) foi estatisticamente significativa ( $\chi^{2}$ $=1469,309 ;$ d.f. $=572 ; \mathrm{p}<0,001)$. 
O SRMR (standardized root mean square residual) foi de 0,160 , superior a 0,08, indicando, inicialmente, uma baixa adequação do modelo. Todos os outros índices indicaram um bom ajuste do modelo aos dados. A razão $\chi 2 /$ d.f. foi de 2,569, inferior ao valor de 3,0 sugerido por Byrne (2010). Por sua vez, o RMSEA (root mean square error of approximation) foi de 0,054 (C. I. de 0,051 até 0,058) ficando abaixo do valor sugerido de 0,08 (HU; BENTLER, 1998). Além disso, os índices de ajuste incrementais ficaram dentro do patamar de 0,90 (BENTLER; BONNET, 1980), com um CFI (comparative fit index) de 0,919, um TLI (Tucker-Lewis index) de 0,908 e um IFI (incremental fit index) de 0,920. Estes resultados encontram-se resumidos na tabela 4.11. Dados os índices apresentados, pode-se concluir que o ajuste do modelo proposto é satisfatório.

Tabela 4.12 - Índices de Ajuste do Modelo Confiança Geral

\begin{tabular}{ccc}
\hline Índice de Ajuste & MCTF2 Geral & Valor Sugerido \\
\hline$\chi^{2} /$ d.f. & 2,569 & $\leq 3,0$ \\
SRMR & 0,160 & $\leq 0,08$ \\
RMSEA & 0,054 & $\leq 0,08$ \\
CFI & 0,919 & $\geq 0,90$ \\
IFI & 0,908 & $\geq 0,90$ \\
TLI & 0,920 & $\geq 0,90$ \\
\hline
\end{tabular}

\subsection{4}

\section{Teste Comparativo entre Modelos}

Conforme sugerido por outros autores (ANDERSON; GERBING, 1988), a comparação entre o modelo proposto e outros modelos alternativos (já modificados pelas hipóteses H12, H13 e H14) permite a avaliação da força e da relevância das diferentes relações entre os construtos. Sendo um dos objetivos deste estudo a comparação das relações de confiança entre os três modelos sugeridos a fím de 
verificar aquele que melhor cumpra sua tarefa de apresentar uma explicação para os dados amostrais e ao mesmo tempo apresente profundidade teórica.

Um dos modelos alternativos, denominado Confiança de Segunda Ordem utiliza o mesmo modelo de mensuração apresentado para o modelo proposto, denominado Dimensões da Confiança, mas as três dimensões da confiança são carregadas como itens do construto de segunda ordem Confiança. O outro modelo estrutural utiliza um modelo de mensuração diferente, pois utiliza uma representação diferente do construto Confiança em que as diferentes dimensões não estão claramente presentes e os itens focam na percepção global de confiança. A fim de comparar os modelos foi feito um teste qui-quadrado para a diferença de ajuste entre modelos (BYRNE, 2010; SCHREIBER et al., 2006). Um teste significativo para a diferença entre as estatísticas qui-quadrado de cada modelo $\left(\Delta \chi^{2}\right)$ indica que os índices de ajuste de um modelo são realmente superiores ao do outro.

Tabela 4.13 - Comparação dos Índices de Ajuste dos Modelos

\begin{tabular}{cccc}
\hline Índice de Ajuste & MCTF2 Dimensões & MCTF2 2a Ordem & MCTF2 Geral \\
\hline$\chi^{\mathbf{2}}$ & 2029,438 & 1993,599 & 1469,309 \\
$\chi^{\mathbf{2} / \text { d.f. }}$ & 2,164 & 2,081 & 2,569 \\
SRMR & 0,073 & 0,0751 & 0,160 \\
RMSEA & 0,047 & 0,045 & 0,054 \\
CFI & 0,920 & 0,924 & 0,919 \\
IFI & 0,921 & 0,925 & 0,908 \\
TLI & 0,910 & 0,916 & 0,920 \\
\hline
\end{tabular}

A análise dos resultados da tabela 4.13 aponta para índices similares para os três modelos, com um desempenho inferior nos índices para o modelo Confiança Geral em relação aos outros dois modelos. O teste qui-quadrado para diferença de ajuste entre os modelos é significativo para as três comparações feitas. A comparação entre os modelos Dimensões da Confiança e Confiança de Segunda 
Ordem $\left(\Delta \chi^{2}=35,839, \mathrm{p}\right.$-valor $\left.=0,016\right)$ indica que o modelo Confiança de Segunda Ordem se ajusta melhor aos dados do que o modelo Dimensões da Confiança. A comparação entre os modelos Dimensões da Confiança e Confiança Geral $\left(\Delta \chi^{2}=\right.$ 560,129 , p-valor < 0,0001) indica que o modelo Dimensões da Confiança se ajusta melhor aos dados do que o modelo Confiança Geral. Por fim, a comparação entre os modelos Confiança de Segunda Ordem e Confiança Geral $\left(\Delta \chi^{2}=524,290\right.$, pvalor $<0,0001)$ indica que o modelo Segunda Ordem se ajusta melhor aos dados do que o modelo Confiança Geral.

A análise estatística comparativa indica que o modelo Confiança de Segunda Ordem apresenta o melhor ajuste em relação aos dados entre os três modelos testados. Entretanto, como o modelo Dimensões da Confiança possui maior detalhamento para força e relevância das relações envolvendo as três dimensões da confiança, serão apresentados os resultados dos testes de hipótese para esses dois modelos a fim de permitir maior profundidade nas comparações.

\subsection{5 \\ Teste das Hipóteses de Pesquisa \\ 4.2.5.1 \\ Modelo Dimensões da Confiança}

A verificação da hipótese de mediação pela Confiança e suas dimensões (H1) das relações entre as características inovadoras dos dispositivos móveis e a Atitude; e entre as entre as características inovadoras dos dispositivos móveis e a Intenção de Compra foi feita por meio do uso de técnicas de bootstrapping (reamostragem), mais precisamente o método de percentis aplicado ao intervalo de confiança de Monte Carlo (LETH-STEESEN; GALLITO, 2015; MACKINNON; LOCKWOOD; WILLIAMS, 2004; PREACHER; SELIG, 2012; SOBEL, 1982). Este método identifica efeitos indiretos presentes nas relações entre os fatores utilizados na modelagem por equações estruturais e permite identificar mediações parciais e completas utilizando intervalos de confiança para a magnitude dos efeitos presentes, na presença de intervalos que incluam o zero os efeitos são considerados não significativos. 
Primeiramente foi verificada a existência de efeito direto entre as variáveis de interesse para cada amostra, ou seja, entre Compatibilidade e Atitude, Compatibilidade e Intenção de Compra, Facilidade de Uso e Atitude, Facilidade de Uso e Intenção de Compra, Vantagem Relativa e Atitude e Vantagem Relativa e Intenção de Compra. Neste teste as relações indiretas foram removidas e relações diretas entre os construtos de interesse foram desenhadas de forma a garantir que apenas os efeitos diretos estivessem sendo mensurados. As tabelas 4.13 e 4.14 apresentam os resultados para o teste de efeitos diretos.

Tabela 4.14 - Efeitos Diretos (amostra Busca)

\begin{tabular}{llcc}
\hline \multicolumn{1}{c}{ Efeito Direto } & \multicolumn{2}{c}{ Intervalo de Confiança 95\% } & $\begin{array}{c}\text { Suporte } \\
\text { da }\end{array}$ \\
\cline { 2 - 3 } & Limite Inferior & Limite Superior & Hipótese \\
\hline Compatibilidade $\rightarrow$ Atitude & 0,152 & 0,410 & SIM \\
Facilidade de Uso $\rightarrow$ Atitude & 0,326 & 0,696 & SIM \\
Vantagem Relativa $\rightarrow$ Atitude & 0,054 & 0,437 & SIM \\
Compatibilidade $\rightarrow$ Intenção & $-0,176$ & 0,103 & NÃO \\
Facilidade de Uso $\rightarrow$ Intenção & 0,102 & 0,597 & SIM \\
Vantagem Relativa $\rightarrow$ Intenção & $-0,268$ & 0,200 & NÃO \\
\hline
\end{tabular}

Os resultados do teste de efeitos diretos na amostra Busca indicam que Compatibilidade, Facilidade de Uso e Vantagem Relativa exercem efeitos diretos significativos sobre a Atitude, mas que apenas Facilidade de Uso exerce efeitos diretos significativos sobre a Intenção de Compra.

Tabela 4.15 - Efeitos Diretos (amostra Experiência)

\begin{tabular}{|c|c|c|c|}
\hline \multirow{2}{*}{ Efeito Direto } & \multicolumn{2}{|c|}{ Intervalo de Confiança 95\% } & \multirow{2}{*}{$\begin{array}{c}\text { Suporte } \\
\text { da } \\
\text { Hipótese }\end{array}$} \\
\hline & Limite Inferior & Limite Superior & \\
\hline Compatibilidade $\rightarrow$ Atitude & 0,149 & 0,354 & SIM \\
\hline Facilidade de Uso $\rightarrow$ Atitude & 0,036 & 0,356 & SIM \\
\hline
\end{tabular}




\begin{tabular}{lllc}
\cline { 2 - 4 } Vantagem Relativa $\rightarrow$ Atitude & 0,074 & 0,336 & SIM \\
Compatibilidade $\rightarrow$ Intenção & 0,050 & 0,338 & SIM \\
Facilidade de Uso $\rightarrow$ Intenção & $-0,052$ & 0,355 & NÃO \\
Vantagem Relativa $\rightarrow$ Intenção & $-0,042$ & 0,318 & NÃO \\
\hline
\end{tabular}

Os resultados do teste de efeitos diretos na amostra Experiência indicam que Compatibilidade, Facilidade de Uso e Vantagem Relativa exercem efeitos diretos significativos sobre a Atitude, mas que apenas Compatibilidade exerce efeitos diretos significativos sobre a Intenção de Compra.

Em seguida foi testada a presença de efeitos indiretos nas duas amostras para as mesmas relações. As relações que apresentassem efeitos indiretos foram então submetidas a uma análise do efeito direto residual. Nos casos em que o efeito direto permanece significativo após a introdução de uma variável mediadora a mediação é considerada parcial e nos casos em que o efeito direto perde sua significância a mediação é considerada total. As tabelas 4.16 e 4.17 apresentam os resultados para o teste do efeito indireto, enquanto que as tabelas 4.18 e 4.19 apresentam os resultados comparativos entre os efeitos diretos com e sem a presença do construto mediador (Benevolência, Integridade, Competência).

\section{Tabela 4.16 - Efeitos Indiretos (amostra Busca)}

\begin{tabular}{lccc}
\hline \multicolumn{1}{c}{ Efeito Indireto } & \multicolumn{2}{c}{ Intervalo de Confiança 95\% } & $\begin{array}{c}\text { Suporte } \\
\text { da }\end{array}$ \\
\cline { 2 - 3 } & Limite Inferior & Limite Superior & Hipótese \\
\hline Compatibilidade $\rightarrow$ Atitude & $-0,151$ & 0,002 & NÃO \\
Facilidade de Uso $\rightarrow$ Atitude & $-0,147$ & 0,060 & NÃO \\
Vantagem Relativa $\rightarrow$ Atitude & $-0,243$ & $-0,005$ & SIM \\
Facilidade de Uso $\rightarrow$ Intenção & 0,108 & 0,375 & SIM \\
\hline
\end{tabular}

Os resultados do teste de efeitos indiretos na amostra Busca indicam que Compatibilidade e Facilidade de Uso não exercem efeitos indiretos significativos sobre a Atitude, mas que Vantagem Relativa sim, e que Facilidade de Uso exerce 
efeitos indiretos significativos sobre a Intenção de Compra. Assim, pode-se concluir que as dimensões da confiança (Benevolência, Competência e Integridade) mediam os efeitos entre Vantagem Relativa e Atitude e entre Facilidade de Uso e Intenção de Compra.

Tabela 4.17 - Efeitos Indiretos (amostra Experiência)

\begin{tabular}{|c|c|c|c|}
\hline \multirow{2}{*}{ Efeito Indireto } & \multicolumn{2}{|c|}{ Intervalo de Confiança 95\% } & \multirow{2}{*}{$\begin{array}{c}\text { Suporte } \\
\text { da } \\
\text { Hipótese }\end{array}$} \\
\hline & Limite Inferior & Limite Superior & \\
\hline Compatibilidade $\rightarrow$ Atitude & $-0,073$ & 0,037 & NÃO \\
\hline Facilidade de Uso $\rightarrow$ Atitude & 0,012 & 0,254 & SIM \\
\hline Vantagem Relativa $\rightarrow$ Atitude & $-0,046$ & 0,062 & NÃO \\
\hline Compatibilidade $\rightarrow$ Intenção & 0,008 & 0,200 & SIM \\
\hline
\end{tabular}

Os resultados do teste de efeitos indiretos na amostra Experiência indicam que Compatibilidade e Vantagem Relativa não exercem efeitos indiretos significativos sobre a Atitude, mas que Facilidade de Uso exerce, e que Compatibilidade exerce efeitos indiretos significativos sobre a Intenção de Compra. Assim, pode-se concluir que as dimensões da confiança (Benevolência, Competência e Integridade) mediam os efeitos entre Facilidade de Uso e Atitude e entre Compatibilidade e Intenção de Compra.

Tabela 4.18 - Efeitos Diretos e Tipo de Mediação (amostra Busca)

\begin{tabular}{lccc}
\hline \multirow{2}{*}{ Relação } & \multicolumn{2}{c}{ p-valor } & Tipo de \\
\cline { 2 - 3 } & $\begin{array}{c}\text { Sem } \\
\text { Mediador }\end{array}$ & $\begin{array}{c}\text { Com } \\
\text { Mediador }\end{array}$ & Mediação \\
\hline Vantagem Relativa $\rightarrow$ Atitude & 0,011 & 0,005 & Parcial \\
Facilidade de Uso $\rightarrow$ Intenção & 0,004 & 0,009 & Parcial \\
\hline
\end{tabular}

Os resultados da comparação dos efeitos diretos na amostra Busca indicam que nas duas relações testadas os efeitos diretos permaneceram significantes, o que aponta para uma mediação parcial por parte das dimensões da confiança 
(Benevolência, Competência e Integridade) das relações entre Vantagem Relativa e Atitude e entre Facilidade de Uso e Intenção de Compra (H1).

Tabela 4.19- Efeitos Diretos e Tipo de Mediação (amostra Experiência)

\begin{tabular}{lccc}
\hline \multicolumn{1}{c}{ Relação } & \multicolumn{2}{c}{$\mathbf{p \text { -valor }}$} & Tipo de \\
\cline { 2 - 3 } & $\begin{array}{c}\text { Sem } \\
\text { Mediador }\end{array}$ & $\begin{array}{c}\text { Com } \\
\text { Mediador }\end{array}$ & Mediação \\
\hline Facilidade de Uso $\rightarrow$ Atitude & 0,016 & 0,057 & Total \\
Compatibilidade $\rightarrow$ Intenção & 0,005 & 0,004 & Parcial \\
\hline
\end{tabular}

Os resultados da comparação dos efeitos diretos na amostra Experiência indicam a presença de uma mediação parcial pelas dimensões da confiança (Benevolência, Competência e Integridade) da relação entre Compatibilidade e Intenção (H1) e a presença de mediação completa entre Facilidade de Uso e Atitude (H1).

A verificação das outras hipóteses de pesquisa para as amostras Busca e Experiência foi realizada por meio da análise da magnitude, direção e significância dos coeficientes não padronizados estimados pelo modelo estrutural (BYRNE, 2010). Segundo Byrne (2010), coeficientes padronizados são específicos para a amostra modelada e não são comparáveis entre diferentes amostras, para que os resultados de duas amostras diferentes possam ser comparados um ao outro é necessário o uso de coeficientes não padronizados. Assim, este estudo se utiliza de coeficientes não padronizados quando tem o propósito de comparar as amostras Busca e Experiência, mas também apresenta os coeficientes padronizados. Os coeficientes padronizados para as relações encontradas são apresentados na figura 4.5. As relações foram consideradas significativas quando o $\mathrm{p}$-valor para o teste $\mathrm{t}$ associado era inferior ao nível de significância de 0,05 (BYRNE, 2010; HAIR et al., 2009). Os coeficientes estimados para o modelo Dimensões da Confiança, assim como as hipóteses de pesquisa e as significâncias associadas são apresentados na tabela 4.20 para a amostra Busca e tabela 4.21 para a amostra Experiência, e encontram-se ilustrados nas figura 4.5 e 4.6 , respectivamente. 


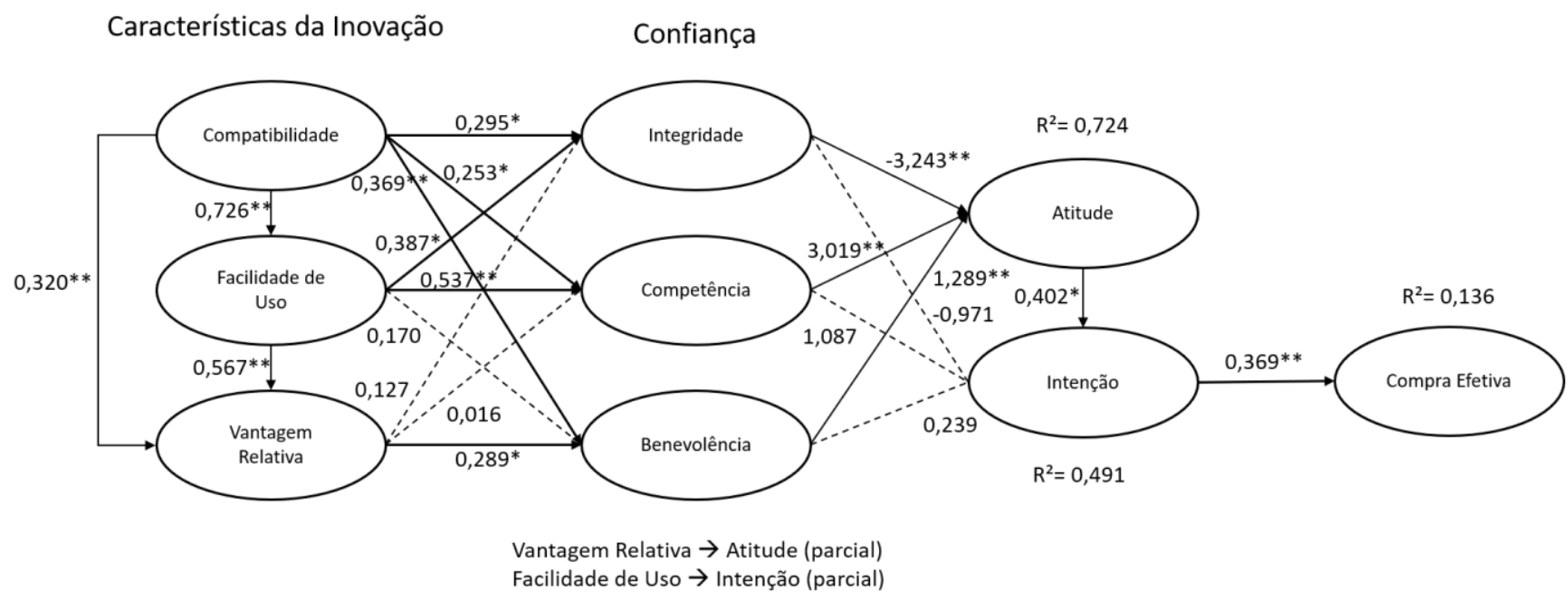

Figura 4.5 - Coeficientes Padronizados Estimados para o MCTF2 Dimensões da Confiança (amostra Busca).

(* indica p-valor $<0,05 ; * *$ indica p-valor $<0,001$; ausência de * indica relação não significativa)

Tabela 4.20 - Coeficientes Não Padronizados Estimados, Hipóteses e Significâncias para o modelo MCTF2 Dimensões da Confiança - Amostra Busca.

\begin{tabular}{|c|c|c|c|}
\hline Relação Proposta & $\begin{array}{c}\text { Coeficiente } \\
\text { Não } \\
\text { Padronizado }\end{array}$ & p-valor & $\begin{array}{c}\text { Suporte } \\
\text { da } \\
\text { Hipótese }\end{array}$ \\
\hline $\mathrm{H}_{2 \mathrm{a}}$ : Benevolência $\rightarrow$ Atitude & 1,105 & $<0,001$ & SIM \\
\hline $\mathrm{H}_{2 b}$ : Integridade $\rightarrow$ Atitude & $-3,242$ & $<0,001$ & NÃO \\
\hline $\mathrm{H}_{2 c}$ : Competência $\rightarrow$ Atitude & 3,064 & $<0,001$ & SIM \\
\hline $\mathrm{H}_{3 a}$ : Benevolência $\rightarrow$ Intenção & 0,192 & 0,386 & NÃO \\
\hline Hзb: Integridade $\rightarrow$ Intenção & $-0,908$ & 0,187 & NÃO \\
\hline $\mathrm{H}_{3 c}$ : Competência $\rightarrow$ Intenção & 1,032 & 0,087 & NÃO \\
\hline H4: Atitude $\rightarrow$ Intenção & 0,367 & 0,006 & SIM \\
\hline H5: Intenção $\rightarrow$ Compra Efetiva & 0,443 & $<0,001$ & SIM \\
\hline H6a: Vantagem $\rightarrow$ Benevolência & 0,439 & 0,015 & SIM \\
\hline H6b: Vantagem $\rightarrow$ Competência & 0,021 & 0,889 & NÃO \\
\hline H6c: Vantagem $\rightarrow$ Integridade & 0,166 & 0,268 & NÃO \\
\hline
\end{tabular}




\begin{tabular}{|c|c|c|c|}
\hline H7a: Facilidade $\rightarrow$ Benevolência & 0,06 & 0,363 & NÃO \\
\hline H7b: Facilidade $\rightarrow$ Competência & 0,551 & $<0,001$ & SIM \\
\hline 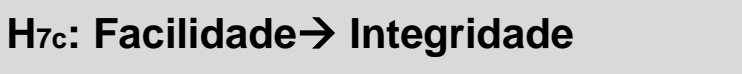 & 0,403 & 0,001 & SIM \\
\hline H8a: Compatibilidade $\rightarrow$ Benevolência & 0,369 & $<0,001$ & SIM \\
\hline Hsb: Compatibilidade $\rightarrow$ Competência & 0,214 & 0,006 & SIM \\
\hline H8c: Compatibilidade $\rightarrow$ Integridade & 0,253 & 0,001 & SIM \\
\hline $\mathrm{H}_{12}:$ Facilidade $\rightarrow$ Vantagem & 0,453 & $<0,001$ & SIM \\
\hline $\mathrm{H}_{13}:$ Compatibilidade $\rightarrow$ Vantagem & 0,211 & $<0,001$ & SIM \\
\hline 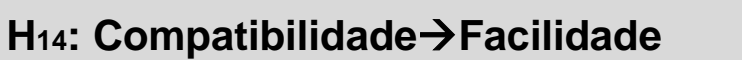 & 0,599 & $<0,001$ & SIM \\
\hline
\end{tabular}

Analisando os resultados apresentados na tabela 4.20 e na figura 4.5, é possível observar que o resultado obtido foi significativo para 13 das 20 hipóteses de pesquisa apresentadas. 11 desses 12 resultados oferecem suporte para as hipóteses formuladas. Dos 13 resultados, oito são significativos a um nível de 0,001, enquanto cinco são significativas a um nível de 0,05 .

É particularmente notável a presença de coeficientes padronizados maiores do que 1. Segundo Jöreskog (1999) e Deegan (1978) se dois ou mais fatores forem correlacionados (oblíquos) ao invés de não correlacionados (ortogonais) eles podem apresentar coeficientes padronizados com magnitudes superiores a 1. Considerando que Integridade, Competência e Benevolência são dimensões de um mesmo construto, a Confiança, não é de se estranhar a presença de colinearidade entre eles, explicando a presença de coeficientes padronizados com magnitudes elevadas.

Compatibilidade (H14) exerce forte efeito sobre a Facilidade de Uso $(0,726)$. Compatibilidade (H13) e Facilidade de Uso (H12) apresentam efeito significativo sobre Vantagem Relativa, mas Facilidade de Uso apresenta o maior coeficiente entre os dois construtos $(0,567)$. Dos 3 construtos utilizados para representar as características inovadoras dos dispositivos móveis, apenas Compatibilidade afeta as 3 dimensões da confiança (H8a, H8b, H8c). Facilidade de Uso afeta duas, Integridade (H7c) e Competência (H7b), e Vantagem Relativa afeta somente a 
Benevolência (H6a). Integridade (H2b), Competência (H2c) e Benevolência (H2a) apresentam fortes efeitos sobre a Atitude, mas nenhum efeito significativo sobre a Intenção (H3a, H3b, H3c). O efeito da Integridade sobre a Atitude $(\mathrm{H} 2 \mathrm{~b})$ apresenta sinal oposto ao esperado, indicando um impacto negativos das percepções de integridade do vendedor. Conforme esperado Atitude afeta Intenção (H4) e Intenção afeta a Compra Efetiva (H5). O modelo Dimensões da Confiança é capaz de explicar 14\% da variância na Compra Efetiva, 49\% da variância da Intenção e $72 \%$ da variância na Atitude para os dados da amostra Busca.

Tabela 4.21 - Coeficientes Não Padronizados Estimados, Hipóteses e Significâncias para o modelo MCTF2 Dimensões da Confiança - Amostra Experiência.

\begin{tabular}{|c|c|c|c|}
\hline Relação Proposta & $\begin{array}{l}\text { Coeficiente } \\
\text { Não } \\
\text { Padronizado }\end{array}$ & p-valor & $\begin{array}{c}\text { Suporte } \\
\text { da } \\
\text { Hipótese }\end{array}$ \\
\hline H2a: Benevolência $\rightarrow$ Atitude & 0,143 & 0,012 & SIM \\
\hline $\mathrm{H}_{2 b}$ : Integridade $\rightarrow$ Atitude & $-0,521$ & $<0,001$ & SIM \\
\hline $\mathrm{H}_{2 c}$ : Competência $\rightarrow$ Atitude & 1,038 & $<0,001$ & SIM \\
\hline Hза: Benevolência $\rightarrow$ Intenção & 0,074 & 0,275 & NÃO \\
\hline $\mathrm{H}_{3 \mathrm{~b}}:$ Integridade $\rightarrow$ Intenção & $-0,344$ & 0,010 & SIM \\
\hline $\mathrm{H}_{3 c}$ : Competência $\rightarrow$ Intenção & 0,711 & $<0,001$ & SIM \\
\hline H4: Atitude $\rightarrow$ Intenção & 0,365 & 0,006 & SIM \\
\hline H5: Intenção $\rightarrow$ Compra Efetiva & 0,578 & $<0,001$ & SIM \\
\hline H6a: Vantagem $\rightarrow$ Benevolência & 0,099 & 0,527 & $\mathrm{NÃO}$ \\
\hline H6b: Vantagem $\rightarrow$ Competência & 0,024 & 0,813 & NÃO \\
\hline H6c: Vantagem $\rightarrow$ Integridade & 0,047 & 0,742 & NÃO \\
\hline H7a: Facilidade $\rightarrow$ Benevolência & 0,214 & 0,253 & NÃO \\
\hline Hzb: Facilidade $\rightarrow$ Competência & 0,639 & $<0,001$ & SIM \\
\hline $\mathrm{H}_{7 c:}$ Facilidade $\rightarrow$ Integridade & 0,397 & 0,023 & SIM \\
\hline H8a: Compatibilidade $\rightarrow$ Benevolência & 0,369 & $<0,001$ & SIM \\
\hline
\end{tabular}




\begin{tabular}{lccc} 
H8b: Compatibilidade $\rightarrow$ Competência & 0,092 & 0,161 & NÃO \\
H8c: Compatibilidade $\rightarrow$ Integridade & 0,093 & 0,312 & NÃO \\
H12: Facilidade $\rightarrow$ Vantagem & 0,760 & $<0,001$ & SIM \\
H13: Compatibilidade $\rightarrow$ Vantagem $_{\text {H14: Compatibilidade } \rightarrow \text { Facilidade }}$ & $-0,015$ & 0,828 & NÃO \\
\hline
\end{tabular}

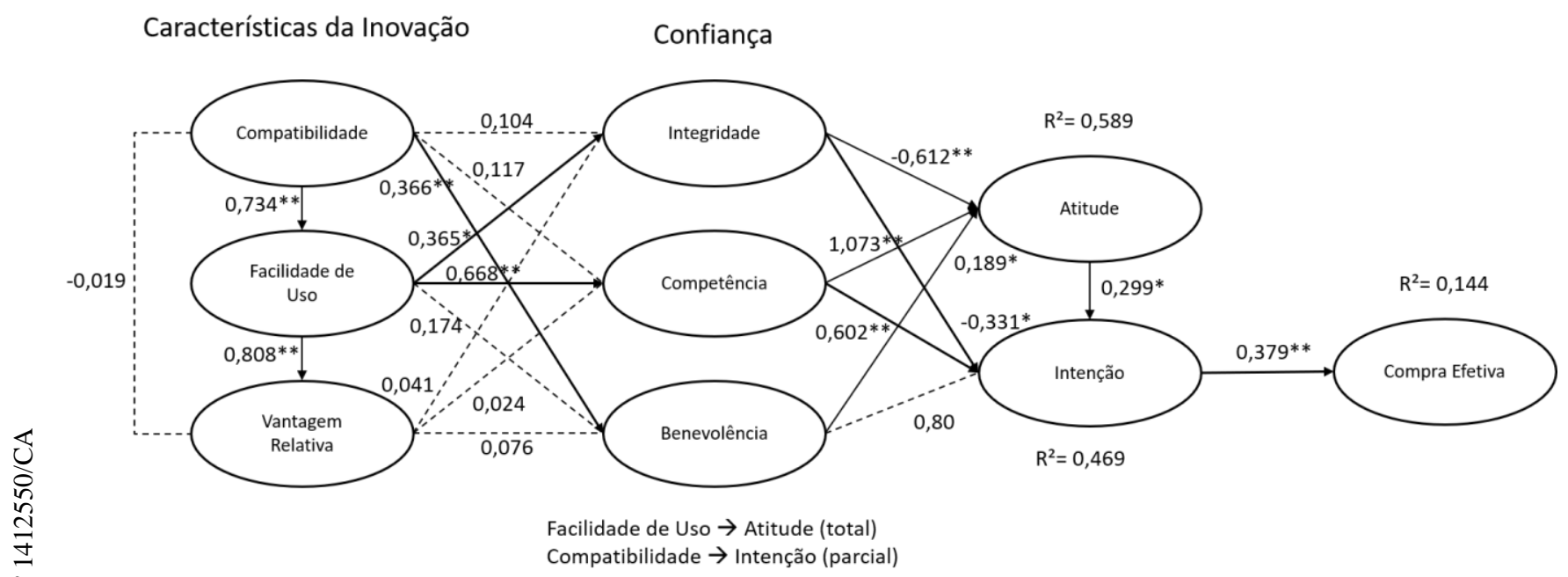

Figura 4.6 - Coeficientes Padronizados Estimados para o MCTF2 Dimensões da Confiança (amostra Experiência).

(* indica p-valor $<0,05 ; * *$ indica p-valor $<0,001$; ausência de * indica relação não significativa)

Analisando os resultados apresentados na tabela 4.21 e na figura 4.6, é possível observar que o resultado obtido foi significativo para 12 das 20 hipóteses de pesquisa apresentadas. 10 desses 12 resultados oferecem suporte para as hipóteses formuladas. Dos 12 resultados, oito são significativos a um nível de 0,001, enquanto quatro são significativas a um nível de 0,05 .

Compatibilidade (H14) exerce forte efeito sobre a Facilidade de Uso $(0,734)$. Apenas Facilidade de Uso (H12) apresenta efeito significativo sobre Vantagem Relativa. Dos 3 construtos utilizados para representar as características inovadoras dos dispositivos móveis, nenhum apresenta efeito sobre as três dimensões da confiança. Compatibilidade afeta apenas Benevolência H8a), Facilidade de Uso afeta duas dimensões, Integridade (H7c) e Competência (H7b), e Vantagem 
Relativa não exerce efeito sobre nenhuma das três dimensões. Integridade (H2b), Competência (H2c) e Benevolência (H2a) apresentam efeitos sobre a Atitude, com Competência exercendo efeito de maior magnitude $(1,073)$ e Integridade exercendo um inesperado efeito negativo (-0,612). Integridade (H3b) e Competência (H3c) exercem efeito significativo sobre a Intenção, com Competência apresentando efeito de magnitude maior $(0,602)$ e Integridade, novamente, apresentando efeito negativo (-0,331). Conforme esperado Atitude afeta Intenção (H4) e Intenção afeta a Compra Efetiva (H5). O modelo Dimensões da Confiança é capaz de explicar 14\% da variância na Compra Efetiva, 47\% da variância da Intenção e 59\% da variância na Atitude para os dados da amostra Experiência.

\subsubsection{1}

\section{Diferenças Entre as Amostras}

Com o objetivo de testar as hipóteses de moderação por tipo de produto (H9, H10 e H11), os respondentes foram divididos em duas amostras, Busca e Experiência. Cada uma das amostras foi analisada em separado e suas diferenças serão agora identificadas.

Uma vez que o uso de coeficientes não padronizados permite a comparação entre amostras (BYRNE, 2010; MARTINS; HOR-MEYLL; FERREIRA, 2013), é possível identificar se o efeito das relações entre os construtos é diferente entre as amostras Busca e Experiência. A tabela 4.22 mostra os coeficientes não padronizados estimados para as hipóteses testadas em cada amostra e seu nível de significância, a tabela 4.23 mostra os intervalos de confiança inferenciais para os coeficientes não padronizados estimados e a figura 4.7 apresenta o modelo comparativo entre as amostras.

Gardner e Altman (1986) aconselham o uso, sempre que possível, de intervalos de confiança no teste de hipóteses no lugar de apenas apresentar o p-valor correspondente, pois intervalos de confiança fornecem mais informação sobre o alcance dos valores para cada estimativa. Caso uma relação se mostre significativa em uma amostra e na outra não, a diferença é evidente, não sendo necessária a avaliação dos coeficientes. O mesmo raciocínio é aplicado a situações onde ambas as relações não são significativas. 
O estabelecimento de um intervalo de confiança de $95 \%$ entre duas médias pertencentes a grupos diferentes só é garantia para a presença de uma diferença estatisticamente significativa se devidamente corrigido (GOLDSTEIN; HEALY, 1995; TYRON, 2001). Este estudo utiliza o calculo de intervalo de confiança sugerido por Tyron (2001) que emprega a razão entre o erro padrão da diferença entre os grupos e a soma dos erros padrões de ambos os grupos e então multiplica o resultado pelo nível de probabilidade (talfa) da distribuição t correspondente e alfa definido para cada caso. Dessa forma, foram calculados os intervalos inferenciais para os coeficientes não padronizados ao nível de significância de 5\% definido para todo este estudo.

Tabela 4.22 - Coeficientes Não Padronizados Estimados e Significância

\begin{tabular}{|c|c|c|c|c|}
\hline \multirow{2}{*}{ Relação } & \multicolumn{2}{|c|}{ Busca } & \multicolumn{2}{|c|}{ Experiência } \\
\hline & Coeficiente & $\mathrm{p}$-valor & Coeficiente & p-valor \\
\hline H2a: Benevolência $\rightarrow$ Atitude & $\mathbf{1 , 1 0 5}$ & $<0,001$ & 0,143 & 0,012 \\
\hline $\mathrm{H}_{2 b}$ : Integridade $\rightarrow$ Atitude & $-3,242$ & $<0,001$ & $-0,521$ & $<0,001$ \\
\hline $\mathrm{H}_{2 c}$ : Competência $\rightarrow$ Atitude & 3,064 & $<0,001$ & $\mathbf{1 , 0 3 8}$ & $<0,001$ \\
\hline Hза: Benevolência $\rightarrow$ Intenção & 0,192 & 0,386 & 0,074 & 0,275 \\
\hline $\mathrm{H}_{3 \mathrm{~b}}:$ Integridade $\rightarrow$ Intenção & $-0,908$ & 0,187 & $-0,344$ & $\mathbf{0 , 0 1 0}$ \\
\hline Hзc: Competência $\rightarrow$ Intenção & 1,032 & 0,087 & 0,711 & $<0,001$ \\
\hline H4: Atitude $\rightarrow$ Intenção & 0,367 & 0,006 & 0,365 & 0,006 \\
\hline H5: Intenção $\rightarrow$ Compra Efetiva & 0,443 & $<0,001$ & $\mathbf{0 , 5 7 8}$ & $<0,001$ \\
\hline H6a: Vantagem $\rightarrow$ Benevolência & 0,439 & $\mathbf{0 , 0 1 5}$ & 0,099 & 0,527 \\
\hline H6b: Vantagem $\rightarrow$ Competência & 0,021 & 0,889 & 0,024 & 0,813 \\
\hline H6c: Vantagem $\rightarrow$ Integridade & 0,166 & 0,268 & 0,047 & 0,742 \\
\hline H7a: Facilidade $\rightarrow$ Benevolência & 0,060 & 0,363 & 0,214 & 0,253 \\
\hline Hbb: Facilidade $\rightarrow$ Competência & $\mathbf{0 , 5 5 1}$ & $<0,001$ & $\mathbf{0 , 6 3 9}$ & $<0,001$ \\
\hline H7c: Facilidade $\rightarrow$ Integridade & 0,403 & $\mathbf{0 , 0 0 1}$ & $\mathbf{0 , 3 9 7}$ & $\mathbf{0 , 0 2 3}$ \\
\hline H8a: Compatibilidade $\rightarrow$ Benevolência & $\mathbf{0 , 3 6 9}$ & $<0,001$ & $\mathbf{0 , 3 6 9}$ & $<0,001$ \\
\hline Hsb: Compatibilidade $\rightarrow$ Competência & 0,214 & 0,006 & 0,092 & 0,161 \\
\hline
\end{tabular}




\begin{tabular}{lcccc} 
H8c: Compatibilidade $\rightarrow$ Integridade & $\mathbf{0 , 2 5 3}$ & $\mathbf{0 , 0 0 1}$ & 0,093 & 0,312 \\
H12: $_{\text {Facilidade } \rightarrow \text { Vantagem }}$ & $\mathbf{0 , 4 5 3}$ & $<\mathbf{0 , 0 0 1}$ & $\mathbf{0 , 7 6 0}$ & $<\mathbf{0 , 0 0 1}$ \\
H13: Compatibilidade $\rightarrow$ Vantagem $_{\text {H }}$ & $\mathbf{0 , 2 1 1}$ & $<\mathbf{0 , 0 0 1}$ & $-0,015$ & 0,828 \\
H14: Compatibilidade $\rightarrow$ Facilidade & $\mathbf{0 , 5 9 9}$ & $<\mathbf{0 , 0 0 1}$ & $\mathbf{0 , 6 0 4}$ & $<\mathbf{0 , 0 0 1}$ \\
\hline
\end{tabular}

(negrito indica relações cujo resultado dá suporte a hipótese de relação entre as variáveis)

Os resultados apresentados na tabela 4.21 apontam para diferenças significativas para as relações entre Integridade e Intenção (H3b), que é não significativa para a amostra Busca e significativa para amostra Experiência, entre Competência e intenção (H3c), que é não significativa para a amostra Busca e significativa para amostra Experiência, entre Vantagem Relativa e Benevolência (H6a), que é significativa para a amostra Busca e não significativa para amostra Experiência, entre Compatibilidade e Competência (H8b), que é significativa para a amostra Busca e não significativa para amostra Experiência, entre Compatibilidade e Integridade (H8c), que é significativa para a amostra Busca e não significativa para amostra Experiência, e entre Compatibilidade e Vantagem Relativa (H13), que é significativa para a amostra Busca e não significativa para amostra Experiência.

As relações entre Benevolência e Intenção (H3a), Vantagem Relativa e Competência (H6b), Facilidade de Uso e Benevolência (H7a) e Vantagem Relativa e Integridade (H6c) não apresentaram resultados significativos, sendo, portanto, desnecessário o teste de diferença entre médias. 


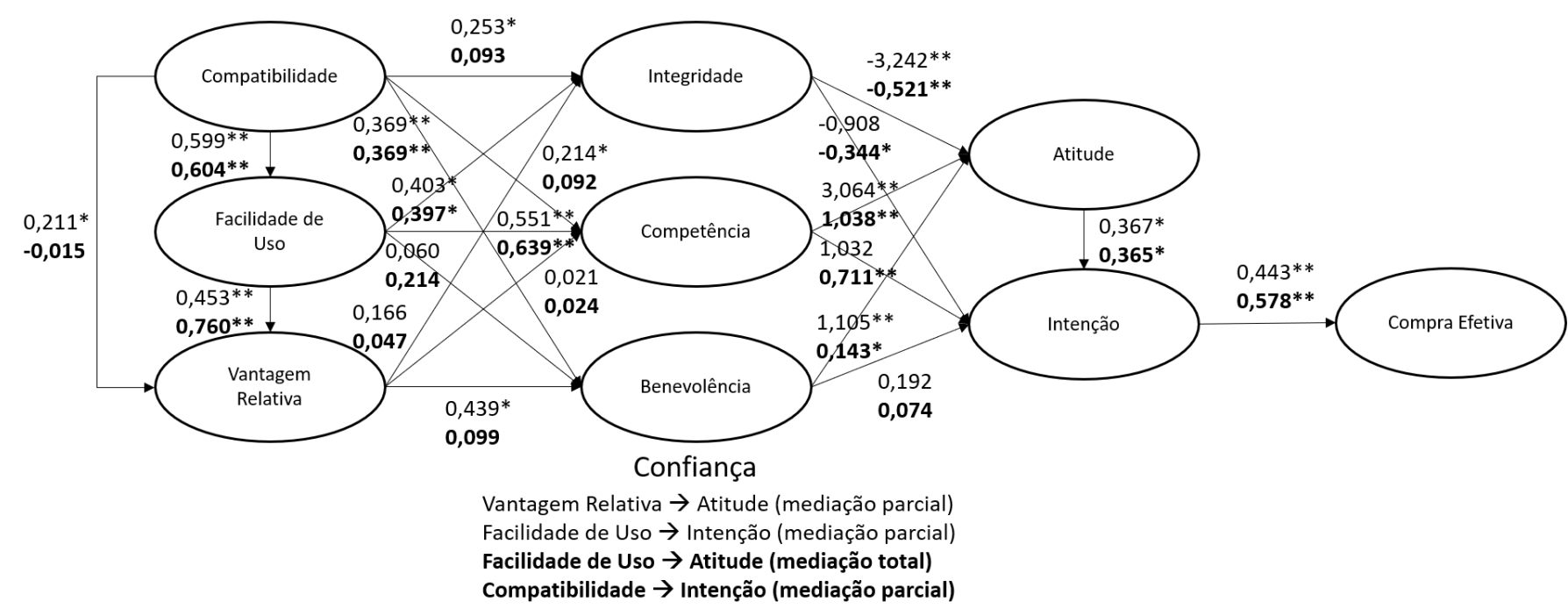

Figura 4.7 - Coeficientes Não Padronizados Estimados para o MCTF2 Dimensões da Confiança (amostras Busca e Experiência).

(valores em negrito indicam amostra Experiência; * indica p-valor < 0,05; ** indica p-valor < 0,001 ; ausência de * indica relação não significativa)

Por fim, foram verificadas as diferenças para as amostras Busca e Experiência das relações entre Intenção de Compra e Compra Efetiva (H5), Atitude e Intenção de Compra (H4), Competência e Atitude (H2c), Benevolência e Atitude (H2a), Integridade e Atitude (H2b), Facilidade de Uso e Competência (H7b), Compatibilidade e Benevolência (H8a), Facilidade de Uso e Integridade (H7c), Facilidade de Uso e Vantagem Relativa (H12) e Compatibilidade e Facilidade de Uso (H14).

Tabela 4.23 - Intervalos de Confiança para os Coeficientes Não Padronizados

\begin{tabular}{|c|c|c|c|c|c|c|}
\hline \multirow{3}{*}{ Relação } & \multicolumn{3}{|c|}{ Busca } & \multicolumn{3}{|c|}{ Experiência } \\
\hline & \multicolumn{4}{|c|}{$\begin{array}{c}\text { Intervalo de } \\
\text { Confiança } 95 \%\end{array}$} & \multicolumn{2}{|c|}{$\begin{array}{c}\text { Intervalo de } \\
\text { Confiança 95\% }\end{array}$} \\
\hline & Coef. & $\begin{array}{l}\text { Limite } \\
\text { Inferior }\end{array}$ & $\begin{array}{l}\text { Limite } \\
\text { Superior }\end{array}$ & Coef. & $\begin{array}{l}\text { Limite } \\
\text { Inferior }\end{array}$ & $\begin{array}{l}\text { Limite } \\
\text { Superior }\end{array}$ \\
\hline H2a: Benevolência $\rightarrow$ Atitude & 1,105 & 0,625 & 1,585 & 0,143 & 0,048 & $\mathbf{0 , 2 3 8}$ \\
\hline $\mathrm{H}_{2 b}$ : Integridade $\rightarrow$ Atitude & $-3,242$ & $-4,853$ & $-1,631$ & $-0,521$ & $-0,699$ & $-0,343$ \\
\hline $\mathrm{H}_{2 c}$ : Competência $\rightarrow$ Atitude & 3,064 & 1,828 & 4,300 & 1,038 & $\mathbf{0 , 8 5 0}$ & 1,226 \\
\hline $\mathrm{H}_{4}:$ Atitude $\rightarrow$ Intenção & 0,367 & 0,185 & 0,567 & 0,365 & 0,210 & 0,520 \\
\hline
\end{tabular}




\begin{tabular}{lcccccc}
\hline H5: Intenção $\rightarrow$ Compra Efetiva & 0,443 & 0,297 & 0,589 & 0,578 & 0,453 & 0,703 \\
H7b: Facilidade $\rightarrow$ Competência & 0,551 & 0,380 & 0,722 & 0,639 & 0,453 & 0,825 \\
H7c: Facilidade $\rightarrow$ Integridade & 0,403 & 0,229 & 0,577 & 0,397 & 0,151 & 0,643 \\
H8a: Compat. $\rightarrow$ Benevolência & 0,369 & 0,239 & 0,499 & 0,369 & 0,228 & 0,510 \\
H12: Facilidade $\rightarrow$ Vantagem & 0,453 & $\mathbf{0 , 3 4 4}$ & $\mathbf{0 , 5 6 2}$ & 0,760 & $\mathbf{0 , 6 1 7}$ & $\mathbf{0 , 9 0 3}$ \\
H14: Compat. $\rightarrow$ Facilidade & 0,599 & 0,521 & 0,677 & 0,604 & 0,524 & 0,684 \\
\hline
\end{tabular}

(valores em negrito indicam intervalos de confiança em que não há sobreposição)

Conforme indicado pela tabela 4.23, há sobreposição da maioria dos intervalos de confiança inferencial para as estimativas, o que indica que não há diferença significativa entre as duas amostras para relações representadas pelas hipóteses H4, H5, H7b, H7c, H8a e H14. As relações que apresentaram diferenças estatísticas significativas foram as entre Benevolência e Atitude (H2a), Integridade e Atitude (H2b), Competência e Atitude (H2c) e Facilidade de Uso e Vantagem Relativa (H12). No caso, a magnitude do efeito das dimensões da Confiança (Benevolência, Integridade e Competência) sobre a Atitude é maior para a amostra Busca do que para a amostra experiência (H10). Não foram encontradas diferenças significativas no efeito da Atitude sobre a Intenção de Compra (H9) ou no efeito da Intenção de Compra sobre a Compra Efetiva (H11). A Facilidade de Uso apresenta efeito de magnitude menor sobre a amostra Busca do que o encontrado na amostra Experiência.

\subsubsection{2}

\section{Modelo Confiança de Segunda Ordem}

A verificação da hipótese de mediação pela Confiança $(\mathrm{H} 1)$ das relações entre as características inovadoras dos dispositivos móveis e a Atitude; e entre as entre as características inovadoras dos dispositivos móveis e a Intenção de Compra foi feita em duas etapas.

Primeiramente foi verificada a existência de efeito direto entre as variáveis de interesse para cada amostra, ou seja, entre Compatibilidade e Atitude, Compatibilidade e Intenção de Compra, Facilidade de Uso e Atitude, Facilidade de Uso e Intenção de Compra, Vantagem Relativa e Atitude e Vantagem Relativa e 
Intenção de Compra. Neste teste as relações indiretas foram removidas e relações diretas entre os construtos de interesse foram desenhadas de forma a garantir que apenas os efeitos diretos estivessem sendo mensurados. As tabelas 4.24 e 4.25 apresentam os resultados para o teste de efeitos diretos.

Tabela 4.24 - Efeitos Diretos (amostra Busca)

\begin{tabular}{lccc}
\hline \multicolumn{1}{c}{ Efeito Direto } & \multicolumn{2}{c}{ Intervalo de Confiança 95\% } & $\begin{array}{c}\text { Suporte } \\
\text { da }\end{array}$ \\
\cline { 2 - 3 } & Limite Inferior & Limite Superior & Hipótese \\
\hline Compatibilidade $\rightarrow$ Atitude & 0,106 & 0,405 & SIM \\
Facilidade de Uso $\rightarrow$ Atitude & 0,316 & 0,740 & SIM \\
Vantagem Relativa $\rightarrow$ Atitude & $-0,129$ & 0,349 & SIM \\
Compatibilidade $\rightarrow$ Intenção & $-0,266$ & 0,068 & NÃO \\
Facilidade de Uso $\rightarrow$ Intenção & 0,197 & 0,716 & SIM \\
Vantagem Relativa $\rightarrow$ Intenção & $-0,268$ & $-0,410$ & NÃO \\
\hline
\end{tabular}

Os resultados do teste de efeitos diretos na amostra Busca indicam que Compatibilidade, Facilidade de Uso e Vantagem Relativa exercem efeitos diretos significativos sobre a Atitude, mas que apenas Facilidade de Uso exerce efeitos diretos significativos sobre a Intenção de Compra.

Tabela 4.25 - Efeitos Diretos (amostra Experiência)

\begin{tabular}{|c|c|c|c|}
\hline \multirow{2}{*}{ Efeito Direto } & \multicolumn{2}{|c|}{ Intervalo de Confiança 95\% } & \multirow{2}{*}{$\begin{array}{c}\text { Suporte } \\
\text { da } \\
\text { Hipótese }\end{array}$} \\
\hline & Limite Inferior & Limite Superior & \\
\hline Compatibilidade $\rightarrow$ Atitude & 0,059 & 0,320 & SIM \\
\hline Facilidade de Uso $\rightarrow$ Atitude & 0,109 & 0,590 & SIM \\
\hline Vantagem Relativa $\rightarrow$ Atitude & $-0,029$ & 0,329 & NÃO \\
\hline Compatibilidade $\rightarrow$ Intenção & $-0,32$ & 0,310 & NÃO \\
\hline Facilidade de Uso $\rightarrow$ Intenção & $-0,087$ & 0,560 & NÃO \\
\hline Vantagem Relativa $\rightarrow$ Intenção & $-0,155$ & 0,326 & NÃO \\
\hline
\end{tabular}


Os resultados do teste de efeitos diretos na amostra Experiência indicam que Compatibilidade, Facilidade de Uso exercem efeitos diretos significativos apenas sobre a Atitude. Nenhum outro efeito direto foi identificado.

Em seguida foi testada a presença de efeitos indiretos nas duas amostras para as mesmas relações. As relações que apresentassem efeitos indiretos foram então submetidas a uma análise do efeito direto residual. Nos casos em que o efeito direto permanece significativo após a introdução de uma variável mediadora a mediação é considerada parcial e nos casos em que o efeito direto perde sua significância a mediação é considerada total. As tabelas 4.26 e 4.27 apresentam os resultados para o teste do efeito indireto, enquanto que as tabelas 4.28 e 4.29 apresentam os resultados comparativos entre os efeitos diretos com e sem a presença do construto mediador (Confiança).

Tabela 4.26 - Efeitos Indiretos (amostra Busca)

\begin{tabular}{|c|c|c|c|}
\hline \multirow{2}{*}{ Efeito Indireto } & \multicolumn{2}{|c|}{ Intervalo de Confiança 95\% } & \multirow{2}{*}{$\begin{array}{c}\text { Suporte } \\
\text { da }\end{array}$} \\
\hline & Limite Inferior & Limite Superior & \\
\hline Compatibilidade $\rightarrow$ Atitude & 0,230 & 0,482 & SIM \\
\hline Facilidade de Uso $\rightarrow$ Atitude & $-0,073$ & 0,178 & $\mathrm{NÃO}$ \\
\hline Vantagem Relativa $\rightarrow$ Atitude & $-0,065$ & 0,065 & NÃO \\
\hline Facilidade de Uso $\rightarrow$ Intenção & 0,049 & 0,419 & SIM \\
\hline
\end{tabular}

Os resultados do teste de efeitos indiretos na amostra Busca indicam que apenas Compatibilidade exerce efeito indireto significativo sobre a Atitude e que Facilidade de Uso exerce efeito indireto significativo sobre a Intenção de Compra. Assim, pode-se concluir que a Confiança (como construto de segunda ordem) media as relações entre Compatibilidade e Atitude e entre Facilidade de Uso e Intenção de Compra. 
Tabela 4.27 - Efeitos Indiretos (amostra Experiência)

\begin{tabular}{|c|c|c|c|}
\hline \multirow{2}{*}{ Efeito Indireto } & \multicolumn{2}{|c|}{ Intervalo de Confiança 95\% } & \multirow{2}{*}{$\begin{array}{c}\text { Suporte } \\
\text { da }\end{array}$} \\
\hline & Limite Inferior & Limite Superior & \\
\hline Compatibilidade $\rightarrow$ Atitude & 0,199 & 0,413 & SIM \\
\hline Facilidade de Uso $\rightarrow$ Atitude & 0,011 & 0,384 & SIM \\
\hline
\end{tabular}

Os resultados do teste de efeitos indiretos na amostra Experiência indicam que tanto Compatibilidade quanto Facilidade de uso exercem efeitos indiretos significativos sobre a Atitude. Assim, pode-se concluir que a Confiança (como construto de segunda ordem) media as relações entre Facilidade de Uso e Atitude e entre Compatibilidade e Atitude.

Tabela 4.28 - Efeitos Diretos e Tipo de Mediação (amostra Busca)

\begin{tabular}{lccc}
\hline \multicolumn{1}{c}{ Relação } & \multicolumn{2}{c}{ p-valor } & Tipo de \\
\cline { 2 - 3 } & $\begin{array}{c}\text { Sem } \\
\text { Mediador }\end{array}$ & $\begin{array}{c}\text { Com } \\
\text { Mediador }\end{array}$ & Mediação \\
\hline Compatibilidade $\rightarrow$ Atitude & 0,001 & 0,005 & Parcial \\
Facilidade de Uso $\rightarrow$ Intenção & 0,001 & 0,009 & Parcial \\
\hline
\end{tabular}

Os resultados da comparação dos efeitos diretos na amostra Busca indicam que nas duas relações testadas os efeitos diretos permaneceram significantes, o que aponta para uma mediação parcial por parte da Confiança (como construto de segunda ordem) das relações entre Compatibilidade e Atitude e entre Facilidade de Uso e Intenção de Compra (H1) para a amostra Busca. 
Tabela 4.29 - Efeitos Diretos e Tipo de Mediação (amostra Experiência)

\begin{tabular}{lccc}
\hline \multicolumn{1}{c}{ Relação } & \multicolumn{2}{c}{ p-valor } & Tipo de \\
\cline { 2 - 3 } & $\begin{array}{c}\text { Sem } \\
\text { Mediador }\end{array}$ & $\begin{array}{c}\text { Com } \\
\text { Mediador }\end{array}$ & Mediação \\
\hline Compatibilidade $\rightarrow$ Atitude & 0,006 & 0,006 & Parcial \\
Facilidade de Uso $\rightarrow$ Atitude & 0,010 & 0,029 & Parcial \\
\hline
\end{tabular}

Os resultados da comparação dos efeitos diretos na amostra Busca indicam que nas duas relações testadas os efeitos diretos permaneceram significantes, o que aponta para uma mediação parcial por parte da Confiança (como construto de segunda ordem) (H1) das relações entre Compatibilidade e Atitude e entre Facilidade de Uso e Atitude para a amostra Experiência.

A verificação das outras hipóteses de pesquisa para as amostras Busca e Experiência foi realizada por meio da análise da magnitude, direção e significância dos coeficientes não padronizados estimados pelo modelo estrutural (BYRNE, 2010). Segundo Byrne (2010), coeficientes padronizados são específicos para modelagens realizadas com apenas uma amostra, no caso de modelagens para dois ou mais grupos os coeficientes não padronizados são mais adequados para fins de comparação das amostras. As relações foram consideradas significativas quando o p-valor para o teste $t$ associado era inferior ao nível de significância de 0,05 (BYRNE, 2010; HAIR et al., 2009). Os coeficientes estimados para o modelo Dimensões da Confiança, assim como as hipóteses de pesquisa e as significâncias associadas são apresentados na tabela 4.30 para a amostra Busca e tabela 4.31 para a amostra Experiência, e encontram-se ilustrados nas figura 4.8 e 4.9, respectivamente. 


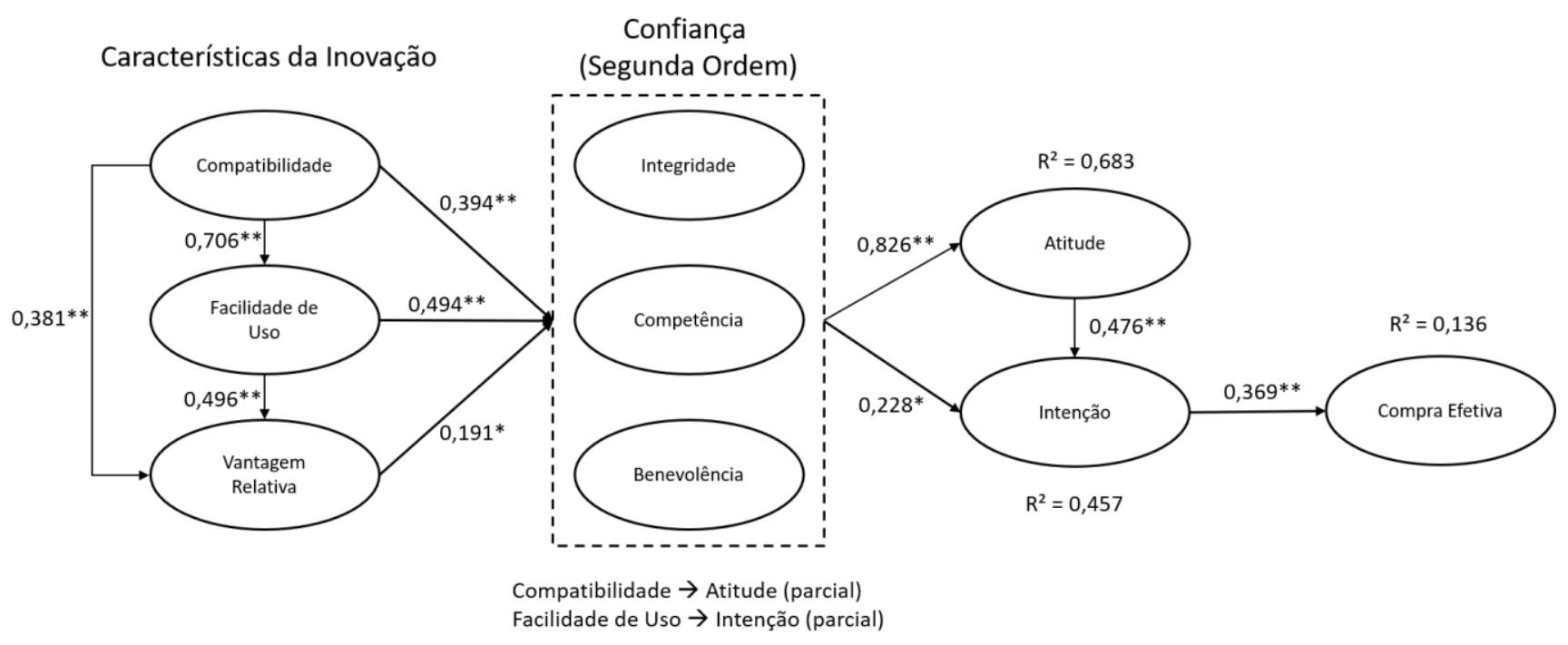

Figura 4.8 - Coeficientes Padronizados Estimados para o MCTF2 Confiança de Segunda Ordem (amostra Busca).

(* indica p-valor $<0,05 ; * *$ indica $\mathrm{p}$-valor $<0,001$; ausência de * indica relação não significativa)

Tabela 4.30 - Coeficientes Não Padronizados Estimados, Hipóteses e Significâncias para o modelo MCTF2 Confiança $2^{\mathrm{a}}$ Ordem - Amostra Busca.

\begin{tabular}{lccc}
\hline \multicolumn{1}{c}{ Relação Proposta } & $\begin{array}{c}\text { Coeficiente } \\
\text { Não } \\
\text { Padronizado }\end{array}$ & $\begin{array}{c}\text { p-valor } \\
\text { H2: Confiança } \rightarrow \text { Atitude }\end{array}$ & $\begin{array}{c}\text { Suporte } \\
\text { dipótese }\end{array}$ \\
\hline H3: Confiança $\rightarrow$ Intenção $^{\prime}$ & 1,108 & $<0,001$ & SIM \\
H4: Atitude $\rightarrow$ Intenção $_{\text {H5: Intenção } \rightarrow \text { Compra Efetiva }}$ & 0,285 & 0,035 & SIM \\
H6: Vantagem $\rightarrow$ Confiança $_{\text {H7: Facilidade } \rightarrow \text { Confiança }}$ & 0,444 & $<0,001$ & SIM \\
H8: Compatibilidade $\rightarrow$ Confiança $_{\text {H12: Facilidade } \rightarrow \text { Vantagem }}$ & 0,444 & $<0,001$ & SIM \\
H13: Compatibilidade $\rightarrow$ Vantagem $_{\text {H14: Compatibilidade } \rightarrow \text { Facilidade }}$ & 0,180 & 0,027 & SIM \\
\hline
\end{tabular}


Analisando os resultados apresentados na tabela 4.30 e na figura 4.8, é possível observar que o resultado obtido foi significativo para todas as hipóteses de pesquisa apresentadas. Todos os resultados oferecem suporte para as hipóteses formuladas. Dos 10 resultados, oito são significativos ao nível de 0,001, enquanto dois são significativas a 0,05 .

Compatibilidade (H14) exerce forte efeito sobre a Facilidade de Uso $(0,602)$. Compatibilidade (H13) e Facilidade de Uso (H12) apresentam efeito significativo sobre Vantagem Relativa, mas Facilidade de Uso apresenta o maior coeficiente entre os dois construtos $(0,429)$. Todos os 3 construtos utilizados para representar as características inovadoras dos dispositivos móveis afetam a confiança (H6, H7, H8), sendo que Facilidade de Uso apresenta o efeito de maior magnitude $(0,403)$. Confiança apresenta forte efeito sobre a Atitude $(\mathrm{H} 2)(1,108)$ e um pequeno efeito sobre a Intenção (H3) (0,285). Conforme esperado Atitude afeta Intenção (H4) e Intenção afeta a Compra Efetiva (H5). O modelo Confiança de Segunda Ordem é capaz de explicar 14\% da variância na Compra Efetiva, $46 \%$ da variância da Intenção e $68 \%$ da variância na Atitude para os dados da amostra Busca.

Tabela 4.31 - Coeficientes Padronizados Estimados, Hipóteses e Significâncias para o modelo MCTF2 Confiança $2^{\mathrm{a}}$ Ordem - Amostra Experiência.

\begin{tabular}{lccc}
\hline \multicolumn{1}{c}{ Relação Proposta } & $\begin{array}{c}\text { Coeficiente } \\
\text { Não } \\
\text { Padronizado }\end{array}$ & $\begin{array}{l}\text { p-valor } \\
\text { H2: Confiança } \rightarrow \text { Atitude }\end{array}$ & $\begin{array}{c}\text { Suporte } \\
\text { da } \\
\text { Hipótese }\end{array}$ \\
\hline H3: Confiança $\rightarrow$ Intenção $^{\prime}$ & 1,202 & $<0,001$ & SIM \\
H4: Atitude $\rightarrow$ Intenção $_{\text {H5: Intenção } \rightarrow \text { Compra Efetiva }}$ & 0,846 & $<0,001$ & SIM \\
H6: Vantagem $\rightarrow$ Confiança & 0,580 & 0,002 & SIM \\
H7: Facilidade $\rightarrow$ Confiança & 0,094 & 0,091 & NÃO \\
H8: Compatibilidade $\rightarrow$ Confiança & 0,342 & $<0,001$ & SIM \\
H12: Facilidade $\rightarrow$ Vantagem & 0,137 & $<0,001$ & SIM \\
& 0,767 & $<0,001$ & SIM \\
\hline
\end{tabular}




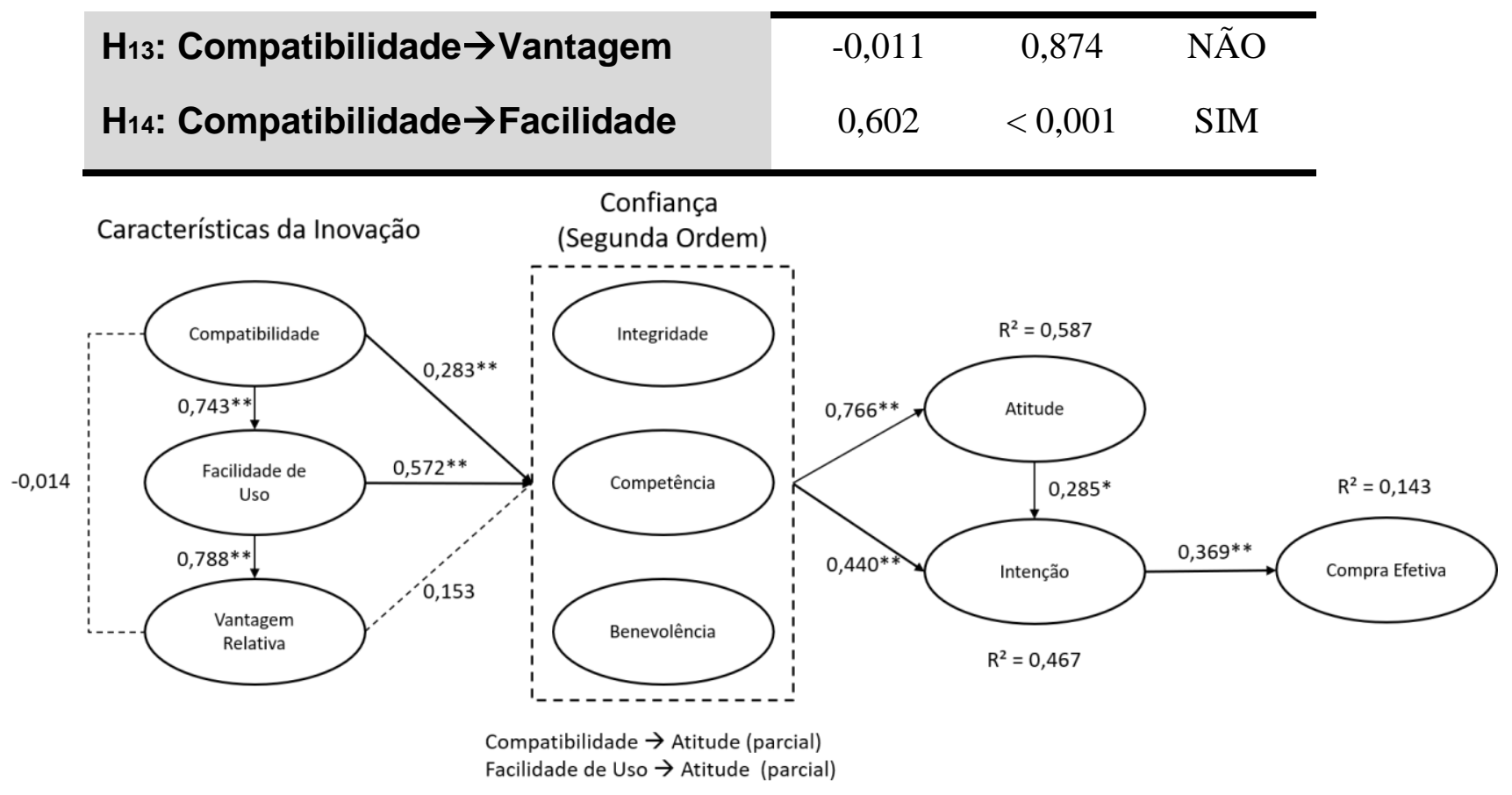

Figura 4.9 - Coeficientes Padronizados Estimados para o MCTF2 Confiança de Segunda Ordem (amostra Experiência).

(* indica p-valor $<0,05 ; * *$ indica p-valor $<0,001$; ausência de * indica relação não significativa)

Analisando os resultados apresentados na tabela 4.31 e na figura 4.9, é possível observar que o resultado obtido foi significativo para oito das 10 hipóteses de pesquisa apresentadas. Todos os resultados significativos oferecem suporte para as hipóteses formuladas. Dos oito resultados significativos, sete são significativos ao nível de 0,001, enquanto um é significativo ao nível de 0,05 .

Compatibilidade (H14) exerce forte efeito sobre a Facilidade de Uso $(0,602)$. Facilidade de Uso (H12) apresenta efeito significativo sobre Vantagem Relativa, mas Compatibilidade (H13) não. Dos três construtos utilizados para representar as características inovadoras dos dispositivos móveis, apenas Vantagem Relativa (H6) não tem efeitos significativos sobre a Confiança. Entre os efeitos sobre a Confiança exercidos pelas características inovadoras, Facilidade de Uso (H7) tem o maior impacto $(0,342)$. Confiança apresenta efeitos sobre a Atitude $(\mathrm{H} 2)$ e sobre a Intenção (H3). Conforme esperado, Atitude afeta Intenção (H4) e Intenção afeta a Compra Efetiva (H5). O modelo Dimensões da Confiança é capaz de explicar 14\% da variância na Compra Efetiva, 47\% da variância da Intenção e 59\% da variância na Atitude para os dados da amostra Experiência. 


\subsubsection{1}

\section{Diferenças Entre as Amostras}

Com o objetivo de testar as hipóteses de moderação por tipo de produto (H9, $\mathrm{H} 10$ e H11), os respondentes foram divididos em duas amostras, Busca e Experiência. Cada uma das amostras foi analisada em separado e suas diferenças foram identificadas.

Uma vez que o uso de coeficientes não padronizados permite a comparação entre amostras (BYRNE, 2010; MARTINS; HOR-MEYLL; FERREIRA, 2013), é possível identificar se o efeito das relações entre os construtos é diferente entre as amostras Busca e Experiência. A tabela 4.32 mostra os coeficientes não padronizados estimados para as hipóteses testadas em cada amostra e seu nível de significância, a tabela 4.33 mostra os intervalos de confiança inferenciais para os coeficientes não padronizados estimados e a figura 4.10 apresenta o modelo comparativo entre as amostras.

Gardner e Altman (1986) aconselham o uso, sempre que possível, de intervalos de confiança inferenciais no teste de hipóteses, no lugar de apenas apresentar o p-valor correspondente, pois intervalos de confiança fornecem mais informação sobre o alcance dos valores para cada estimativa. Caso uma relação se mostre significativa em uma amostra e na outra não, a diferença é evidente, não sendo necessária a avaliação dos coeficientes. O mesmo raciocínio é aplicado a situações onde ambas as relações não são significativas.

O estabelecimento de um intervalo de confiança de $95 \%$ entre duas médias pertencentes a grupos diferentes só é garantia para a presença de uma diferença estatisticamente significativa se devidamente corrigido (GOLDSTEIN; HEALY, 1995; TYRON, 2001). Este estudo utiliza o cálculo de intervalo de confiança sugerido por Tyron (2001), que emprega a razão entre o erro padrão da diferença entre os grupos e a soma dos erros padrões de ambos os grupos e então multiplica o resultado pelo nível de probabilidade (talfa) da distribuição t correspondente e alfa definido para cada caso. Dessa forma, foram calculados os intervalos inferenciais para os coeficientes não padronizados ao nível de significância de 5\% definido para todo este estudo. 
Tabela 4.32 - Coeficientes Não Padronizados Estimados e Significância

\begin{tabular}{llllll}
\hline \multicolumn{1}{c}{ Relação } & \multicolumn{2}{c}{ Busca } & \multicolumn{2}{c}{ Experiência } \\
\cline { 2 - 5 } & $\begin{array}{l}\text { Coefi- } \\
\text { ciente }\end{array}$ & p-valor & $\begin{array}{l}\text { Coefi- } \\
\text { ciente }\end{array}$ & p-valor \\
\hline H2: Confiança $\rightarrow$ Atitude & $\mathbf{1 , 1 0 8}$ & $<\mathbf{0 , 0 0 1}$ & $\mathbf{1 , 2 0 2}$ & $<\mathbf{0 , 0 0 1}$ \\
H3: Confiança $\rightarrow$ Intenção & $\mathbf{0 , 2 8 5}$ & $\mathbf{0 , 0 3 5}$ & $\mathbf{0 , 8 4 6}$ & $<\mathbf{0 , 0 0 1}$ \\
H4: Atitude $\rightarrow$ Intenção & $\mathbf{0 , 4 4 4}$ & $<\mathbf{0 , 0 0 1}$ & $\mathbf{0 , 3 4 8}$ & $\mathbf{0 , 0 0 2}$ \\
H5: Intenção $\rightarrow$ Compra Efetiva & $\mathbf{0 , 4 4 4}$ & $<\mathbf{0 , 0 0 1}$ & $\mathbf{0 , 5 8 0}$ & $<\mathbf{0 , 0 0 1}$ \\
H6: Vantagem $\rightarrow$ Confiança & $\mathbf{0 , 1 8 0}$ & $\mathbf{0 , 0 2 7}$ & 0,094 & 0,091 \\
H7: Facilidade $\rightarrow$ Confiança & $\mathbf{0 , 4 0 3}$ & $<\mathbf{0 , 0 0 1}$ & $\mathbf{0 , 3 4 2}$ & $<\mathbf{0 , 0 0 1}$ \\
H8: Compatibilidade $\rightarrow$ Confiança & $\mathbf{0 , 2 5 1}$ & $<\mathbf{0 , 0 0 1}$ & $\mathbf{0 , 1 3 7}$ & $<\mathbf{0 , 0 0 1}$ \\
H12: Facilidade $\rightarrow$ Vantagem & $\mathbf{0 , 4 2 9}$ & $<\mathbf{0 , 0 0 1}$ & $\mathbf{0 , 7 6 7}$ & $<\mathbf{0 , 0 0 1}$ \\
\hline H13: Compatibilidade $\rightarrow$ Vantagem & $\mathbf{0 , 2 5 7}$ & $<\mathbf{0 , 0 0 1}$ & $-0,011$ & 0,874 \\
\hline H14: Compatibilidade $\rightarrow$ Facilidade & $\mathbf{0 , 6 0 2}$ & $<\mathbf{0 , 0 0 1}$ & $\mathbf{0 , 6 0 2}$ & $<\mathbf{0 , 0 0 1}$ \\
\hline
\end{tabular}

(negrito indica relações cujo resultado dá suporte à hipótese de relação entre as variáveis)

Os resultados apresentados na tabela 4.32 apontam para diferenças significativas para as relações entre Vantagem Relativa e Confiança (H6), que é significativa para a amostra Busca e não significativa para a amostra Experiência e entre Compatibilidade e Vantagem Relativa (H13), que é significativa para a amostra Busca e não significativa para a amostra Experiência. 


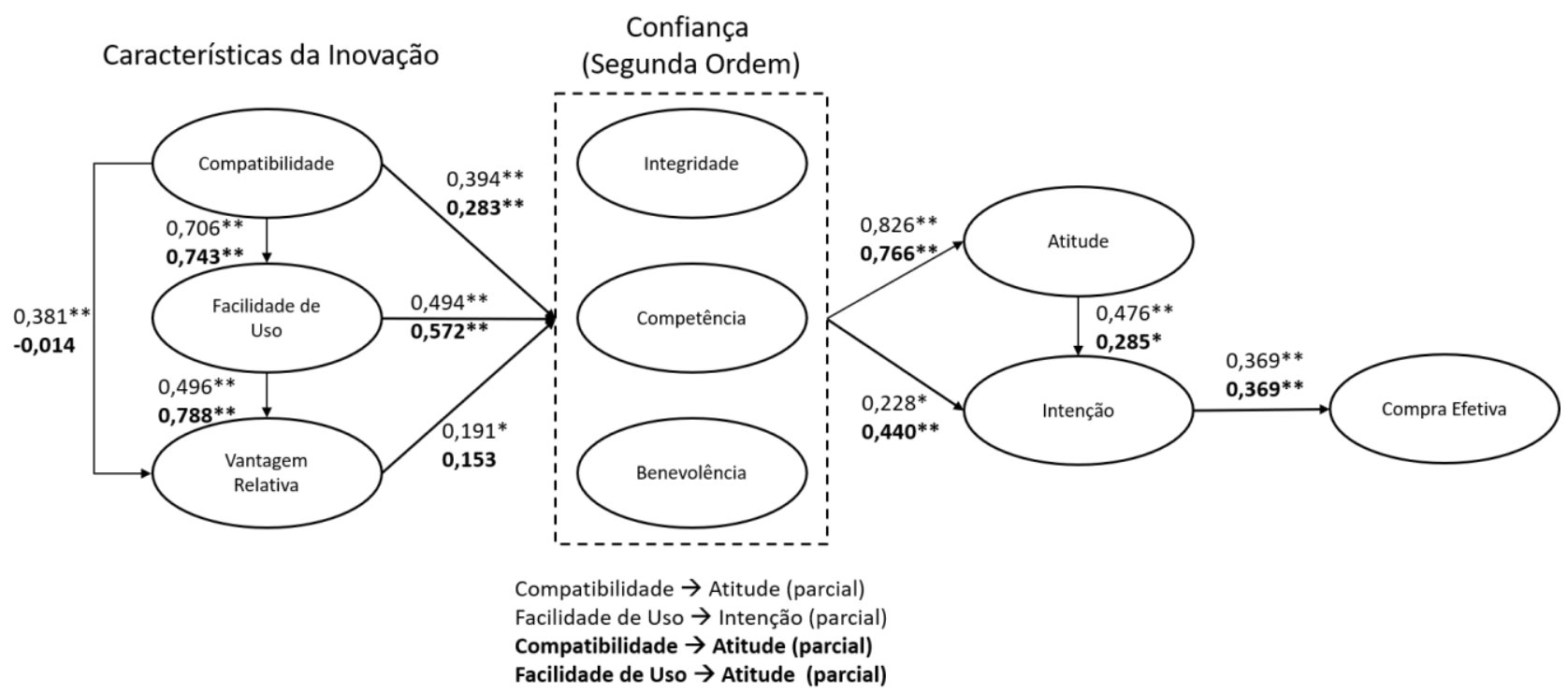

Figura 4.10 - Coeficientes Não Padronizados Estimados para o MCTF2 Confiança de Segunda Ordem (amostras Busca e Experiência).

(valores em negrito indicam amostra Experiência; * indica p-valor < 0,05; ** indica p-valor < 0,001 ; ausência de * indica relação não significativa)

Por fim, foram verificadas as diferenças para as amostras Busca e Experiência das relações entre Intenção de Compra e Compra Efetiva (H5), Atitude e Intenção de Compra (H4), Confiança e Atitude (H2), Facilidade de Uso e Confiança (H7), Compatibilidade e Confiança (H8), Facilidade de Uso e Vantagem Relativa (H12) e Compatibilidade e Facilidade de Uso (H14).

Tabela 4.33 - Intervalos de Confiança para os Coeficientes Não Padronizados

\begin{tabular}{|c|c|c|c|c|c|c|}
\hline \multirow{3}{*}{ Relação } & \multicolumn{3}{|c|}{ Busca } & \multicolumn{3}{|c|}{ Experiência } \\
\hline & \multicolumn{4}{|c|}{$\begin{array}{c}\text { Intervalo de } \\
\text { Confiança } 95 \%\end{array}$} & \multicolumn{2}{|c|}{$\begin{array}{c}\text { Intervalo de } \\
\text { Confiança } 95 \%\end{array}$} \\
\hline & Coef. & $\begin{array}{l}\text { Limite } \\
\text { Inferior }\end{array}$ & $\begin{array}{l}\text { Limite } \\
\text { Superior }\end{array}$ & Coef. & $\begin{array}{l}\text { Limite } \\
\text { Inferior }\end{array}$ & $\begin{array}{l}\text { Limite } \\
\text { Superior }\end{array}$ \\
\hline H2: Confiança $\rightarrow$ Atitude & 1,108 & 0,951 & 1,265 & 1,202 & 0,967 & 1,437 \\
\hline $\mathrm{H}_{3}:$ Confiança $\rightarrow$ Intenção & 0,285 & $\mathbf{0 , 0 9 3}$ & 0,477 & 0,846 & 0,561 & 1,131 \\
\hline H4: Atitude $\rightarrow$ Intenção & 0,444 & 0,303 & 0,585 & 0,348 & 0,195 & 1,501 \\
\hline $\mathrm{H}_{5}:$ Intenção $\rightarrow$ Compra Efetiva & 0,444 & 0,297 & 0,591 & 0,580 & 0,455 & 0,705 \\
\hline H7: Facilidade $\rightarrow$ Confiança & 0,403 & 0,302 & 0,504 & 0,342 & 0,230 & 0,454 \\
\hline
\end{tabular}




\begin{tabular}{lcccccc} 
H8: Compat. $\rightarrow$ Confiança & 0,251 & 0,183 & 0,319 & 0,137 & 0,080 & 0,194 \\
H12: Facilidade $\rightarrow$ Vantagem & 0,429 & $\mathbf{0 , 3 2 1}$ & $\mathbf{0 , 5 3 7}$ & 0,767 & $\mathbf{0 , 6 2 1}$ & $\mathbf{0 , 9 1 3}$ \\
H14: Compat. $\rightarrow$ Facilidade & 0,551 & 0,476 & 0,626 & 0,602 & 0,522 & 0,682 \\
\hline
\end{tabular}

(valores em negrito indicam intervalos de confiança em que não há sobreposição)

Conforme indicado na tabela 4.33 , há sobreposição da maioria dos intervalos de confiança inferencial para as estimativas das duas amostras. As relações que apresentaram diferenças estatísticas significativas foram as entre Confiança e Intenção (H3) e Facilidade de Uso e Vantagem Relativa (H12). No caso, a magnitude do efeito da Confiança sobre a Intenção é maior para a amostra Experiência do que para a amostra Busca 6 (H10). Não foram encontradas diferenças significativas no efeito da Atitude sobre a Intenção de Compra (H9) ou no efeito da Intenção de Compra sobre a Compra Efetiva (H11). A Facilidade de Uso apresenta efeito de magnitude menor sobre a amostra Busca do que o encontrado na amostra Experiência. 
Quadro 4.9 - Sumário dos Resultados

\begin{tabular}{|c|c|c|c|c|}
\hline \multirow{2}{*}{ Modelo } & \multirow{2}{*}{\multicolumn{2}{|c|}{ Relações Testadas }} & \multicolumn{2}{|c|}{ Suporte } \\
\hline & & & Amostra Busca & Amostra Experiência \\
\hline \multirow[t]{7}{*}{ Dimensões da Confiança } & \multirow{2}{*}{$\begin{array}{l}\text { H1: Mediação } \\
\text { pela Confiança }\end{array}$} & Parcial & $\begin{array}{l}\text { Vantagem Relativa } \rightarrow \text { Atitude } \\
\text { Facilidade de Uso } \rightarrow \text { Intenção }\end{array}$ & Compatibilidade $\rightarrow$ Intenção \\
\hline & & Total & NÃO & Facilidade de Uso $\rightarrow$ Atitude \\
\hline & \multicolumn{2}{|c|}{ H2a: Benevolência $\rightarrow$ Atitude } & SIM & SIM \\
\hline & \multicolumn{2}{|c|}{ H2b: Integridade $\rightarrow$ Atitude } & NÃO & SIM \\
\hline & \multicolumn{2}{|c|}{ H2c: Competência $\rightarrow$ Atitude } & SIM & SIM \\
\hline & \multicolumn{2}{|c|}{ H3a: Benevolência $\rightarrow$ Intenção } & NÃO & NÃO \\
\hline & \multicolumn{2}{|c|}{ H3b: Integridade $\rightarrow$ Intenção } & NÃO & SIM \\
\hline
\end{tabular}




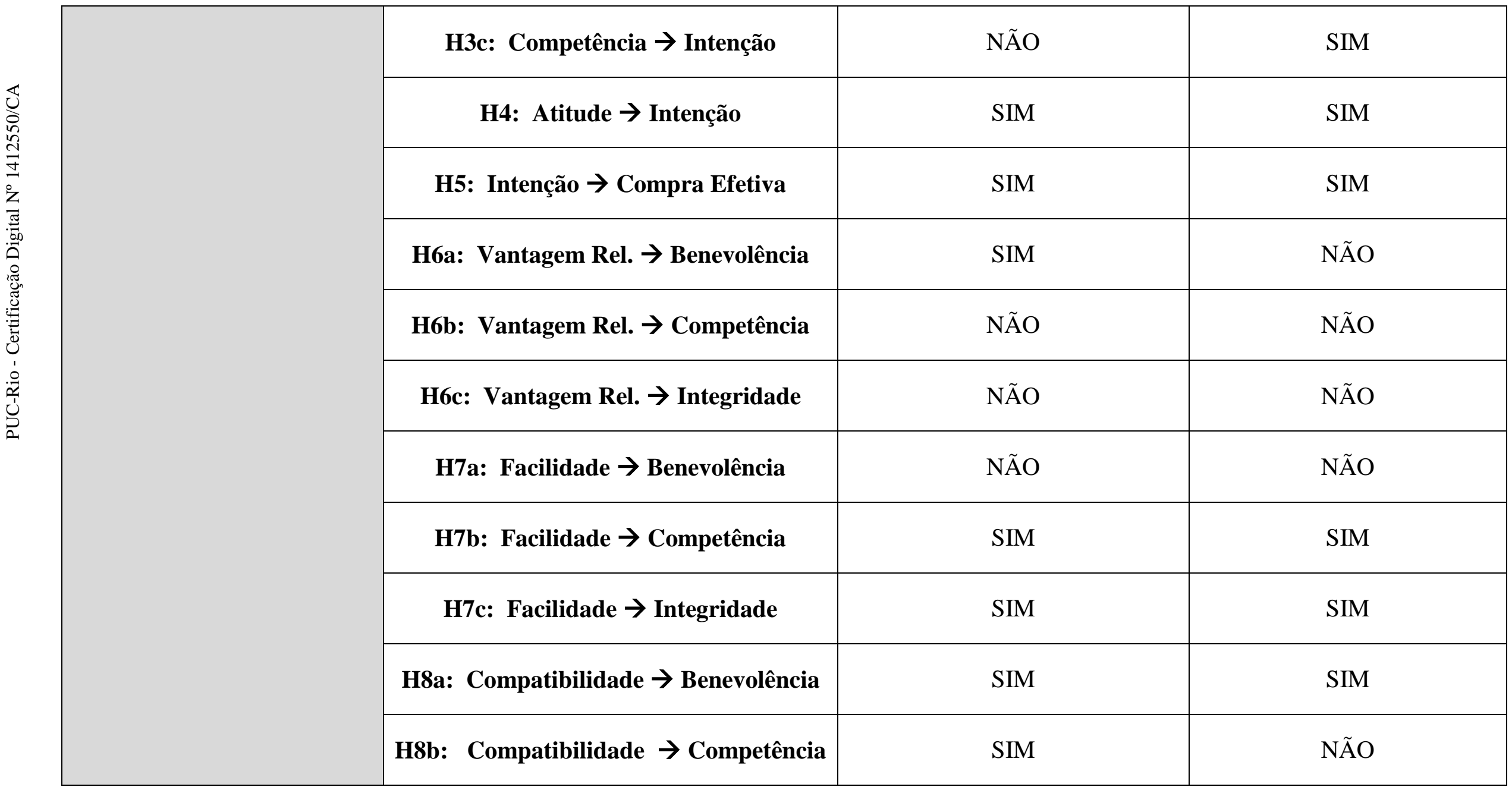




\begin{tabular}{|c|c|c|c|}
\hline & H8c: Compatibilidade $\rightarrow$ Integridade & SIM & NÃO \\
\hline & $\begin{array}{c}\text { H9: Tipo de Produto Modera a relação } \\
\text { Confiança } \rightarrow \text { Atitude }\end{array}$ & \multicolumn{2}{|c|}{$\begin{array}{c}\text { Benevolência } \rightarrow \text { Atitude } \\
\text { Integridade } \rightarrow \text { Atitude } \\
\text { Competência } \rightarrow \text { Atitude } \\
(\text { Facilidade de Uso } \rightarrow \text { Vantagem Relativa*) }\end{array}$} \\
\hline & $\begin{array}{c}\text { H10: Tipo de Produto Modera a relação } \\
\text { Confiança } \rightarrow \text { Intenção }\end{array}$ & \multicolumn{2}{|c|}{ NÃO } \\
\hline & $\begin{array}{l}\text { H11: Tipo de Produto Modera a relação } \\
\text { Intenção } \rightarrow \text { Compra Efetiva }\end{array}$ & \multicolumn{2}{|c|}{$\mathrm{NÃO}$} \\
\hline & H12: Facilidade $\rightarrow$ Vantagem Rel. & SIM & SIM \\
\hline & H13: Compatibilidade $\rightarrow$ Vantagem Rel. & SIM & $\mathrm{NÃO}$ \\
\hline & H14: Compatibilidade $\rightarrow$ Facilidade & SIM & SIM \\
\hline Confiança de $2^{a}$ Ordem & $\begin{array}{l}\text { H1: Mediação } \\
\text { pela Confiança }\end{array}$ & $\begin{aligned} \text { Compatibilidade } & \rightarrow \text { Atitude } \\
\text { Facilidade de Uso } & \rightarrow \text { Intenção }\end{aligned}$ & $\begin{array}{l}\text { Compatibilidade } \rightarrow \text { Atitude } \\
\text { Facilidade de Uso } \rightarrow \text { Atitude }\end{array}$ \\
\hline
\end{tabular}




\begin{tabular}{|c|c|c|}
\hline Total & NÃO & NÃO \\
\hline H2: Confiança $\rightarrow$ Atitude & SIM & SIM \\
\hline H3: Confiança $\rightarrow$ Intenção & SIM & SIM \\
\hline H4: Atitude $\rightarrow$ Intenção & SIM & SIM \\
\hline H5: Intenção $\rightarrow$ Compra Efetiva & SIM & SIM \\
\hline H6: Vantagem Rel. $\rightarrow$ Confiança & SIM & NÃO \\
\hline H7: Facilidade $\rightarrow$ Confiança & SIM & SIM \\
\hline H8: Compatibilidade $\rightarrow$ Confiança & SIM & SIM \\
\hline $\begin{array}{c}\text { H9: Tipo de Produto Modera a relação } \\
\text { Confiança } \rightarrow \text { Atitude }\end{array}$ & \multicolumn{2}{|c|}{$\mathrm{NA} \mathrm{O}$} \\
\hline $\begin{array}{l}\text { H10: Tipo de Produto Modera a relação } \\
\text { Confiança } \rightarrow \text { Intenção }\end{array}$ & \multicolumn{2}{|c|}{$\begin{array}{c}\text { SIM } \\
(\text { Facilidade de Uso } \rightarrow \text { Vantagem Relativa*) }\end{array}$} \\
\hline
\end{tabular}




\begin{tabular}{|c|c|c|}
\hline H11: Tipo de Produto Modera a relação & \multicolumn{2}{|c|}{ NÃO } \\
\hline H12: Facilidade $\rightarrow$ Vantagem Rel. & SIM & SIM \\
\hline H13: Compatibilidade $\rightarrow$ Vantagem Rel. & SIM & NÃO \\
\hline H14: Compatibilidade $\rightarrow$ Facilidade & SIM & SIM \\
\hline
\end{tabular}

(* representa moderação de relação não proposta nas hipóteses originalmente formuladas) 


\section{3 \\ Discussão dos Resultados}

\subsection{1}

\section{As Diferentes Representações da Confiança}

A relação entre confiança e atitude, hipótese H2, está de acordo com os resultados obtidos por outros pesquisadores (GIOVANNINI et al., 2015; KIM; PETERSON, 2017; LEE， 2005; LIÉBANA-CABANILLAS; SÁNCHEZFERNÁNDEZ; MUÑOZ-LEIVA, 2014; PAVLOU; FYGENSON, 2006; OH et al., 2009; WU; KE, 2015) para ecommerce e mcommerce, e aponta para um efeito positivo direto e significativo da confiança na formação da atitude do consumidor em relação a comprar por meio de dispositivos móveis. Essa relação entre a confiança e a atitude é suportada pelos resultados dos três modelos testados e para ambas as amostras.

Entretanto, o modelo Dimensões da Confiança fornece detalhes da relação entre confiança e atitude que os outros modelos, por utilizarem representações holísticas da confiança, não conseguem fornecer. A relação entre competência e atitude, hipótese $\mathrm{H} 2 \mathrm{c}$, apontando um efeito positivo direto, está de acordo com os resultados obtidos em outros estudos (LIN, 2011) e se revela a dimensão mais importante na construção da confiança em contextos comprador-vendedor, como a compra online, o que está de acordo com o trabalho de Xu e Cenfetelli (2016) e Oliveira et al. (2017). A relação entre benevolência e atitude, hipótese H2a, que apresenta efeitos positivos e diretos, não se alinha com outros estudos de confiança em ambientes móveis (LIN, 2011). Por outro lado, estudos tem apontado para a relevância da benevolência em contextos de compra online, embora sua importância seja menor do que a da competência (OLIVEIRA et al., 2017; XU; CENFETELLI, 2016), resultado similar ao encontrado aqui. Entretanto Lin (2011) estudou a adoção de serviços bancários e não comércio de produtos e serviços. Quanto a relação entre integridade e atitude, hipótese $\mathrm{H} 2 \mathrm{~b}$, esta apresentou efeito direto negativo, contrariando as expectativas e outros estudos (LIN, 2011; OLIVEIRA et al., 2017), tanto para o ambiente móvel quanto para contextos de compra online.

A relação entre confiança e intenção de compra, representada pela hipótese H3, também é suportada e está de acordo com estudos anteriores (LU; YANG; CHAU; CAO, 2011; ZHOU, 2011; DIMITRIADIS; KYREZIS, 2010; KIM et al., 
2008; KUAN; BOCK, 2006; LEE, 2005; GEFEN et al., 2003), apontando para um efeito positivo direto e significativo da confiança móvel sobre a intenção do consumidor de comprar por meio de dispositivos móveis. Essa relação é suportada nos três modelos, embora o modelo Dimensões da Confiança apresente somente efeitos da integridade e da competência, e apenas para a amostra Experiência.

Para a relação entre confiança e intenção de compra, o detalhamento fornecido pelas diferentes dimensões da confiança é particularmente interessante para a discussão dos resultados. Enquanto que para os modelos que utilizam versões holísticas da confiança a confiança sempre afeta a intenção de forma direta para ambas as amostras, no modelo Dimensões da Confiança isso nem sempre ocorre. $\mathrm{Na}$ amostra Busca as dimensões da confiança não exercem nenhuma influência direta significativa sobre a intenção e somente a benevolência exerce alguma influência indireta, o que contradiz estudos anteriores sobre compras online (CHEN, 2012), que apontam para efeitos diretos das dimensões da confiança na intenção de compra e no comportamento de compra. Na amostra experiência, os efeitos da integridade e da competência são significativos, mas enquanto a relação entre competência e intenção $(\mathrm{H} 2 \mathrm{c})$ apresenta efeitos positivos diretos conforme o resultado de outros estudos sobre compras online e ambientes móveis (CHEN, 2012; XU; CEFETELLI, 2016), a relação entre integridade e confiança (H3b) apresenta um efeito direto negativo que contradiz estudos anteriores (CHEN, 2012; XU; CEFETELLI, 2016).

Esses resultados, contraditórios e paradoxais, entre a integridade e atitude e entre a integridade e a intenção de compra podem ser melhor compreendidos quando relacionados com os estudos de Kim, Ferrin, Cooper e Dirks (2004) e de Lado, Dant e Tekleab (2008) sobre confiança.

Kim et al. (2004) afirmam que indivíduos valorizam mais informações negativas sobre a integridade alheia do que as positivas e que se desculpar tem mais impacto sobre a reparação de confiança traída do que a negação do problema. Segundo os autores, a confiança é reparada de forma mais efetiva quando parceiros não confiáveis se desculpam por violações relacionadas a competência e negam a culpa em questões de integridade. O consumidor por seu lado é menos afetado pelas violações da integridade quando ela é negada do que quando são oferecidas 
desculpas pelo ocorrido. Além disso, violações da confiança depositada frequentemente são ambíguas e percebidas de forma diferenciada para cada situação, então a perda e a reparação da confiança vão depender de como as violações foram interpretadas pelo consumidor.

Já Lado, Dant e Tekleab (2008) abordam o paradoxo dos relacionamentos organizacionais no comércio de produtos e serviços, onde desempenho geral é mais importante que violações ocasionais da confiança. Os autores afirmam que a presença de oportunismo benigno (violação da integridade) não é suficiente para frustrar o relacionamento com a outra parte se um mínimo de confiança puder ser mantido. Altos níveis de confiança baseada em competência podem manter o comprometimento de quem confia e relacionamentos que geram valor, desde que o ganho potencial da colaboração seja maior do que os custos associados com o comportamento oportunista.

Assim, não é difícil imaginar que um indivíduo mantenha relacionamentos paradoxais com os vendedores de quem compra com frequência baseados em ganhos com aquele relacionamento e presunção das violações da confiança. Neste caso, a percepção de que as violações serão resolvidas de alguma forma através dos processos existentes (competência) somado as barganhas e acesso a produtos e serviços de baixo custo (ganhos) podem levar o consumidor a manter relações com vendedores que percebem como não sendo integros. E a, possivelmente, manterem relações com esse tipo de vendedores propositalmente, o que levaria a uma percepção negativa de integridade nos vendedores em geral e naqueles com quem não se relaciona cara-a-cara em particular.

A relação entre atitude e intenção de compra, hipótese H4, encontra suporte nos resultados obtidos nos três modelos para ambas as amostras. O efeito da atitude sobre a intenção é significativo, direto e positivo. O coeficiente padronizado varia entre os modelos e amostras indo de 0,285 até 0,580, indicando que a atitude tem papel importante na intenção de compra. Esse resultado está de acordo com aqueles obtidos anteriormente por outros pesquisadores para adoção de inovações tecnológicas, compras online e uso de serviços móveis (BRUNNER; KUMAR, 2005; FERREIRA et al., 2014; FERREIRA; SILVA; GIOVANNINI; RAMOS, 
2016; ZHANG; ZHU; LIU, 2012; LU et al., 2011; OH et al., 2009; NYSVEEN et al., 2005).

A relação entre intenção de compra e compra efetiva, hipótese H5, encontra suporte nos resultados obtidos nos três modelos para ambas as amostras. $\mathrm{O}$ efeito da intenção sobre a compra efetiva é significativo, direto e positivo. Os coeficientes (padronizado e não padronizado) não apresentam diferenças significativas entre modelos e amostras, reportando valores entre 0,366 e 0,580, indicando que a intenção de compra tem papel importante na compra efetiva ainda que outros fatores não considerados pelo modelo sejam mais importantes. Esse resultado está de acordo com aqueles obtidos anteriormente por outros pesquisadores para adoção de inovações tecnológicas, compras online e uso de serviços móveis (BRUNNER; KUMAR, 2005; FERREIRA et al., 2014; FERREIRA; SILVA; GIOVANNINI; RAMOS, 2016; ZHANG; ZHU; LIU, 2012; LU et al., 2011; OH et al., 2009; NYSVEEN et al., 2005).

\subsection{2 \\ O Papel Mediador da Confiança}

A confiança apresenta papel mediador, hipótese H1, nas relações entre as características inovadoras dos dispositivos móveis e a atitude e entre as caracacterísticas inovadoras dos dispositivos móveis e a intenção de compra. Esse resultado está de acordo com os encontrados por outros estudos para compras online (CHE; CHEUNG; THADANI, 2017; GEFEN; KARAHANNA; STRAUB, 2003; GIOVANNINI et al., 2015; KIM; PETERSON, 2017; OLIVEIRA et al., 2017; ZHANG; MAO, 2008). Novamente, as diferentes representações da confiança utilizadas nos modelos testados evidencia que quando consideradas separadamente as dimensões da confiança influenciam as relações estudadas. Não foram encontrados estudos sobre mediação por parte dos construtos representantes das diferentes dimensões da confiança nas relações entre os construtos da teoria de difusão de inovações e atitude e intenção de compra para fins de comparação entre estudos.

O modelo Dimensões da Confiança apresentou mediação parcial por parte das dimensões da confiança competência e benevolência para a relação entre vantagem 
relativa e atitude e entre facilidade de uso e intenção de compra para a amostra Busca; e entre compatibilidade e intenção de compra para a amostra Experiência. A mediação foi total para a relação entre facilidade de uso e atitude para a amostra Experiência. A presença e o grau de mediação pela confiança dependem do contexto em que a decisão de compras ocorre e em compras de serviços e produtos a competência aje como um importante mediador entre as percepções de vantagens relativas e de facilidade de uso dos dispositivos móveis.

O modelo Confiança de Segunda Ordem apresentou mediação parcial para as relações entre compatibilidade e atitude para ambas as amostras, para as relações entre facilidade de uso e intenção de compra para a amostra Busca e para as relações entre facilidade de uso e atitude para a amostra Experiência. O mesmo resultado foi encontrado no modelo Confiança Geral.

\subsection{4}

\section{O Impacto dos Fatores Inovadores dos Dispositivos Móveis}

A relação entre vantagem relativa e confiança, hipótese H6, varia de acordo com o modelo e a amostra. Para a amostra Experiência, nos três modelos testados, e para a amostra Busca do modelo Confiança Geral, vantagem relativa não exerce efeito significativo sobre os construtos holísticos de confiança nem sobre as diferentes dimensões da confiança. Este resultado não pode ser comparado de forma direta com outros estudos pois não foram identificados estudos utilizando relações entre os construtos vantagem relativa e confiança na literatura estudada. Entretanto o núcleo do construto vantagem relativa é formado pelos itens de outro construto, a utilidade percebida. Assim, é possível fazer uma comparação com a literatura que aborda as relações entre vantagem relativa e utilidade. Neste caso, os resultados obtidos são contrários aos resultados obtidos por outros pesquisadores (DIMITRIADIS; KYREZIS, 2010; GEFEN et al., 2003; LI; YEH, 2010; OFUONYE; BEATY; REAY; DICK; MILLER, 2008). Entretanto, pode-se dizer que, devido as dificuldades representadas pelos produtos de experiência no processo decisório de sua compra, é possível que o uso de dispositivos móveis realmente não apresente nenhuma vantagem real na percepção dos respondentes. Para essa amostra, preocupada com um produto ou serviço essencialmente hedônico 
e sensorial, uma perspectiva utilitária do processo pode ser rejeitada. Por outro lado, para a amostra Busca, tanto do modelo Confiança de Segunda Ordem quanto para o modelo Dimensões da Confiança, há um efeito positivo direto da vantagem relativa sobre a consiança, resultado que está de acordo com os o de outros estudos similares ao usarmos a utilidade novamente como proxy (DIMITRIADIS; KYREZIS, 2010; GEFEN et al., 2003; LI; YEH, 2010; OFUONYE; BEATY; REAY; DICK; MILLER, 2008). Cabe ressaltar que para a amostra Busca do modelo Dimensões da Confiança, vantagem relativa afeta apenas a dimensão benevolência (H6a), indicando que a percepção das vantagens utilitárias oferecidas pelos dispositivos móveis para comprar produtos e serviços não afetam as percepções do consumidor sobre a integridade ou competência dos vendedores.

A relação entre facilidade de uso e a confiança, hipótese $\mathrm{H} 7$ se mostrou positiva e direta, em todos os modelos, para ambas as amostras, se alinhando com outros estudos sobre o impacto da facilidade de uso sobre a confiança (DIMITRIADIS; KYREZIS, 2010; GEFEN et al., 2003; GIOVANNINI et al.; 2015; LEE, 2009; LI; YEH, 2010; ZHANG; MAO, 2008) para ecommerce e mcommerce, e aponta para um efeito positivo direto e significativo da vantagem relativa percebida no uso de dispositivos móveis para compras na formação da confiança do consumidor. Ressalta-se que, diferentemente da utilidade, a facilidade de uso tem efeito positivo direto sobre as dimensões competência (H7c) e integridade (H7b) para ambas as amostras do modelo Dimensões da Confiança. Os coeficientes (padronizados e não padronizados) das duas relações indicam que a percepção de facilidade do uso dos dispostitivos móveis na realização da compra de produtos e serviços é igualmente importante para a formação das percepções do consumidor sobre a capacidade do vendedor de entregar a oferta e de sua capacidade de se manter fiel a certos princípios.

A relação entre compatibilidade e confiança, hipótese $\mathrm{H} 8$, encontra suporte nos resultados para ambas as amostras nos três modelos testados. O efeito da compatibilidade sobre a confiança é significativo, direto e positivo. Assim como no caso da vantagem relativa, poucos estudos utilizam o construto compatibilidade, e aqueles que o fazem não o relacionam a confiança. Uma meta-análise feita por Zhang, Zhu e Liu (2012), abrangendo um período de 9 anos (2002 a 2010), sobre a adoção do comercio móvel utilizou dados de 53 artigos e não identificou nehuma 
relação envolvendo confiança e compatibilidade ou confiança e vantagem relativa nestes trabalhos. Ressalta-se que compatibilidade tem efeito direto e positivo sobre as dimensões benevolência (H8a) e competência (H8c) na amostra Busca do modelo Dimensões da Confiança e efeito direto e positivo apenas sobre a benevolência na amostra Experiência. A compatibilidade dos dispositivos móveis com os hábitos e experiencias de compra do consumidor é um fator preponderante na formação da confiança quando se trata da compra de produtos e serviços de fácil avaliação, mas quando esses produtos são mais complicados ou sensoriais a benevolência assume o papel central.

A relação entre facilidade de uso e vantagem relativa, hipótese $\mathrm{H} 12$, apresentou efeitos significativos, diretos e positivos para ambas as amostras nos três modelos. O coeficiente padronizado elevado em ambas as amostras, especialmente a de Experiência, indica que a facilidade de uso é um importante influenciador das percepções de vantagem relativa do uso dos dispositivos móveis na compra de produtos e serviços. Esse resultado se encontra de acordo com os resultados de estudos similares (usando utilidade como proxy da vantagem relativa) apresentados por outros autores para o comércio online e a adoção de dispositivos móveis (AGREBI; JALLAIS, 2015; FERREIRA et al., 2016; WANG; LIN; LUARN, 2006; ZHOU, 2011).

A relação entre compatibilidade e vantagem relativa, hipótese H13, apresentou efeitos significativos, diretos e positivos para a amostra Busca nos três modelos. Já para amostra Experiência a relação não teve efeitos significativos em nenhum dos tr6es modelos. Esse resultado indica que a compatibilidade dos dispositivos móveis com os hábitos e experiências de compras do consumidor age como um influenciador da percepção das vantagens do uso de dispositivos móveis apenas na compra de produtos e serviços de fácil avaliação, mas que conforme o processo fica mais complexo e exige mais esforço a compatibilidade deixa de ser um fator relevante.

A relação entre compatibilidade e facilidade de uso, hipótese H14, apresentou efeitos significativos, diretos e positivos para ambas as amostras nos três modelos. O coeficiente padronizado igualmente elevado em ambas as amostras, indica que a percepção de compatibilidade entre os hábitos e a experiência de compra do 
consumidor age sobre suas percepções do nível de esforço que será necessário para realizar compras de produtos e serviços via dispositivos móveis.

\subsection{5}

\section{A Influência do Tipo de Produto}

Primeiro, faz-se necessário expor o caráter relativo da classificação de tipo de produto entre busca e experiência. Muitos produtos considerados produtos de experiência no passado ganharam características de busca com a popularização da Internet e o volume de compartilhamento de experiências entre pares. Para este estudo, dois importantes produtos/serviços, frequentemente adquiridos pelo consumidor brasileiro via dispositivos móveis não puderam ser utilizados na moderação pois foram percebidos como pertencentes à zona central docontínuo formado pelos polos busca e experiência, foi o caso dos livros (digitais ou não) e das refeições (delivery). Embora o uso de tipologias facilite a interpretação de dados e comportamentos, ela também cria problemas ao criar zonas de exclusão. A tipologia escolhida para este estudo, embora relevante, apresenta características indesejadas para o estudo de comportamentos de compra online e móvel.

Os resultados do teste de intervalo de confiança inferencial para a hipótese H9 revelaram um efeito oposto ao esperado no modelo Dimensões da Confiança. Aparentemente, as relações entre as dimensões da confiança e a atitude são intensificadas pelos produtos de busca. Talvez isso ocorra por causa da sutil distinção entre atitude e intenção. Enquanto a intenção é marcada pelo grau de intensidade com que um indivíduo deseja engajar-se em um comportamento (ZHANG et al. 2010) e, portanto, sujeita a ser mais impactada por fontes externas que confirmem ou rejeitem o comportamento, atitude é um sentimento positivo ou negativo sobre o comportamento (FISHBEIN; AJZEN, 1975) e, portanto, formada antes do desejo de se engajar no comportamento. No caso da atitude é bem possível que o fato de os produtos de busca permitirem uma avaliação mais fácil de seus atributos e desempenho, e dos custos e benefícios envolvidos, reforce as percepções de confiança no vendedor e potencialize a relação entre confiança e atitude.

Os resultados do teste de intervalo de confiança inferencial, tanto para o modelo Dimensões da confiança quanto para o modelo Confiança de Segunda 
Ordem, oferecem suporte para a hipótese H10, indicando que o tipo de produto não apenas modera as relações entre as dimensões da confiança, como este efeito é mais intenso para produtos de experiência, já que as características deste tipo de produtos dificultam o processo de avaliação dos mesmos, tornando o processo de formação da intenção de compra mais dependente da confiança depositada no vendedor.

Já a hipótese H11 não é suportada em nenhum dos dois modelos. As relações entre a intenção de comprar por meio de dispositivos móveis e o comportamento real de compra não sofrem efeitos do tipo de produto, indicando que o tipo de produto e o grau de informações disponibilizadas para a sua avaliação só apresentam relevância para o processo de decisão na fase de intensificar ou reduzir o desejo por realizar a compra do mesmo e que outros fatores influenciarão a relação entre a intenção de compra e a compra efetiva.

Cabe ressaltar que o tipo de produto também demonstrou moderar outras relações não previstas a priori. No caso do modelo Dimensões da Confiança, as relações entre compatibilidade e competência, vantagem relativa e benevolência, compatibilidade e integridade, e compatibilidade e vantagem relativa só se mostraram significativas para os produtos de busca. É possível que, para produtos que sejam mais fáceis de terem suas características e desempenho avaliados antes da compra ou uso, essas características utilitárias alterem suas percepções e potencializem os efeitos dos construtos utilitários associados a elas. O modelo Confiança de Segunda Ordem aponta um efeito similar nas relações entre vantagem relativa e confiança, e entre compatibilidade e vantagem relativa.

Já os efeitos da facilidade de uso sobre a vantagem relativa são intensificados pelos produtos de experiência, indicando que quando um produto é difícil de ser avaliado a facilidade do procedimento de compra via dispositivos móveis é visto como uma grande vantagem pelo consumidor.

\subsection{6}

\section{Modelo MCTF2 - Determinação do Melhor Modelo}

O teste comparativo entre os três modelos apresentados pelo estudo indica que o modelo com a confiança modelada como construto de segunda ordem produz 
ajustes significativamente melhores do que o uso das dimensões da confiança em separado ou do que o uso de construtos de primeira ordem em que as dimensões da confiança não estejam claramente presentes nos itens que os compõem. Além disso, o modelo de segunda ordem foi capaz de apontar a moderação pelo produto de forma muito similar ao modelo com as dimensões separadas, embora com menos detalhes.

Os construtos representantes das dimensões da confiança, embora altamente correlacionados, obtiveram validade discriminante e validade convergente adequadas, indicando que os respondentes são capazes de distinguir e avaliar as diferentes dimensões da confiança. O problema da colinearidade desaparece quando os três construtos (Competência, Integridade, Benevolência) são carregados como itens do construto de segunda ordem, Confiança.

Os resultados encontrados indicam que cada uma das dimensões da confiança é afetada de formas diferentes por diferentes antecedentes e que cada uma delas também exerce diferentes efeitos sobre outras variáveis. A substituição das dimensões por construtos holísticos da confiança, sobretudo daqueles que não apresentam itens o suficiente para representar as diferentes dimensões presentes, reduz a riqueza da análise e possivelmente induz ao erro.

A importância da manutenção das diferentes dimensões da confiança e do uso delas na formação de um construto de segunda ordem na modelagem de comportamentos também é suportada pelos trabalhos de Lankton e McKnight (2011) e Miguens, Vázquez e Turnes (2014). 


\section{5 \\ Conclusões e Recomendações}

Após um breve sumário da pesquisa realizada são discutidas as contribuições e impactos do estudo, tanto teóricos quanto práticos. Ao final são apontadas as limitações do estudo e sugeridas alternativas de pesquisas futuras.

\section{1}

\section{Sumário do Estudo}

Este estudo investigou o papel da confiança, das características inovadoras dos dispositivos móveis e do tipo de produto na adoção e uso de dispositivos móveis para a realização de compras online, buscando alcançar uma melhor compreensão sobre os fatores que influenciam a atitude, a intenção e o comportamento de compra dos consumidores no comércio móvel.

A revisão da literatura, englobando teorias de inovação, aceitação e adoção de tecnologias, confiança, comportamento do consumidor e aspectos cognitivos e emocionais relacionados aos dispositivos móveis, revelou construtos e modelos que foram, ao longo dos anos, propostos e testados a fim de identificar as razões que levam indivíduos a adotarem e confiarem em novas tecnologias.

O surgimento da internet levou à adaptação de teorias (ROGERS, 2003; COHEN; BASU, 1987; AJZEN; FISHBEIN, 1980; FISHBEIN; AJZEN, 1975), modelos (DAVIS, 1989) e construtos criados para tecnologias offline (DAVIS, 1989; MORGAN; HUNT, 1994), a fim de que estes pudessem ser aplicados ao recém-criado ambiente online (MCKNIGHT et al., 2002), e a descoberta de novos construtos exclusivos do ambiente online (BOYD, 2003; DONEY; CANNON, 1997). Características exclusivas do ambiente online trazem novas questões para os pesquisadores (SHANKAR; BALASUBRAMANIAN, 2009; LEE, 2005). Em seguida, a evolução da tecnologia móvel revelou novos construtos relevantes para o ambiente móvel, dando aos dispositivos móveis características inovadoras que poderiam impactar em sua aceitação e adoção (LEE et al., 2003; LEE et al., 2006; LI et al., 2012; MOON; KIM, 2001; OH et al., 2009). Essa trajetória evolutiva é organizada de forma a criar um grupo coeso de teorias e construtos, que poderiam explicar a formação da confiança, seu papel mediador e sua influência sobre a atitude e intenção de compra do consumidor via dispositivos móveis. 
A fim de unir as teorias, modelos e construtos relacionados à formação da confiança e comportamento do consumidor na adoção e aceitação de tecnologias em um único modelo, este estudo desenvolveu o modelo MCTF2 (Mobile Commerce Trust Formation 2), que deriva sua estrutura teórica dos conceitos de adoção e uso de ideias inovadoras encontrados na literatura, fazendo uso de construtos cognitivos usados em modelos baseados no TAM, na teoria de difusão de inovações e modelos de formação de confiança. Três modelos, suportados pela teoria, apresentando diferentes representações da confiança foram propostos, cada um apresentando possíveis vantagens sobre seus rivais.

Em seguida foi elaborado um instrumento de pesquisa composto por escalas pré-existentes, desenvolvidas e testadas em outros estudos (FENG et al., 2016; GIOVANNINI et al., 2015; MCKNIGHT et al., MOON; KIM, 2001; MOORE; BENBASAT, 1991; 2002; OLIVEIRA et al., 2017) e cuidadosamente traduzidas e adaptadas para o português. O questionário foi então distribuído em um levantamento online, resultando em 534 questionários válidos respondidos por usuários de redes sociais (Facebook e WhatsApp). O modelo de mensuração para cada um dos modelos propostos foi analisado e seus resultados indicam adequadas validade e confiabilidade dos construtos medidos por meio das escalas selecionadas, possibilitando seu uso em modelos estruturais e a comparação entre diferentes modelos.

As hipóteses de pesquisa foram testadas com o uso de modelagem de equações estruturais (BYRNE, 2010; HAIR et al, 2009; KULVIWAT et al, 2007; OLSSON et al, 2000; ANDERSON; GERBING, 1988) e diversas análises estatísticas foram feitas com os resultados apresentados para os três modelos propostos, embora o estudo só tenha se aprofundado na comparação entre dois dos modelos. Por fim, as comparações entre os modelos MCTF2 Dimensões da Confiança e Confiança de Segunda Ordem foram utilizadas para discutir aspectos do papel da confiança na formação da atitude e Intenção do consumidor brasileiro em relação a compra via dispositivos móveis. 


\section{2 \\ Conclusões e Contribuições}

Os resultados e relações apontados na pesquisa representam uma contribuição para as teorias de inovação, adoção e aceitação de tecnologia, assim como para o estudo da formação da confiança e sua influência no comportamento do consumidor. Este estudo também apresenta algumas implicações práticas para empresas que oferecem serviços de compras que possam ser acessados por meio de dispositivos móveis.

\subsection{1 \\ Contribuições do Estudo}

Este estudo contribui para o corpo teórico sobre a adoção de inovações ao utilizar os construtos da teoria de difusão de inovações de Rogers (2003) juntamente com a TRA de Fishbein e Ajzen (1975) para propor um modelo para a adoção do comércio móvel. O modelo proposto leva em consideração dois fatores ignorados por outros estudos sobre a adoção de dispositivos móveis para a compra de bens e serviços: a confiança e a influência do tipo de produto. A confiança é considerada como mediadora das relações entre as características inovadoras dos dispositivos móveis e a atitude e intenção de usa-los para a compra de produtos e serviços, o que representa uma segunda contribuição do estudo.

No que diz respeito ao corpo teórico sobre a confiança, o estudo é construído sobre a teoria de confiança e comprometimento de Morgan e Hunt (1994), que pressupõe que a confiança atua como mediadora em relações entre vendedores e consumidores e, sobretudo, que ambos desejam que estas sejam duradouras a fim de oferecer uma perspectiva comparativa entre diferentes representações da confiança. $\mathrm{O}$ estudo contribui neste campo apresentando evidências de que cada uma das diferentes dimensões da confiança exerce influência particular sobre a intenção e a atitude, ao ponto de algumas dimensões terem efeitos significativos enquanto outras apresentam efeitos insignificantes. Por outro lado, cada uma das diferentes dimensões é afetada de maneira particular por seus antecedentes. Quanto à mediação entre as características inovadoras dos dispositivos móveis e os construtos utilizados para mensurar a adoção da compra via o uso destes (atitude e intenção), as dimensões da confiança mediam alguns efeitos parcialmente e outros 
integralmente, indicando que a mediação depende do contexto específico entre vendedor e comprador. O estudo também aponta para a importância do uso de um construto de confiança multidimensional sempre que possível, seja este representado pelas dimensões pertinentes da confiança em separado, seja através de um construto de segunda ordem.

Outra contribuição deste estudo é sobre o efeito do tipo de produto nas relações entre a confiança e a atitude e a intenção de compra via dispositivos móveis, e nas relações entre as características inovadoras dos dispositivos móveis e a confiança. As evidências apresentadas neste estudo indicam que os processos de adoção e uso de dispositivos móveis para compras é fortemente impactado pelo tipo de produto a ser adquirido. Enquanto produtos de busca tornam os efeitos da confiança na atitude mais intensos, os produtos de experiência intensificam os impactos da confiança na intenção. Assim, a confiança influencia nos sentimentos do consumidor sobre comportamentos de compra futuros quando o consumidor encara decisões de compra simples e na prontidão do consumidor para se engajar em um comportamento de compra quando este encara decisões de compra mais complexas.

\section{2 .2 \\ Implicações Teóricas}

Em primeiro lugar, o estudo confirma o papel da confiança na formação da atitude do consumidor em relação a adoção de inovações tecnológicas e da intenção comportamental.

Em segundo lugar, os resultados indicam que o uso das diferentes dimensões da confiança em modelos comportamentais oferece mais informações sobre as percepções e comportamentos da amostra estudada do que construtos holísticos. O estudo ressalta a importância das percepções de competência na construção de confiança em ambientes de comércio móvel e seu impacto direto sobre atitude e intenção de compra por meio de dispositivos móveis. Por outro lado, benevolência, parece exercer uma pequena influência constante, mas de forma evasiva e indireta, sobre a intenção de compra por dispositivos móveis. Construtos utilitários afetam diferentes dimensões da confiança de forma individual e cada dimensão afeta a 
atitude e a intenção de compra por dispositivos móveis também de forma individualizada.

Em terceiro lugar, o estudo apoia a ideia de que a confiança age como mediadora para construtos utilitários e que percepções de elementos externos podem ser internalizadas quando há confiança no agente ou meio.

Em quarto lugar, o estudo aponta a importância do uso de construtos cognitivos utilitários na adoção e uso de dispositivos móveis para compra de produtos e serviços. Entretanto, percepções de facilidade de uso e compatibilidade com o estilo de vida são mais importantes no processo de adoção dos dispositivos móveis para a compra de produtos e serviços do que as vantagens utilitárias percebidas em seu uso. É particularmente importante apontar que a compatibilidade, construto raramente utilizado em modelagens do comportamento de adoção e uso por parte do consumidor de novas tecnologias e ideias, teve importante impacto direto sobre a formação da confiança, e impactos indiretos, mas significativos, na formação da atitude e da intenção de compra por meio de dispositivos móveis. Facilidade de uso permanece um importante construto no processo de adoção e uso de tecnologias, gerando mais relações significativas do que seu usual companheiro utilidade (cujos itens são o cerne do construto Vantagem Relativa utilizado neste estudo).

Em quinto lugar, o estudo indica que o uso de tecnologias e interfaces fáceis de operar, simples e familiares é mais importante na construção da confiança do consumidor e no processo de adoção de inovações e da compra por dispositivos móveis do que o uso daquelas que exigem interações complexas. A introdução de novas tecnologias e interface de compras deve seguir caminhos similares aos existentes a fim de ter sua aceitação facilitada. De fato, a quebra de paradigmas no que se refere as interfaces de compras online pode dificultar o processo de difusão da inovação.

Em sexto lugar, o estudo aponta para uma forte influência exercida pelo tipo de produto comprado sobre as relações entre os construtos envolvidos na adoção e uso de dispositivos móveis para a compra de produtos e serviços. Os impactos da confiança sobre a intenção de compra são geralmente mais intensos e significativos para produtos de experiência do que para produtos de busca. Por outro lado, quando 
consideradas separadamente, o impacto das dimensões da confiança sobre a atitude se mostra mais intenso para produtos de busca do que para produtos de experiência. É razoável afirmar, portanto, que, em relação às compras por meio de dispositivos móveis, os produtos de busca, por serem fáceis de serem avaliados, apesar de requererem menos confiança do consumidor para serem adquiridos, têm o impacto da confiança na atitude potencializado pelas características predominantemente utilitárias da dimensão competência, principal componente da confiança formada na situação estudada. Também é razoável considerar que os produtos de experiência, por serem mais difíceis de serem avaliados e requisitarem mais confiança por parte do consumidor para serem adquiridos, têm o impacto da confiança na intenção de compra potencializado, pois a compra em si passa a ser uma opção de fato, e a dificuldade na obtenção das informações necessárias para que o consumidor realize uma correta avaliação se torna um problema, fazendo com que a confiança depositada na competência do vendedor ganhe em importância.

Por fim, o estudo aponta para o uso de um construto de segunda ordem nas modelagens de comportamentos em que a mensuração das influências de dimensões particulares da confiança não é necessária, preservando a multidimensionalidade da confiança ao mesmo tempo em que simplifica a interpretação das relações estudadas. Os resultados da comparação entre os modelos apontam para ajustes melhores e boa capacidade de análise para construtos da confiança holísticos que utilizem suas dimensões de forma integral. O uso de construtos para confiança que não apresentem itens específicos para cada dimensão produz ajustes menos adequados do modelo aos dados e perda de capacidade analítica por eliminar variáveis importantes do processo.

\subsection{3 Implicações Práticas}

Primeiramente, o estudo aponta para a importância de uma interface de compras de uso simplificado e rápido, onde o consumidor não perde tempo tentando encontrar o produto desejado ou realizando a transação de compra em si. Facilidade de uso é o segredo para fomentar a realização de compras via dispositivos móveis. 
Aparentar competência operacional é mais importante do que apresentar-se honesto e sincero, para o consumidor garantias de eficácia no processo e na interface de compras são mais importantes do que garantias de integridade. Apresentar procedimentos claros de garantia, devolução e reembolso pode ser mais efetivo que aparentar idoneidade.

Igualmente importante é que a experiência de compra via dispositivos móveis seja compatível com as experiencias anteriores do consumidor com processos de compra online. Tanto o uso de processos similares adotados por outros sites e aplicativos de uso comum, como interfaces de compra e consulta fáceis de operar e intuitivas, têm o potencial de aumentar a confiança do consumidor nos serviços oferecidos por um site ou aplicativo novo e desconhecido.

Por fim, os resultados também apontam para as deficiências na qualidade dos serviços e dispositivos móveis de compras oferecidos que poderiam afetar negativamente o procedimento de compra por criar a percepção de falta de competência e excesso de esforço envolvido no processo. É o caso de pouca responsividade de um site à sua visualização em dispositivos móveis ou demora no acesso aos serviços disponíveis no site ou aplicativo. o que poderia reduzir sua relevância para o consumidor.

\section{3 \\ Limitações do Estudo}

A amostragem por snowballing tende a gerar vieses de comunidade e base, uma vez que pode não cobrir adequadamente a população desejada ou pode seguir uma tendência comportamental presente na rede de relacionamentos acessada. Por outro lado, o propósito do estudo é testar a estrutura de relações entre as variáveis propostas e não a validade externa dos resultados, portanto, a representatividade da amostra não precisa ser vista como uma limitação neste caso.

Como este estudo se baseia em um questionário conceitual, e não em um com base numa experiência específica, é possível que em muitos resultados os respondentes não tenham conseguido associar os conceitos apresentados a uma experiência real anterior. Apesar de ter sido requisitada a escolha de um produto 
específico, as experiências pessoais de cada um com o produto selecionado podem ter caído em escalas de aquisição e uso diferentes de um respondente para o outro. Isso poderia afetar o impacto de construtos relacionados ao uso da tecnologia ou a formação da confiança, gerando algumas das relações inesperadas encontradas neste estudo.

Quanto a metodologia de análise, é possível que o estudo apresente erros de estimação na modelagem realizada, particularmente porque a premissa de normalidade multivariada dos dados foi violada, apesar de Olsson et al. (2000) afirmarem que a estimação por máxima verossimilhança fornece resultados confiáveis e estáveis mesmo para dados não-normais.

\section{4}

\section{Sugestões para Pesquisas Futuras}

Dadas as limitações apresentadas por este estudo, a primeira sugestão para pesquisas futuras seria a realização de estudos similares com uma amostra maior com perfil diferente daquele aqui apresentado.

Seria interessante verificar, possivelmente por meio de um experimento controlado, se o uso de um serviço ou serviços móveis específicos (marcas) influenciaria as relações testadas. Também seria interessante checar se as motivações, sejam elas hedônicas ou utilitárias, afetam as percepções das qualidades dos dispositivos móveis e seus impactos na confiança e na intenção de comprar do consumidor. Efeitos moderadores oriundos de outras variáveis, demográficas por exemplo, poderiam ser também investigados.

Questões relativas à segurança e a qualidade dos serviços e sites de compras via dispositivos móveis, assim como das empresas responsáveis pelo serviço de telefonia móvel, parecem ser particularmente relevantes ao contexto e sua influência na formação da confiança móvel deveria ser avaliada.

Por fim, o panorama mundial de incerteza e insegurança e o comportamento online dos indivíduos e instituições trazem diversas possibilidades para o estudo da confiança, inclusive questões relacionais, oportunismo e desconfiança. A inclusão de construtos que representem essa desconfiança relacionada a integridade e 
credibilidade poderia trazer mais profundidade para a discussão sobre o uso de dispositivos e aplicativos móveis na compra de produtos e serviços. 


\section{6 Referências bibliográficas}

ABNT. NBR6023:2002 Informação e documentação - Referências Elaboração. Disponível em: http://www.habitus.ifcs.ufrj.br/pdf/abntnbr6023.pdf. Acesso em 30/08/13.

AJZEN, I. The theory of planned behavior. Organizational Behavior and human decision processes, v. 50, p. 179-211, 1991.

AJZEN, I.; MADDEN, T. J. Prediction of goal-directed behavior: Attitudes, intentions, and perceived behavioral control. Journal of Experimental Social Psychology, v. 22, p. 453-474, 1986.

ALBAUM, G.; ROSTER, C. A.; WILEY, J.; ROSSITER, J.; SMITH, S. M. Designing Web surveys in Marketing research: Does use of forced answering affect completion rates?. Journal of marketing theory and practice, v. 18, n. 3, p. 285294, 2010.

AL-JABRI, I. M.; SOHAIL, M. S. Mobile bamking adoption: Application of diffusion of innovation theory. Journal of Electronic Commerce Research, v. 13, n. 4 , p. $379-391,2012$.

ANDERSON, J. C.; GERBING, D.W. Structural equation modeling in practice: A review and recommended two-step approach. Psychological Bulletin, v. 103, p. 411-23, 1988.

ANG, S. H.; LIM, E. A. The Influence of Metaphors and Product Type on Brand Personality Perceptions and Attitude. Journal of Advertising, v. 35, n. 2, p. 39-53, 2006.

ARNOLD, M. J.; REYNOLDS, K. E. Hedonic shopping motivations. Journal of Retailing, v. 79, n. 2, p. 77-95, 2003.

BABBIE, E. Survey Research Methods. Belmont, CA: Wadsworth, 1990. 
BABIN, B. J.; DARDEN, W. R.; GRIFFIN, M. Work and/or fun: Measuring hedonic and utilitarian shopping value. Journal of Consumer Research, v. 20, p. 644-656, 1994.

BAGOZZI, R. P.; PHILLIPS, L. Representing and Testing Organizational Theories: A Holistic Construal. Administrative Science Quarterly, v. 17, p. 459489, 1982.

BALLESTER, E. D.; ESPALLARDO, M. H. Effect of brand associations on consumer reactions to unknown on-line brands. International Journal of Electronic Commerce, v. 12, n. 3, p. 88-113, 2008.

BART, Y.; SHANKAR, V.; SULTAN, F.; URBAN, G. L. Are the drivers and role of online trust the same for all web sites and consumers? A large-scale exploratory empirical study. Journal of Marketing, v. 69, p. 133-152, 2005.

BARDHI, F.; ROHM, A. J.; SULTAN, F. Tuning in and tuning out: Media multitasking practices and experiences among Generation Y consumers. Journal of Consumer Behaviour, v. 9, p. 316-332, 2010.

BELDAD, A.; DE JONG, M.; STEEHOUDER, M. How shall I trust the faceless and the intangible? A literature review on the antecedents of online trust. Computers in Human Behavior, v. 26, n. 5, p. 857-869, 2010.

BENTLER, P. M. Comparative Fit Indexes in Structural Models. Psychological Bulletin, v. 107, n. 2, p. 238-246, 1990.

BINET, L.; FIELD, P. Marketing in the Era of Accountability. World Advertising Research Center:UK, 2007.

BINET, L.; FIELD, P. The long and the short of it: Balancing short and long-term marketing strategies. Institute of Practitioners in Advertising, 2013. Disponível em: https://barbanouille.files.wordpress.com/2016/07/the_long_and_short_of_it_pdf_ doc.pdf

BONE, P. F. Word-of-mouth effects on short-term and long-term product judgments. Journal of Business Research, v. 32, n. 3, p. 213-223, 1995. 
BOYD, J. The rhetorical construction of trust online. Communication Theory, v. 13, n. 4, p. 392-410, 2003.

BRADLEY, C.; TODD, C.; GORTON, T.; SYMONDS, E.; MARTIN, A.; PLOWRIGHT, R. The development of an individualized questionnaire measure of perceived impact of diabetes on quality of life: the ADDQoL. Quality of Life Research, v. 8, p. 79-91, 1999.

BROWNE, K. Snowball Sampling: Using Social Networks to research nonhetrosexual women. International journal of social Research Methodology, v. 8, n. 1, p. 47-60, 2005.

BRUNER, G. C. II; KUMAR, A. Explaining consumer acceptance of handheld internet devices. Journal of Business Research, v. 58, p. 553-558, 2005.

BYRNE, B. M. Structural Equation Modeling with AMOS: Basic Concepts, Applications and Programming. 2a ed. Routledge, NY, 2010.

CALLEGARO, M.; MANFREDA, K. L.; VEHOVAR, V. Web survey methodology. Sage, 2015.

CAMPONOVO, G.; PIGNEUR, Y.; RANGONE, A.; RENGA, F. Mobile customer relationship management: an explorative investigation of the italian consumer market, Proceedings of the 4th International Conference on Mobile Business (ICMB 2005), Sydney, IEEE Computer Society, Los Alamitos, CA, p. 42-48, 2005.

CHAUDHURI, A. (2002). A study of emotion and reason in products and services. Journal of Consumer Behavior, v. 1, n. 3, p. 138-143, 2002.

CHE, J. W. S.; CHEUNG, C. M. K.; THADANI, D. R. Consumer Purchase Decision in Instagram Stores: The Role of Consumer Trust. Proceedings of the 50 $^{\text {th }}$ Hawaii International Conference on System Sciences, p. 24-33, 2017.

CHEN, H. The influence of perceived value and trust on online buying intention. Journal of Computers, v. 7, n.7, p. 1655-1662, 2012.

CHEN, S. C.; DHILLON, G. S. Interpreting dimensions of consumer trust in ecommerce. Information Technology and Management, v. 4, n. 2-3, p. 303-318, 2003. 
CHEN, G.; KOTZ, D. A survey of context-aware mobile computing research, Dartmouth Computer Science Technical Report, TR2000-381, 2000.

CHEN, Y.; WANG, Q.; XIE, J. Online social interactions: A natural experiment on word of mouth versus observational learning. Journal of marketing research, v. 48, n. 2, p. 238-254, 2011.

CHEONG, J. H.; PARK, M. Mobile internet acceptance in Korea. Internet Research, v. 15, n. 2, p. 125-140, 2005.

CHEUNG, C. M.; XIAO, B. S.; LIU, I. L. Do actions speak louder than voices? The signaling role of social information cues in influencing consumer purchase decisions. Decision Support Systems, v. 65, p. 50-58, 2014.

CHILDERS, T. L.; CARR, C. L.; PECK, J.; CARSON, S. Hedonic and utilitarian motivation for online retail shopping behavior. Journal of Retailing, v. 77, p. 511$535,2001$.

CHUNG, J.; TAN, F. B. Antecedents of perceived playfulness: An exploratory study on user acceptance of general information-searching websites. Information \& Management, v. 41, n. 7, p. 869-881, 2004.

CHURCHILL, G. A. A Paradigm for Developing Better Measures of Marketing Constructs. Journal of Marketing, v. 16, p. 64-73, 1979.

CHURCHILL, G. A.; IACOBUCCI, D. Marketing Research: Methodological Foundations. 10a ed., South-Western College Pub, 2009.

CLARK, D. Why does half the world distrust government? Voices, 2016. Disponível em: https://blogs.worldbank.org/voices/why-does-half-world-distrustgovernment

COHEN, R. The Age of Distrust. The New York Times, setembro, 2016. Disponível em: https://www.nytimes.com/2016/09/20/opinion/the-age-ofdistrust.html

NANCY, J. Major changes in European public opinion regarding the European Union: Exploratory study. European Parliament Research Service, nevembro, 2016. Disponível em: 
COHEN, J. B.; BASU, K. Alternative models of categorization: towards a contingent processing framework. Journal of Consumer Research, v. 13, n. 4, p. 455-472, 1987.

CORBITT, B. J., THANASANKIT, T., YI, H. Trust and e-commerce: a study of consumer perceptions. Electronic Commerce Research and Applications, v. 2, p. 203-215, 2003.

CRESWELL, J. W. Research design: Qualitative, quantitative, and mixed methods approaches. Sage, Kindle Edition, 2009.

DAVIS, F. D.; BAGOZZI, R. P.; WARSHAW P. R. Extrinsic and intrinsic motivation to user computers in the workplace. Journal of Applied Social Psychology, v. 22, p. 1111-1132, 1992.

DAVIS, F. D. Perceived usefulness, perceived ease of use, and user acceptance of information technology. MIS Quaterly, v. 13, n.3, p. 319-340, 1989.

DEEGAN, J. JR. On the Occurrence of Standardized Regression Coefficients Greater Than One. Educational and Psychological Measurement, v. 38, n. 4, p. 873-888, 1978.

DIMITRIADIS, S.; KYREZIS, N. Linking Trust to Use Intention for Technologyenabled bank channels: The Role of Trusting Intentions. Psychology \& Marketing, v. 27, n. 8 , p. $799-820,2010$.

DONEY, P. M.; CANNON, J. P.; MULLEN, M. R. Understanding the influence of national culture on the development of trust. Academy of Management Review, v. 23, n. 3, p. 601-620, 1998.

EBIT. Webshoppers. $36^{\mathrm{a}}$ Ed., 2017. Disponível em: https://www.ebit.com.br/webshoppers

FANG, H.; GUO, G.; ZHANG, J. Multi-faceted trust and distrust prediction for recommender systems. Decision Support Systems, v. 71, p. 37-47, 2015.

FARMER, T. Using the Internet for primary research data collection. Market Research Library, 1998. 
FAQIH, K. M.; JARADAT, M. I. R. M. Assessing the moderating effect of gender differences and individualism-collectivism at individual-level on the adoption of mobile commerce technology: TAM3 perspective. Journal of Retailing and Consumer Services, v. 22, p. 37-52, 2015.

FENG, X.; FU, S.; QIN, J. Determinants of consumers' attitudes toward mobile advertising: The mediating roles of intrinsic and extrinsic motivations. Computers in Human Behavior, v, 63, p. 334-341, 2016.

FERREIRA, J. B.; ROCHA, A; SILVA, J. F. Impacts of Technology Readiness on Emotions and Cognition in Brazil. Journal of Business Research, 2013, 9p. In Press. Disponível em: http://dx.doi.org/10.1016/j.jbusres.2013.07.005

FERREIRA, J. B.; SILVA, J. F.; GIOVANNINI, C. J.; RAMOS, F. L. Fatores que afetam a adoção da internet móvel. Pretexto, v. 17, n. 4, p. 47-64, 2016.

FIGGE, S. Situation-dependent services-a challenge for mobile network operators, Journal of Business Research, v. 57, p. 1416-1422, 2004.

FINK, A. How to conduct surveys: A step-by-step guide. Sage Publications, 2012. FISHBEIN, M.; AJZEN, I. Beliefs, attitude, intention and behavior: An introduction to theory and research. Reading: Addison-Wesley, 1975.

FLANAGIN, A. J.; METZGER, M. J.; PURE, R., MARKOV, A.; HARTSELL, E. Mitigating risk in ecommerce transactions: perceptions of information credibility and the role of user-generated ratings in product quality and purchase intention. Electronic Commerce Research, v. 14, n. 1, p. 1-23, 2014.

FORNELL, C.; LARCKER, D. F. Evaluating Structural Equation Models with Unobservable Variables and Measurement Error. Journal of Marketing Research, v. 18, fevereiro, p.39-50, 1981.

GAO, T.; ROHM, A. J.; SULTAN, F.; HUANG, S. Antecedents of Consumer Attitudes Toward Mobile Marketing: A Comparative Study of Youth Markets in the United States and China. Thunderbird International Business Review, v. 54, n. 2, p. 211-224, 2012. 
GARBARINO, E.; JOHNSON, M. S. The different roles of satisfaction, trust, and commitment in customer relationships. Journal of Marketing, v. 63, n. 2, p. 7087, 1999.

GARDNER, M. J.; ALTMAN, D. G. Confidence intervals rather than p values: estimation rather than hypothesis testing. British Medical Journal, v. 292, n. 6522, p. 746-750, 1986.

GARVER, M. S.; MENTZER, J. T. Logistics Research Methods: Employing Structural Equation Modeling to Test for Construct Validity. Journal of Business Logistics, v. 20, p. 33-57, 1999.

GEFEN, D. E-commerce: the role of familiarity and trust. Omega, v. 28, n. 6, p. 725-737, 2000.

GEFEN, D.; KARAHANNA, E.; STRAUB, D. W. Trust and TAM in online shopping: an integrated model. MIS Quaterly, v. 27, n. 1, p. 51-90, 2003.

GIOVANNINI, C. J.; FERREIRA, J. B.; SILVA, J. F.; FERREIRA, D. B. The effects of trust transference, mobile attributes and enjoyment on mobile trust. BARBrazilian Administration Review, v. 12, n. 1, p. 88-108, 2015.

GOLDSTEIN, H.; HEALY, M. J. R. The graphical presentation of a collection of means. Journal of the Royal Statistical Society, v. 158, n. 1, p. 175-177, 1995.

GOODMAN, L. A. Snowball Sampling. Annals of Mathematical Statistics, v. 32, n. 1, p. 148-170, 1961.

GRABNER-KRAEUTER, S. The role of consumers' trust in online-shopping. Journal of Business Ethics, v. 39, n. 1/2, p. 43-50, 2002.

HAIR, J. F.; BLACK, W. C.; BABIN, B. J.; ANDERSON, R. E. Multivariate Data Analysis,. 7a ed., Upper Saddle River: Prentice-Hall, 2009.

HAHN, K. H.; KIM, J. The effect of offline brand trust and perceived internet confidence on online shopping intention in the integrated multi-channel context. International Journal of Retail \& Distribution Management, v. 37, n. 2, p. 126$141,2009$. 
HASSANEIN, K.; HEAD, M. The impact of infusing social presence in the web interface: An investigation across product types. International Journal of Electronic Commerce, v. 10, n. 2, p. 31-55, 2005.

HIRSCHMAN, E.; HOLBROOK, M. Hedonic consumption: Emerging concepts, methods and propositions. Journal of Marketing, v. 46, p. 92-101, 1982.

HOFFMAN, D. L.; NOVAK, T. P.; PERALTA, M. Building consumer trust online. Communications of the ACM, v. 42, n. 4, p. 80-85, 1999.

HOLBROOK, M.; HIRSCHMAN, E. The Experimental Aspects of Consumption: Consumer fantasies, feelings and fun. Journal of Consumer Research, v. 9, n. 2, p. 132-140, 1984.

HOOPER, D.; COUGHLAN, J.; MULLEN, M. R. Structural Equation Modelling: Guidelines for Determining Model Fit. The Electronic Journal of Business Research Methods, v. 6, n. 1, p. 53 - 60, 2008.

HSIEH, Y; CHIU, H; CHIANG, M. Maintaining a committed online customer: a study across search-experience-credence products. Journal of Retailing, v. 81, n. 1, p. 75-82, 2005.

HU, L. T.; BENTLER, P. M. Cutoff Criteria for Fit Indexes in Covariance Structure Analysis: Conventional Criteria Versus New Alternatives. Structural Equation Modeling, v. 6, n. 1, p. 1-55, 1999.

HUANG, P.; LURIE, N. H.; MITRA, S. Searching for experience on the web: an empirical examination of consumer behavior for search and experience goods. Journal of marketing, 73(2), 55-69, 2009.

HWANG, Y.; KIM, D. J. Customer Self-Service Systems: The effects of perceived Web quality with service contents on enjoyment, anxiety and e-Trust. Decision Support Systems, v. 43, p. 746-760, 2007.

JOUBERT, J.; VAN BELLE, J. The role of trust and risk in mobile commerce adoption within South Africa. International Journal of Business, Humanities and Technology, v. 3, n. 2, p. 27-38, 2013. 
IPSOS. Global Trends: fragmentation, cohesion \& uncertainty. Ipsos, 2017. Disponível em: https://www.ipsos.com/sites/default/files/201707/Ipsos\%20Global\%20Trends\%202017\%20report.pdf

JÖRESKOG, K. G. How Large Can a Standardized Coefficient be? June 22, 1999. Disponível em:

http://www.ssicentral.com/lisrel/techdocs/HowLargeCanaStandardizedCoefficient be.pdf

JÖRESKOG, K.; SÖRBOM, D. LISREL 8: Structural Equation Modeling with the SIMPLIS Command Language. Chicago, IL: Scientific Software International Inc, 1993.

KENNY, D. A.; MCCOACH, D. B. Effect of the Number of Variables on Measures of Fit in Structural Equation Modeling. Structural Equation Modeling, v. 10, n. 3, p. 333-351, 2003.

KHALIFA, M.; SHEN, K. N. Explaining the adoption of transactional B2C mobile commerce. Journal of Enterprise Information Management, v. 21, n. 2, p. 110 $124,2008$.

KIM, C.; MIRUSMONOV, M.; LEE, I. An empirical examination of factors influencing the intention to use mobile payment. Computers in Human Behavior, v. 26, n. 3, p. 310-322, 2010.

KIM, D. J.; FERRIM, D. L.; RAO, H. R. Trust and Satisfaction, two Stepping Stones for Successful e-Commerce Relationships: A Longitudinal Exploration. Information Systems Research, v. 20, n. 2, p. 237-257, 2008.

KIM, H.; KIM, J.; LEE, Y.; CHAE, M.; CHOI, Y. An empirical study of the use contexts and usability problems in mobile internet, Proceedings of the 35th Hawaii International Conference on System Sciences, 2002.

KIM, S. S.; MALHOTRA, N. K.; NARASIMHAN, S. Research note-two competing perspectives on automatic use: A theoretical and empirical comparison. Information Systems Research, v. 16, n. 4, p. 418-432, 2005. 
KIM, Y.; PETERSON, R. A. A Meta-analysis of Online Trust Relationships in Ecommerce. Journal of Interactive Marketing, v. 38, p. 44-54, 2017.

KING, M. F.; BALASUBRAMANIAN, S. K. The Effects of Expertise, End Goal, and Product Type on Adoption of Preference Formation Strategy. Journal of Academy of Marketing Science, v. 22, n. 2, p. 146-159, 1994.

KLINE, R.B. Principles and Practice of Structural Equation Modeling (2a ed.). New York: The Guilford Press, 2005.

KOLLER, M. Risk as a determinant of trust. Basic and Applied Social Psychology, v. 9, n. 4, p. 265-276, 1988.

KROSNICK, J. A. Survey research. Annual review of psychology, v. 50, n. 1, p. 537-567, 1999.

KRISHNAN, B. C.; HARTLINE, M. D. Brand equity: is it more important in services?. Journal of services marketing, v. 15, n. 5, p. 328-342, 2001.

KUAN, H..; BOCK, G. Trust transference in brick and click retailers: An investigation of the before-online-visit phase. Information \& Management, v. 44, n. 2, p. 175-187, 2007.

KULVIWAT, S.; BRUNER II, G. C.; KUMAR, A.; NASCO, S. A.; CLARK, T. Toward a Unified Theory of Consumer Acceptance Technology. Psychology \& Marketing, v. 24, n. 12, p. 1059-1084, 2007.

KUKULSKA-HULME, A.; SHARPLES, M.; MILRAD, M.; ARNEDILLOSANCHEZ, I.; VAVOULA, G. The genesis and development of mobile learning in Europe. In D. Parsons (Ed.), Combining E-Learning and M-Learning: New Applications of Blended Educational Resources, p. 151-177. Hershey, PA: IGI Global, 2011.

LANKTON, N. K.; MCKNIGHT, D. H. What does it mean to trust Facebook?: examining technology and interpersonal trust beliefs. ACM SIGMIS Database: The DATABASE for Advances in Information Systems, v. 42, n. 2, p. 32-54, 2011. 
LEE, H-H., FIORE, A. M., KIM, J. The role of the technology acceptance model in explaining effects of image interactivity technology on consumer responses. International Journal of Retail \& Distribution Management, v. 34, n. 8, p. 621644, 2006.

LEE, T-M; JUN, J-K. Contextual perceived value? Investigating the role of contextual marketing for customer relationship management in a mobile commerce context. Business Process Management Journal, v. 13, n. 6, p. 798-814, 2007.

LEE, K. C., KANG, I.; MCKNIGHT, D. H. Transfer from offline trust to key online perceptions: an empirical study. IEEE Transactions on Engineering Management, v. 54, n. 4, p. 729-741, 2007.

LEE, T. The impact of perceptions of interactivity on customer trust and transaction intentions in mobile commerce. Journal of Electronic Commerce Research, v. 6, n. 3, p. 165-181, 2005.

LEE, M. S. Y.; MCGOLDRICK, P. J.; KEELING, K. A.; DOHERTY, J. Using ZMET to explore barriers to the adoption of $3 \mathrm{G}$ mobile banking services. International Journal of Retail \& Distribution Management, v. 31, n. 6, p. 340$348,2003$.

LEE, M. K. O.; TURBAN, E. A trust model for consumer internet shopping. International Journal of Electronic Commerce, v. 6, n. 1, p. 75-91, 2001.

LETH-STEENSEN, C.; GALliTO, E. Testing Mediation in Structural Equation Modeling. Educational and Psychological Measurement, v. 76, n. 2, p. 339-351, 2015.

DE LEEUW, E. D.; HOX, J.; DILLMAN, D. International handbook of survey methodology. Routledge, 2012

LI, Y. M.; YEH, Y. S. Increasing trust in mobile commerce through design aesthetics. Computers in Human Behavior, v. 26, n. 4, p. 673-684, 2010.

LI, M.; DONG, Z.Y.; CHEN, X. Factors influencing consumption experience of mobile commerce: A study from experiential view. Internet Research, v. 22, n. 2, p. 120-141, 2012. 
LIAO, Z.; CHEUNG, M. T. Internet-based e-banking and consumer attitudes: an empirical study. Information \& Management, v. 39, n. 4, p. 283-295, 2002.

LIÉBANA-CABANILLAS, F.; SÁNCHEZ-FERNÁNDEZ, J.; MUÑOZ-LEIVA, F. Antecedents of the adoption of the new mobile payment systems: The moderating effect of age. Computers in Human Behavior, v. 35, p. 464-478, 2014.

LIN, J.; LU, Y.; WANG, B.; WEI, K. K. The role of inter-channel trust transfer in establishing mobile commerce trust. Electronic Commerce Research and Applications, v. 10, p. 615-625, 2011.

LU, L.; CHANG, W.; CHANG, H. Consumer attitudes toward blogger's sponsored recommendations and purchase intention: The effect of sponsorship type, product type, and brand awareness. Computers in Human Behavior, v. 34, p. 258-266, 2014.

LU, Y.; YANG, S.; CHAU, P. Y. K.; CAO, Y. Dynamics between the trust transfer process and intention to use mobile payment services: a cross-environment perspective. Information \& Management, v. 48, p. 393-403, 2011.

LYYTINEN, K.; YOO, Y. The next wave of nomadic computing. Information Systems Research, v. 13, n. 4, p. 377-388, 2002.

MACKINNON, D. P.; LOCKWOOD, C. M.; WILLIAMS, J. Confidence Limits for the Indirect Effect: Distribution of the Product and Resampling Methods. Multivariate Behavior Research, v. 39, n. 1, p. 99-128, 2004.

MAUTE, M. F.; FORRESTER, W. R. The effect of attribute qualities on consumer decision making: a causal model of external information search. Journal of Economic Psychology, v. 12, p. 643-666, 1991.

MAYER, R. C.; DAVIS, J. H.; SCHOORMAN, F. D. An integrative model of organization trust. Academy of Management Review, v. 20, n. 3, p. 709-734, 1995.

MAITY, M.; DASS, M. Consumer decision-making across modern and traditional channels: E-commerce, m-commerce, in-store. Decision Support Systems, v. 61, p. 34-46, 2014. 
MCDONALD, R. P.; HO, M.-H. R. Principles and Practice in Reporting Statistical Equation Analyses. Psychological Methods, v. 7, n. 1, p. 64-82, 2002.

MCINTOSH, C. Rethinking fit assessment in structural equation modelling: A commentary and elaboration on Barrett. Personality and Individual Differences, v. 42, n. 5, p. 859-67, 2006.

MCKNIGHT, D. H.; CHOUDHURY, V.; KACMAR, C. Developing and Validating Trust Measures for e-Commerce: An integrative typology. Information Systems Research, v. 13, n. 3, p. 334-359, 2002.

MCKNIGHT, D. H.; CUMMINGS, L. L.; CHERVANY, N. L. Initial trust formation in new organizational relationship. Academy of Management Review, v. 23, n. 3, p. 473-490, 1998.

METZGER, M. J. Effects of Site, Vendor, and Consumer Characteristics on Web Site Trust and Disclosure. Communication Research, v. 33, n. 3, p. 155-179, 2006. MIGUENS, M. J. L.; VÁZQUEZ, E. G.; TURNES, P. B. (2014). Multilevel and multidimensional scale for online trust. Revista de Administração de Empresas, v. 54, n. 2, p. 187-200, 2014.

MILLER, J. Online Marketing Research. In GROVER, R.; VRIENS, M. (ed) The Handbook of Marketing Research. Thousand Oaks: CA, p. 110-131, 2006.

MOON, J.-W.; KIM, Y.-G. Extending the TAM for World-Wide-Web context. Information \& Management, v. 38, p. 217-230, 2001.

MOORMAN, C.; DESHPANDÉ, R.; ZALTMAN, G. Factors Affecting Trust in Market Research Relationships. Journal of Marketing, v. 57, p. 81-101, 1993.

MOORE, G. C.; BENBASAT, I. Development of an Instrument to Measure the Perceptions of Adopting an Information Technology Innovation. Information Systems Research, v. 2, n. 3, p. 192-222, 1991.

MORGAN, D. L. The SAGE Encyclopedia of Qualitative Research Methods. SAGE Publications, 2008. 
MORGAN, R. M.; HUNT, S. D. The Commitment-Trust Theory of Relationship Marketing. Journal of Marketing, v. 58, p. 20-38, 1994.

MUDAMBI, S. M.; SCHUFF, D. What Makes a Helpful Online Review? A Study of Customer Reviews on Amazon.com. MIS Quarterly, v. 34, n. 1, p. 185-200, 2010.

NASCO, S. N.; KULVIWAT, S.; KUMAR, A.; BRUNER II, G. C. The CAT model: Extensions and Moderators of Dominance in Technology Acceptance. Psychology \& Marketing, v. 25, n. 10, p. 987-1005, 2008.

NELSON, P. Advertising as information. Journal of Political Economy, v. 82, n. 4, p. 729-754, 1974.

NELSON, P. Information and Consumer Behavior. Journal of Political Economy, v. 78 , n. 3, p. 311-329, 1970.

NILASHI, M., IBRAHIM, O., MIRABI, V. R.; EBRAHIMI, L.; ZARE, M. The role of Security, Design and Content factors on customer trust in mobile commerce. Journal of Retailing and Consumer Services, v. 26, p. 57-69, 2015.

NOY, C. Sampling Knowledge: the hermeneutics of Snowball Sampling in Qualitative Research. International Journal of Social Research Methodology, v. 11, n. 4, p. 327-344, 2008.

NUnNally, J.; BERnSteIn, I. Psychometric Theory. 3a ed., McGraw-Hill Humanities/Social Sciences/Languages, 1994.

NYSVEEN, H.; PEDERSEN, P.; THORBJØRNSEN, H. Intentions to use mobile services: antecedents and cross-service comparisons. Journal of the Academy of Marketing Science, v. 33, n. 3, p. 330-346, 2005.

OH, S.; KIM, Y.; LEE, C.; SHIM, G.; PARK, M.; JUNG, H. Consumer Adoption of Virtual Stores in Korea: Focusing on the Role of Trust and Playfulness. Psychology \& Marketing, v. 26, n. 7, p. 652-668, 2009.

OLIVEIRA, T.; ALHINHO, M.; RITA, P.; DHILLON, G. Modelling and testing consumer trust dimensions in e-commerce. Computers in Human Behavior, v. 71, p, 153-164, 2017. 
OLSSON, U. H.; FOSS, T.; TROYE, S. V.; HOWELL, R. D. The performance of ML, GLS and WLS Estimation in Structural Equation Modeling Under Conditions of Misspecification and Non-normality. Structural Equation Modeling, v. 7, n. 4, pp. 557-595, 2000.

ROGERS, E. M. The diffusion of innovation. New York: Free Press, 2003.

PAIVA, F. Panorama Mobile Time/Opinion Box - Comércio Móvel no Brasil.

Outubro, 2016.2 Disponível em:

http://pesquisasmobiletime.com.br/pdf/Panorama_m-commerce_OUT2016-

FINAL.pdf

PARASURAMAN, A.; GREWAL, D.; KRISHNAN, R. Marketing Research. 2. ed., South-Western College Pub, 2006.

PARK, C.; LEE, T. M. Information direction, website reputation and eWOM effect: A moderating role of product type. Journal of Business Research, v. 62, p. 61-67, 2009.

PARK, C.; MOON, B. The relationship between Product Involvement and Product Knowledge: Moderating roles of Product Type and Product Knowledge Type. Psychology \& Marketing, v. 20, n. 11, p. 977-997, 2003.

PEPPERS, D.; ROGERS, M. Managing customers relationships: a strategic framework. New Jersey: Wiley, 2011.

PERKS, H.; HALLIDAY, S. V. Sources, signs and signaling for fast trust creation in organizational relationships. European Management Journal, v. 21, n. 3, p. 338-350, 2003.

PAVLOU, P. A.; FYGENSON, M. Understanding and Predicting Electronic Commerce Adoption: An Extension of the Theory of Planned Behavior. MIS Quarterly, v. 30, n. 1, p. 115-143, 2006.

PINA, F.; KURTZ, R.; FERREIRA, J. B.; FREITAS, A.; SILVA, J. F. D.; GIOVANNINI, C. J. M-LEARNING ADOPTION IN HIGHER EDUCATION: THE PROFESSOR'S POINT OF VIEW. REAd. Revista Eletrônica de Administração (Porto Alegre), v. 22, n. 2, p. 279-306, 2016. 
PINSONNEAULT, A.; KRAEMER, K. Survey research methodology in management information systems: an assessment. Journal of management information systems, v. 10, n. 2, p. 75-105, 1993.

PREACHER, K. J.; SELIG, J. Advantages of Monte Carlo Confidence Intervals for Indirect Effects. Communication Methods and Measures, v. 6, p. 77-98, 2012.

PUC-RIO. Pós-Graduação PUC-Rio: normas para apresentação de teses e dissertações / Pontifícia Universidade Católica do Rio de Janeiro; [supervisão: Bergmann, J. R.; organização e redação: Souza, A. G.] Rio de Janeiro: PUC-Rio, Vice-Reitoria para Assuntos Acadêmicos, 2001.

RAINIE, L.; ANDERSON, J. The Fate of Online Trust in the Next Decade. Trust, Facts and Democracy. Pew Research Center, Agosto, 2017. Disponível em: http://www.pewinternet.org/2017/08/10/the-fate-of-online-trust-in-the-nextdecade/

ROSANVALlON, P. Counter-Democracy: politics in a age of distrust. Cambridge University Press, 2008.

ROSSEAU, D. M.; SITKIN, S. B.; BURT, R. S.; CAMERER, C. Not so different after all: Across-discipline view of trust. Academy of Management Review, v. 23, n. 3, p. 393-404, 1998.

SCHNEIDER, C. E. Family Law in the Age of Distrust. Family Law Quarterly, v. 33, n. 3, p. 447-460, 1999.

SCHREIBER, J. B.; STAGE, F. K.; KING, J.; NORA, A.; BARLOW, E. A. Reporting Structural Equation Modeling and Confirmatory Factor Analysis Results: A Review. Journal of Educational Research, v. 99, p. 323-337, 2006.

SHANKAR, V.; BALASUBRAMANIAN, S. Mobile Marketing: synthesis and prognosis. Journal of Interactive Marketing, v. 23, n. 2, p. 118-129, 2008.

SHANKAR, V.; VENKATESH, A.; HOFACKER, C.; NAIK, P. Mobile Marketing in the Retailing Environment: Current Insights and Future Research Avenues. Journal of Interactive Marketing, v. 24, n. 2, p. 111-120, 2010. 
SHANKAR, V.; URBAN, G. L.; SULTAN, F. Online trust: A stakeholder perspective, concepts, implications, and future directions. Journal of Strategic Information Systems, v. 11, p. 325-344, 2002.

SHARIF, M. S.; SHAO, B.; XIAO, F.; SAIF, M. K. The impact of psychological factors on consumers trust in adoption of $\mathrm{m}$-commerce. International Business Research, v. 7, n. 5, p. 148-155, 2014.

SIAU, K.; SHENG, H.; HOON, F. F.; DAVIS, S. A. A qualitative investigation on consumer trust in mobile commerce. International Journal of Electronic Business, v. 2, n. 3, p. 283-300, 2004.

SIAU, K.; SHEN, Z. Building customer trust in mobile commerce. Communications of the ACM, v. 46, n. 4, p. 91-94, 2003.

SIAU, K.; LIM, E. P.; SHEN, Z. Mobile commerce: promises, challenges, and research agenda. Journal of Database Management, v. 12, n. 3, p. 4-14, 2001.

SIAU, K.; LIM, E.; SHEN, Z. Mobile commerce: current states and future trends", In: Lim, E.; Siau, K. (Eds), Advances in Mobile Commerce Technologies, p. 118. Pennsylvania: Idea Group Pub, 2003.

SOBEL, M. E. Asymptotic Confidence Intervals for Indirect Effects in Structural Equation Modeling. Sociological Methodology, v. 13, p. 290-312, 1982.

SØRENSEN, C.; AL-TAITOON, A.; KIETZMANN, J.; PICA, D.; WIREDU, G.; ELALUF-CALDERWOOD, S.; BOATENG, K.; KAKIHARA M.; GIBSON, D. Exploring enterprise mobility: Lessons from the field. Information Knowledge Systems Management, v. 7, n. 1, p. 243-271, 2008.

SPERBER, A. D. Translation and validation of study instrument for cross-cultural research. Gastroenterology, v. 126, n. 1, p. 124-128, 2004.

STEIGER, J. H.; LIND, J. C. Statistically based tests for the number of common factors. annual meeting of the Psychometric Society, Iowa City, IA. v. 758, 1980.

STEIGER, J. H. A note on multiple sample extensions of the RMSEA fit index. Structural Equation modeling: A Multidisciplinary Journal, v. 5, n. 4, p. 411419, 1998. 
STEWART, K. J. How hypertext links influence consumer perceptions to build and degrade trust online. Journal of Management Information Systems, v. 23, n. 1, p. 183-210, 2006.

STEWART, K. J. Trust transfer on the world wide web. Organization Science, v. 14, n. 1, p. 5-17, 2003.

TENNANT, A.; PALLANT, J. F. The root mean square error of approximation (RMSEA) as a supplementary statistic to determine fit to the Rasch Model with large sample sizes. Rasch Measurement Transactions, v. 25, n. 4, p. 1348-1349, 2012.

TYRON, W. W. Evaluating statistical difference, equivalence, and indeterminacy using inferential confidence intervals: An integrated alternative method of conducting null hypothesis statistical tests. Psychological Methods, v. 6, n. 4, p. 371-386, 2001.

URBAN, G. L.; AMYX, C.; LORENZON, A. Online Trust: State of the Art, New Frontiers, and Research Potential. Journal of Interactive Marketing, v. 23, n. 2, 179-190, 2009.

VARNALI, K.; TOKER, A. Mobile marketing research: The-state-of-the-art. International Journal of Information Management, v. 30, n. 2, p. 144-151, 2010.

VENKATESH, V.; DAVIS, F. D. A Theoretical extension of the technology acceptance model: Four longitudinal Field studies. Management Science, v. 46, n. 2, p. 186-204, 2000.

WANG, R. J. H.; MALTHOUSE, E. C.; KRISHNAMURTHI, L. On the go: How mobile shopping affects customer purchase behavior. Journal of Retailing, v. 91, n. 2, p. 217-234, 2015.

WANG, H; WANG, S. User acceptance of mobile internet based on the unified theory of acceptance and use of technology: investigating the determinants and gender differences. Social behavior and Personality, v. 38, n. 3, p. 415-426, 2010. 
WEATHERS, D.; SHARMA, S.; WOOD, S. L. Effects of online communication practices on consumer perceptions of performance uncertainty for search and experience goods. Journal of retailing, v. 83, n. 4, p. 393-401, 2007.

WOODS, W. Psychological Dimensions of Consumer Decision. Journal of Marketing, v. 24, n. 1, p. 15-19, 1960.

WU, W.-Y.; KE, C.-C. An online shopping behavior model integrating personality traits, perceived risk, and technology acceptance. Social Behavior and Personality, v.43, n. 1, p. 85-98, 2015.

XU, J.; CENFETELLI, R. T.; AQUINO, K. Do diferente kinds of trust matter? An examination of the three trusting beliefs on satisfaction and purchase behavior in the buyer-seller context. Journal of Strategic Information Systems, v. 25, p. 15$31,2016$.

YADAV, M. S.; DE VALCK, K.; HENNIG-THURAU, T.; HOFFMAN, D. L.; SPANN, M. Social commerce: a contingency framework for assessing marketing potential. Journal of Interactive Marketing, v. 27, n. 4, p. 311-323, 2013.

YAMAGISHI, T.; YAMAGISHI, M. Trust and commitment in the United States and Japan. Motivation and emotion, v. 18, n. 2, p. 129-166, 1994.

YANG, C.; HSU, Y.-C.; TAN, S. Predicting the Determinants of User's Intentions for Using YouTube to Share Video: Moderating Gender Effects. Cyberpsychology, Behavior, and Social Networking, v. 13, n. 2, p. 141-151, 2010 .

YEH, Y. S.; LI, Y. M. (2009). Building trust in m-commerce: contributions from quality and satisfaction. Online Information Review, v. 33, n. 6, p. 1066-1086, 2009.

YOUSAFZAI, S. Y.; FOXALL, G. R.; PALLISTER, J. G. Technology Acceptance: a Meta-Analysis of the TAM: Part 1. Journal of Modeling in Management, v. 2, n. 3, p. 251-280, 2007. 
ZEITHAML, V. How consumer evaluation processes differ between goods and services In J. Donnelly; W. George (Ed.). Marketing of Services, p. 186-190. Chicago: American Marketing, 1981.

ZHANG, J.; MAO, E. Understanding the acceptance of mobile SMS advertising among Young Chinese consumers. Psychology \& Marketing, v. 25, n. 8, p. 787$805,2008$.

ZHANG, L.; ZHU, J.; LIU, Q. A meta-analysis of mobile commerce adoption and the moderating effect of culture. Computers in Human Behavior, v. 28, p. 19021911, 2012.

ZHOU, T. An empirical examination of initial trust in mobile banking. Internet Research, v. 21, n. 5, p. 527-540, 2011. 


\section{Apêndice A \\ Instrumento de Pesquisa - Versão para Impressão}

Leia atentamente as perguntas abaixo antes de responder. O questionário leva cerca de 10 minutos para ser respondido.

C1 1. Você possui algum desses dispositivos móveis? (Você pode marcar mais de uma opção)

Smartphone (aparelhos como o iPhone ou Samsung Galaxy) . (1)

Tablet (aparelhos como o iPad). (2)

Celulares com acesso a Internet (modelos mais antigos que não possuem muitas capacidades). (3)

Não possuo nenhum desses dispositivos, mas tenho acesso a um deles (uso o de outra pessoa). (4)

Não possuo nenhum dispositivo móvel e não tenho acesso a um. (5)

C2 2. Qual desses dispositivos móveis você usa com mais frequência?

Smartphone (1)

Tablet (2)

Celular com acesso a Internet (3)

C3 3. Qual a marca e modelo do dispositivo móvel que você usa com mais frequência? (ex. Apple iPhone, Samsung Galaxy)

D1 4. Qual a sua idade? 
D2 5. Qual o seu nível de escolaridade?
O Fundamental incompleto (1)
O Fundamental completo (2)
O Médio incompleto (3)
O Médio completo (4)
O Superior incompleto (5)
O Superior completo (6)
O Pós-graduação incompleto (7)
O Pós-graduação completo (8)

D3 6. Qual a sua faixa de renda familiar?

O Mais de 15 salários mínimos ( $R \$ 14.000$ ou mais) (1)

O De 5 a 15 salários mínimos ( $R \$ 5.000$ a $R \$ 14.000)$ (2)

- De 3 a 5 salários mínimos ( $R \$ 3.000$ a $R \$ 5.000)$ (3)

- De 1 a 3 salários mínimos ( $R \$ 1.000$ a $R \$ 3.000)$ (4)

O Até 1 salário mínimo $(\mathrm{R} \$ 1.000)$

O Não desejo declarar (6)

\section{D4 7. Qual o seu sexo?}

( )Masculino (1) ( )Feminino (2)

C4 8. Você já utilizou um dispositivo móvel (smartphone, tablet ou celular com acesso a internet) para fazer a compra de um produto ou serviço?

$$
\text { ( ) } \operatorname{Sim}(1) \quad(\quad \text { ) Não (2) }
$$

C7 9. Como você costuma comprar produtos ou serviços usando seu tablet ou smartphone (Você pode selecionar mais de uma resposta)

Visito diretamente a página do vendedor usando o navegador de Internet (1)

Uso um aplicativo específico do vendedor (2)

Uso um aplicativo genérico, com várias opções de vendedores (iFood, Wish, Expedia etc.) (3)

Visito um website de buscas e procuro pelo que quero

A única coisa que compro são aplicativos (5) 
C8 10. Quais destes produtos e serviços você compra quando usa seu tablet ou smartphone? Selecione todas as respostas aplicáveis.

Roupas (1)

Sapatos (2)

Passagens de avião (3)

Livros (4)

Computadores (5)

Televisores (6)

Refeições (delivery) (7)

Diárias de hotel (8)

Música (CDs ou faixas) (9)

Celulares e Smartphones (10)

Nunca comprei nenhum dos produtos e serviços listados acima, mas compro outros (11)

Não compro nenhum tipo produto ou serviço (12)

C9 11. Dentre os tipos de produto ou serviço selecionados acima qual você compra com mais frequência usando seu tablet ou smartphone? Selecione apenas uma opção.

O Roupas (1)

- Sapatos (2)

- Passagens de avião (1)

O Computadores (1)

- Televisores (1)

O Diárias de hotel (2)

- Música (CDs ou faixas) (2)

- Celulares e Smartphones (2) 
VAR 12. Qual o seu grau de concordância com as seguintes afirmativas sobre o uso de dispositivos móveis para a compra de produtos e serviços em geral?

\begin{tabular}{|c|c|c|c|c|}
\hline $\begin{array}{l}\text { Discordo } \\
\text { totalmente (1) }\end{array}$ & $\begin{array}{l}\text { Discordo } \\
\text { parcialmente } \\
\text { (2) }\end{array}$ & $\begin{array}{l}\text { Nem concordo } \\
\text { nem discordo } \\
\text { (3) }\end{array}$ & $\begin{array}{l}\text { Concordo } \\
\text { parcialmente } \\
\text { (4) }\end{array}$ & $\begin{array}{l}\text { Concordo } \\
\text { totalmente (5) }\end{array}$ \\
\hline
\end{tabular}

Usar meu tablet ou smartphone me permite comprar com maior rapidez. (1)

Usar meu tablet ou smartphone melhora a qualidade das compras que eu faço. (2)

Usar meu tablet ou smartphone torna minhas compras mais fáceis. (3)

Usar meu tablet ou smartphone melhora minha efetividade na hora de comprar. (4)

Usar meu tablet ou smartphone me dá naior controle sobre como compro. (5)

FAU 13. Qual o seu grau de concordância com as seguintes afirmativas sobre o uso de dispositivos móveis para a compra de produtos e serviços em geral?

\begin{tabular}{|c|c|c|c|c|}
\hline $\begin{array}{l}\text { Discordo } \\
\text { totalmente } \\
\text { (1) }\end{array}$ & $\begin{array}{l}\text { Discordo } \\
\text { parcialmente (2) }\end{array}$ & $\begin{array}{l}\text { Nem } \\
\text { nem } \\
\text { (3) }\end{array}$ & $\begin{array}{r}\text { concordo } \\
\text { discordo }\end{array}$ & $\begin{array}{l}\text { Concordo } \\
\text { parcialmente (4) }\end{array}$ \\
\hline
\end{tabular}

Minhas interações de compras usando neu tablet ou smartphone são fáceis e laras. (1)

Eu acredito que é fácil fazer meu tablet ou smartphone fazer aquilo que eu quero que ele faça. (2)

No geral, eu acredito que usar meu tablet ou smartphone para comprar é fácil. (3)

Aprender a usar meu tablet ou smartphone para comprar produtos ou serviços é fácil para mim. (4)

$\begin{array}{lllll}0 & 0 & 0 & 0 & 0 \\ 0 & 0 & 0 & 0 & 0 \\ 0 & 0 & 0 & 0 & 0 \\ 0 & 0 & 0 & 0 & 0 \\ 0 & 0 & 0 & 0 & 0\end{array}$

0 
COM 14. Qual o seu grau de concordância com as seguintes afirmativas sobre o uso de dispositivos móveis para a compra de produtos e serviços em geral?

\begin{tabular}{|c|c|c|c|c|}
\hline $\begin{array}{l}\text { Discordo } \\
\text { totalmente } \\
\text { (1) }\end{array}$ & $\begin{array}{l}\text { Discordo } \\
\text { parcialmente } \\
\text { (2) }\end{array}$ & $\begin{array}{l}\text { Nem } \\
\text { concordo } \\
\text { nem discordo } \\
\text { (3) }\end{array}$ & $\begin{array}{l}\text { Concordo } \\
\text { parcialmente } \\
\text { (4) }\end{array}$ & $\begin{array}{l}\text { Concordo } \\
\text { totalmente } \\
\text { (5) }\end{array}$ \\
\hline
\end{tabular}

Usar meu tablet ou smartphone para comprar produtos ou serviços é compatível com todos os aspectos dos meus hábitos de compras. (1)

Eu acho que usar meu tablet ou smartphone para comprar produtos ou serviços é compatível com minha situação atual. (2)

Usar meu tablet ou smartphone tem tudo a ver com meu estilo de fazer compras. (3)

$\begin{array}{lllll}0 & 0 & 0 & 0 & 0 \\ 0 & 0 & 0 & 0 & 0 \\ 0 & 0 & 0 & 0 & 0\end{array}$

CBE 15. Qual o seu grau de concordância com as seguintes afirmativas sobre o uso de dispositivos móveis para a compra de produtos e serviços em geral?

1 acredito que os aplicativos e sites de mpras que acesso pelo meu tablet ou lartphone agem segundo o que é Ilhor para mim. (1)

Caso eu precise, os aplicativos e sites de compras que acesso pelo meu tablet ou smartphone fariam o melhor possível para me ajudar a decidir. (2)

Os aplicativos e sites de compras que acesso pelo meu tablet ou smartphone se preocupam com os meus interesses e

\section{Discordo} totalmente

(1)
Discordo
parcialment

(2)
Nem
concordo
nem discordo (3)

\section{Concordo} parcialmente

(4)
Concordo totalmente

(5) não apenas com os deles. (3) 
CIN 16. Qual o seu grau de concordância com as seguintes afirmativas sobre o uso de dispositivos móveis para a compra de produtos e serviços em geral?

\begin{tabular}{|c|c|c|c|c|}
\hline $\begin{array}{l}\text { Discordo } \\
\text { totalmente } \\
\text { (1) }\end{array}$ & $\begin{array}{l}\text { Discordo } \\
\text { parcialmente } \\
\text { (2) }\end{array}$ & $\begin{array}{l}\text { Nem } \\
\text { concordo } \\
\text { nem discordo } \\
\text { (3) }\end{array}$ & $\begin{array}{l}\text { Concordo } \\
\text { parcialmente } \\
\text { (4) }\end{array}$ & $\begin{array}{l}\text { Concordo } \\
\text { totalmente } \\
\text { (5) }\end{array}$ \\
\hline
\end{tabular}

Os aplicativos e sites de compras que acesso pelo meu tablet ou smartphone são verdadeiros em suas relações comigo. (1)

Eu considero os aplicativos e sites de compras que acesso pelo meu tablet ou smartphone honestos. (2)

Os aplicativos e sites de compras que acesso pelo meu tablet ou smartphone mantém os compromissos que assumem. (3)

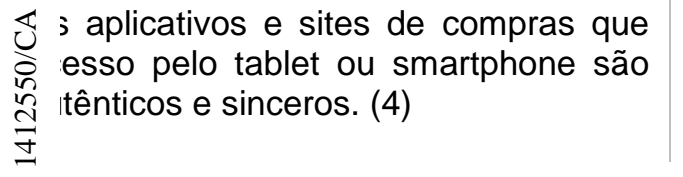
0
0
0
0
$\begin{array}{lllll}0 & 0 & 0 & 0 & 0 \\ 0 & 0 & 0 & 0 & 0 \\ 0 & 0 & 0 & 0 & 0\end{array}$

CCO 17. Qual o seu grau de concordância com as seguintes afirmativas sobre o uso de dispositivos móveis para a compra de produtos e serviços em geral?

\begin{tabular}{|c|c|c|c|c|}
\hline $\begin{array}{l}\text { Discordo } \\
\text { totalmente (1) }\end{array}$ & $\begin{array}{l}\text { Discordo } \\
\text { parcialmente } \\
\text { (2) }\end{array}$ & $\begin{array}{l}\text { Nem } \\
\text { concordo } \\
\text { nem discordo } \\
\text { (3) }\end{array}$ & $\begin{array}{l}\text { Concordo } \\
\text { parcialmente } \\
\text { (4) }\end{array}$ & $\begin{array}{l}\text { Concordo } \\
\text { totalmente (5) }\end{array}$ \\
\hline
\end{tabular}

; aplicativos e sites de compras que acesso pelo meu tablet ou smartphone são canais de compras competentes e efetivos. (1)

Os aplicativos e sites de compras que acesso pelo meu tablet ou smartphone desempenham seu papel de canal de compras muito bem. (2)

No geral, os aplicativos e sites de compras que acesso pelo meu tablet ou smartphone são provedores de serviços competentes e habilidosos. (3)

No geral, os aplicativos e sites de compras que acesso pelo meu tablet ou smartphone são bem informados sobre os produtos e serviços que vendem. (4)

$\begin{array}{lllll}0 & 0 & 0 & 0 & 0 \\ 0 & 0 & 0 & 0 & 0 \\ 0 & 0 & 0 & 0 & 0 \\ 0 & 0 & 0 & 0 & 0\end{array}$


CCG 18. Qual o seu grau de concordância com as seguintes afirmativas sobre o uso de dispositivos móveis para a compra de produtos e serviços em geral?

$\begin{array}{lllll}\text { Discordo } & \text { Discordo } & \text { Nem concordo } & \text { Concordo } & \text { Concordo } \\ \text { totalmente (1) } & \text { parcialmente (2) } & \begin{array}{l}\text { nem discordo } \\ \text { (3) }\end{array} & & \begin{array}{l}\text { parcialmente (4) } \\ \text { totalmente (5) }\end{array}\end{array}$

Eu confio nos aplicativos e sites de compras que acesso pelo meu tablet ou smartphone (1)

Eu acho os aplicativos e sites de compras que acesso pelo meu tablet ou smartphone confiáveis. (2)

Eu sinto segurança nos aplicativos e sites de compras que acesso pelo meu tablet ou smartphone (3)

Eu valorizo as características merecedoras de confiança dos aplicativos e sites de compras que ac ;o pelo meu tablet ou $\mathrm{si}_{\varangle}$ phone (4)

$\begin{array}{lllll}0 & 0 & 0 & 0 & 0 \\ 0 & 0 & 0 & 0 & 0 \\ 0 & 0 & 0 & 0 & 0 \\ 0 & 0 & 0 & 0 & 0\end{array}$

ATT 19. Qual o seu grau de concordância com as seguintes afirmativas sobre o uso de dispositivos móveis para a compra de produtos e serviços em geral?

Discordo Discordo Nem concordo Concordo Concordo totalmente (1) parcialmente (2) nem discordo (3) parcialmente (4) totalmente (5)

er compras usando meu tablet ou ¿ Irtphone é uma boa ideia. (1)

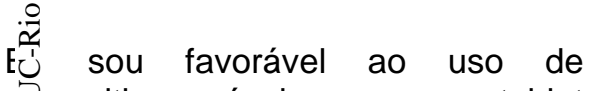

CQ. ositivos móveis, como meu tablet ou smartphone para a compra de produtos e serviços. (2)

Comprar usando meu tablet ou smartphone é uma ideia inteligente. (3)

No geral, minha atitude em relação ao uso do tablet ou smartphone para comprar produtos e serviços é positiva. (4)
0

0

0

0

0

0

0

0

0

0 
CE1 20. Com que frequência você compra produtos ou serviços usando seu tablet ou smartphone?

O Nunca comprei nada (1)

O Menos de uma vez por mês (2)

- Cerca de uma vez por mês (3)

O De 2 a 3 vezes no mês (4)

- Várias vezes no mês (5)

- pelo menos uma vez por semana (6)

O mais de uma vez por semana (7)

CE2 21. Quanto você gasta em média por mês comprando produtos ou serviços pelo seu tablet ou smartphone

O Nunca comprei nada (1)

O Menos de $\mathrm{R} \$ 100$ (2)

- Entre $R \$ 100$ e $R \$ 250$

- Entre $\mathrm{R} \$ 250$ e $\mathrm{R} \$ 400$

- Entre $R \$ 400$ e $R \$ 600$

- Entre $R \$ 600$ e $R \$ 1.200$ (6)

○ Mais de $\mathrm{R} \$ 1.200$ (7) 
INT 22. Qual o seu grau de concordância com as seguintes afirmativas sobre o uso de dispositivos móveis para a compra de produtos e serviços?

\begin{tabular}{|c|c|c|c|c|c|c|}
\hline $\begin{array}{l}\text { Discordo } \\
\text { totalmente } \\
\text { (1) }\end{array}$ & Discordo (2) & $\begin{array}{l}\text { Discordo } \\
\text { parcialmente } \\
\text { (3) }\end{array}$ & $\begin{array}{l}\text { Nem } \\
\text { concordo } \\
\text { nem discordo } \\
\text { (4) }\end{array}$ & $\begin{array}{l}\text { Concordo } \\
\text { parcialmente } \\
\text { (5) }\end{array}$ & Concordo (6) & $\begin{array}{l}\text { Conco } \\
\text { rdo } \\
\text { totalm } \\
\text { ente } \\
\text { (7) }\end{array}$ \\
\hline
\end{tabular}

Eu pretendo continuar comprando produtos e serviços utilizando meu tablet ou smartphone. (1)

Eu provavelmente vou comprar produtos e serviços usando meu tablet ou cmartphone no futuro. (2)

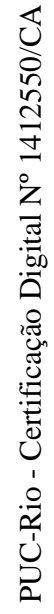

odutos e serviços em um uro próximo. (3)

I tenho a intenção de nos

j́ximos 6 meses comprar

odutos e serviços usando

əu tablet ou smartphone (4)

\begin{abstract}
0
\end{abstract}
0

○

0

0

0

0

0000

0

$\circ$

0

\section{FIM}

MUITO OBRIGADO PELA SUA PARTICIPAÇÃO!

Estamos gratos pela sua colaboração neste projeto de pesquisa.

Cada participação é de extrema importância.

Todos os dados coletados são anônimos e serão utilizados apenas para fins estatísticos.

Estamos abertos à sugestões e comentários sobre esta pesquisa e sobre projetos futuros. 